\title{
6 Zwischen Triumph und Katastrophe
}

Beinahe dreißig Jahre, nachdem Chosroes II. infolge des Sturzes seines Verbündeten Maurikios den Krieg gegen Rom erklärt und sukzessive die Ostprovinzen bis an die Grenze Anatoliens besetzt hatte, vier Jahre nachdem Herakleios auf seine Himmelfahrtsmission ins persische Kernland aufgebrochen war, hatte sich nun tatsächlich das Blatt gewendet: Ein entscheidender militärischer Sieg, der die persischen Truppen bis zur Handlungsunfähigkeit dezimiert hätte, war zwar nicht errungen worden - die Schlacht von Niniveh sollte in ihrer militärischen Bedeutung nicht überschätzt werden; doch interne Instabilität und Verwerfungen innerhalb der persischen Elite, befeuert durch den Einfall der römischen Truppen, hatten Herakleios in die Hände gespielt. Nach Chosroes' Sturz war es der römische Kaiser, der sich nach Jahrzehnten der Schwäche beim politischen Kräftemessen im Nahen Osten wieder in die stärkere Position aufgeschwungen hatte. Doch mit dem Friedensangebot des Seiroe im März 628 sollte bei Weitem noch nicht das letzte Wort im Konflikt zwischen Rom und Persien gesprochen sein. ${ }^{1}$ Über zwei Jahre würde es stattdessen dauern, bis die Details der Beziehungen der beiden Großmächte zueinander ausgehandelt und praktisch umgesetzt werden konnten. Eine exakte chronologische Rekonstruktion der Abläufe dieser zwei Jahre ist angesichts der extrem problematischen und oft widersprüchlichen Quellenlage kaum möglich. ${ }^{2}$ Anstatt im Folgenden den Eindruck einer konzisen Erzählung zu erwecken, soll die Aufmerksamkeit vielmehr auf die für meine Fragestellung entscheidenden Entwicklungen gelenkt werden: Herakleios’ Bemühungen, seine Rückkehr in die Hauptstadt nach langer Abwesenheit möglichst positiv zu gestalten, sowie sein Ringen darum, die römische Hoheit in den Ostprovinzen zu festigen. Das Kapitel endet mit Blick auf eine Entwicklung, welche die Kräfteverhältnisse im Nahen Osten erneut ins Wanken brachte: Ab 633/634 sahen sich die römischen Ostprovinzen mit den Vorstößen der muslimischen Araber konfrontiert. Die römische Verteidigung, durch Jahrzehnte des Krieges mit Persien geschwächt, hatte dem Aggressor nicht viel entgegenzusetzen. Wenige Jahre nach ihrer spektakulären Rückgewinnung durch Herakleios wurden die Ostprovinzen bis an die Grenze Kleinasiens erneut der römischen Kontrolle entzogen; Herakleios' Restitutionswerk war dahin.

Das vorherige Kapitel hat nachvollzogen, wie Herakleios' Erfolg in der Öffentlichkeit besprochen wurde. Dabei hat sich gezeigt, wie wichtig es ist, bei der Analyse zwischen verschiedenen Kommunikationskontexten $\mathrm{zu}$ unterscheiden: Die spezifischen Anforderungen und Erwartungen, die das hauptstädtische Umfeld an den Kaiser richtete, resultierten in einer Repräsentation kaiserlicher Sieghaftigkeit, die sich deutlich von Diskursen unterschied, wie sie in den rückgewonnenen römischen

$1 \mathrm{Zu}$ den Abläufen siehe oben Kap. 5.4.1.

2 Zuletzt hat Zuckerman 2013 versucht, alle Quellen zusammenzubringen und ein Itinerar herauszuarbeiten; das Ergebnis ist zwar beeindruckend, aber im Detail bisweilen nicht ganz überzeugend, siehe die Diskussion im Folgenden.

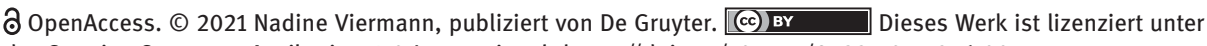
der Creative Commons Attribution 4.0 International. https://doi.org/10.1515/9783110711356-007 
Ostprovinzen zu beobachten sind. Während in den Ostprovinzen, die wesentlich direkter von den machtpolitischen Verwerfungen der letzten Jahrzehnte betroffen waren, akut eschatologisches Gedankengut florierte, oszillierte der Diskurs in Konstantinopel zwischen zwei komplementären Polen: Der ostentativen Zurückhaltung des Herakleios stand dessen Überhöhung durch Georg von Pisidien gegenüber, der seinen kriegführenden Kaiser angesichts des Sieges zum Agenten eines neuen, positiven Zeitalters erhob. Die nun folgende Analyse wird herausarbeiten, wie sich Herakleios' Rückkehr in die Hauptstadt praktisch gestaltete.

\subsection{Mit dem Sieg im Rücken}

\subsubsection{Rückkehr nach Konstantinopel I}

Im März 628 hatte der neue persische Großkönig Kavadh Seiroe zugesichert, die von den Persern besetzten Gebiete zu räumen; in der Praxis waren diese Konditionen allerdings nicht ohne Weiteres umzusetzen. Von dem Umsturz in Ctesiphon und der militärischen Kursänderung in Kenntnis gesetzt, weigerten sich die persischen Truppen, dem Befehl des neuen Großkönigs nachzukommen und die römischen Provinzen freizugeben. Die erneute Einrichtung einer römischen Verwaltung, eine zentrale Voraussetzung für die effektive Konsolidierung der Provinzen, gestaltete sich also schwierig. Anstatt einer friedlichen Räumung der Gebiete, wie sie den beiden Herrschern vorgeschwebt hatte, kam es erneut zu bewaffneten Zusammenstößen zwischen den persischen Besatzern und den aus dem Osten zurückkehrenden römischen Truppen unter der Führung von Herakleios' Bruder Theodor: Die persische Garnison im strategisch wichtigen Zentrum Edessa in Nordmesopotamien etwa widersetzte sich lange einer Übernahme durch die Römer; die jüdische Bevölkerung stand dabei auf ihrer Seite. Doch selbst nach dem Rückzug der Perser herrschte keine Einigkeit: Als Herakleios selbst in Edessa eintraf, verweigerte der miaphysitische Bischof der Stadt ihm die Kommunion. ${ }^{3}$ Auch der herausragende General des zurückliegenden Krieges, Shahrbaraz, dessen Loyalität gegenüber der persischen Zentrale sich zuletzt bereits unter Chosroes als fragil erwiesen hatte, machte vorerst keine Anstalten, dem Befehl nachzukommen und aus dem von ihm eroberten Gebiet abzurücken. ${ }^{4}$

3 Siehe Chron. 1234, 102 (Chabot I, 185); Hoyland 2011, 79-81; die griechischen Quellen schweigen dazu. Zur militärischen Konsolidierung der Ostprovinzen vgl. Flusin 1992 II, 282-288.

4 Von der Weigerung des Shahrbaraz berichtet allein Sebeos 39 (Thomson/Howard-Johnston I, 86); ebd. 39 (Thomson/Howard-Johnston I, 84 f.) wird außerdem vermerkt, dass Shahrbaraz dem Chosroes angesichts der römischen Invasion nicht zu Hilfe kam; aus ebd. 40 (129) ist zu schließen, dass Shahrbaraz sich in Alexandria aufhielt. In späteren Quellen (Theoph. Conf. AM 6118 [De Boor 323f.]; Mich. Syr. 11.3 [Chabot II, 408f.]; Chron. 1234, 98[Chabot I, 181f.]) findet sich wiederholt der Bericht (offenbar ausgehend von der Geschichte des Theophilos von Edessa, siehe Howard-Johnston 2010, 203f.), dass Chosroes den Shahrbaraz bereits 626 habe beseitigen wollen und der General in Reaktion darauf eine 
Der Osten war also mit der Vereinbarung des Frühjahrs 628 keinesfalls befriedet und Herakleios begab sich in den darauffolgenden Jahren wiederholt persönlich an die jeweiligen Krisenherde. Doch nachdem zumindest die akute Gefahr eines aggressiven Chosroes beseitigt worden war, musste der Kaiser seine Aufmerksamkeit auch verstärkt wieder der Hauptstadt zuwenden: Während der zurückliegenden Jahre war das Schicksal des römischen Reiches auf Messers Schneide gestanden; Konstantinopel hatte sich ohne die psychologisch wichtige Präsenz des Kaisers in der Stadt einer feindlichen Belagerung erwehren müssen. Die hauptstädtische Bevölkerung, die durch die Felddepeschen im Detail über den erfolgreichen Ausgang der römischen Expedition in Kenntnis gesetzt worden war, erwartete den Senior Augustus bereits sehnsüchtig. ${ }^{5}$ Auf welchem Wege, wann genau und wie oft Herakleios allerdings an den Bosporus zurückkehrte und wie lange er sich in den folgenden Jahren dort aufhielt, ist angesichts der diffusen Quellenlage umstritten. ${ }^{6}$ Mir scheint es indes plausibel, dass Herakleios sich nach dem Friedensschluss mit Seiroe schnellstmöglich nach Konstantinopel begab und dort im Spätsommer oder Herbst 628 eintraf. ${ }^{7}$

Indem Herakleios sich als Kaiser entgegen der Gewohnheit seiner Vorgänger von Konstantinopel entfernt hatte, hatte er mit etablierter monarchischer Verhaltenspraxis gebrochen. Dass diese Transgression im hauptstädtischen Sozialgefüge bewältigt werden konnte, war nicht zuletzt dem Umstand geschuldet, dass es Akteuren in der Hauptstadt gelang, eine positive Deutung von Herakleios’ Aktivität als Feldherr zu etablieren. Doch ebenso wie die Abwesenheit des Kaisers hatte bewältigt werden müssen, stellte auch seine Rückkehr eine praktische wie kommunikative Herausforderung dar. Nachdem Konstantinopel sich über vier Jahre hinweg selbst überlassen gewesen war und anstelle des Kaisers zunehmend alternative Akteure in den Fokus der Öffentlichkeit gerückt waren, musste Herakleios nun wieder in das hauptstädtische Beziehungsgeflecht integriert werden. Der Sieg über die Perser bot sicherlich eine erfolgversprechende Basis, wenn es darum ging, diese Reintegration möglichst gewinnbringend $\mathrm{zu}$ vollziehen; doch anstatt die Modi dieses Prozesses nach Gutdünken gestalten zu können, musste sich Herakleios, wie im Folgenden deutlich wird, erneut in das enge Korsett hauptstädtischer Verhaltenserwartungen fügen. Herakleios' Rückkehr nach Konstantinopel stand im Bezug zu einer jahrhundertealten Tradition römisch-imperialer Triumphalpraxis und reagierte gleichzeitig auf spezifische Anforderungen seiner Zeit.

Der Triumph war ein Schlüsselmoment römisch-imperialer Herrschaft. Nachdem in Zeiten der Republik siegreiche Feldherren mit ihren Soldaten in Rom eingezogen

Koalition mit Herakleios eingegangen sei; dabei handelt es sich aber aller Wahrscheinlichkeit nach um ein Gerücht; vgl. etwa Flusin 1992 II, 289; Mango 1985, 107-109; Kaegi 2003, 150 -153. Zu den Bewegungen des Shahrbaraz seit dem Sommer 626 in Chalkedon siehe auch Stratos 1968, 231-234.

5 Verlesung der Siegesdepesche in der Hagia Sophia: Chron. Pasch. AD 628 (727); ebd. (734) zur Rückkehr über Armenien, so auch Act. Anast. Pers. 43.

6 Vgl. Stratos 1968, 237.

7 Eingehende Überlegungen zur Datierung siehe unten S. 256-260. 
waren, blieb der Triumph seit der Einrichtung der Alleinherrschaft durch Augustus dem Kaiser vorbehalten. Mit den strukturellen Verschiebungen, die die römische Monarchie seit dem dritten Jahrhundert durchlief, änderten sich auch die Parameter, innerhalb derer sich Siegesfeierlichkeiten entfalteten: Als die Bindung der Kaiser an die alte Hauptstadt Rom zu erodieren begann, lockerte sich sukzessive auch das Monopol Roms als Austragungsort von Triumphen. Mit der Festigung einer hauptstädtischen Konfiguration von Monarchie in Konstantinopel avancierte schließlich die neue Kapitale am Bosporus zum Kristallisationspunkt für die Zurschaustellung kaiserlicher Sieghaftigkeit. Parallel zu dieser geographischen Verlagerung ist eine Anpassung des zeremoniellen Vollzuges zu beobachten: Mit der fortschreitenden Christianisierung römischer Monarchie seit Konstantin wurde der Triumph seiner pagan-religiösen Konnotation entkleidet; der Zug durch die Stadt, als dessen Höheund Endpunkt der Jupiter-Tempel auf dem Kapitol fungiert hatte, verlor gegenüber den Feierlichkeiten im Hippodrom an Bedeutung. ${ }^{8}$ Ein entscheidender Faktor für die Entwicklung römischer Triumphalpraxis in der Spätantike war der Umstand, dass die Kaiser ab dem 5. Jahrhundert das römische Heer nicht mehr persönlich anführten, sondern dieses Geschäft ihren Generälen überließen. ${ }^{9}$ Wie ich im Kapitel 2 bereits betont habe, lag die Stabilität oströmischer Herrschaft nicht zuletzt darin begründet, dass es den Kaisern vor allem im frühen 6. Jahrhundert gelang, die von Generälen errungenen Siege konsequent auf die eigene Person zu beziehen; in Konstantinopel blieb selbst dem unkriegerischen Kaiser die Repräsentation von Sieghaftigkeit weitestgehend vorbehalten. Mit der Bindung monarchischer Herrschaft an die neue Hauptstadt wich bei Triumphen das dynamische Element des Einzuges endgültig einer Feier im Hippodrom, die sich auf den im Kathisma thronenden, statischen Kaiser ausrichtete. ${ }^{10}$ Gleichzeitig vollzog sich jedoch auch eine Ausdifferenzierung der Triumphalpraxis: Siegesfeierlichkeiten der sesshaften Kaiser wurden durch verschiedene zeremonielle Versatzstücke angereichert und mit anderen Formen öffentlicher Interaktion kombiniert, etwa liturgischen Prozessionen, sodass zunehmend auch christliche Elemente Eingang in den Vollzug fanden. ${ }^{11}$ Im frühen 7. Jahrhundert verschoben

\footnotetext{
8 Siehe dazu grundlegend McCormick 1986, 35-79. Die Entwicklung kaiserlicher Siegesfeierlichkeiten hat zuletzt Diefenbach 2019 untersucht; ein konziser Überblick findet sich ebd. 65-69; zum römischen Triumph in der Spätantike siehe auch Pfeilschifter 2016. Während Kaiser in der alten Hauptstadt Rom an eine starke Tradition gebunden waren, konnten sie Siegesfeierlichkeiten in den Provinzen und auch in der neuen Hauptstadt Konstantinopel in wesentlich höherem Maße nach ihrem Gutdünken gestalten, was zu einer Dynamisierung in der Entwicklung des Zeremoniells beitrug.

9 Siehe McCormick 1986, 47 f.; „imperial triumphal entries were now deprived of their drama”.

10 Dies wird besonders deutlich beim Vandalentriumph des Justinian, bei dem sowohl der besiegte König Gelimer als auch der General Belisar, der den Sieg errungen hatte, dem Kaiser im Kathisma ihre Ehrerbietung darbrachten; zu dem Triumph siehe, mit verschiedenen Deutungen hinsichtlich der Details, Meier 2003a, 150 -165; Börm 2013; Diefenbach 2019, 92-100; Meier 2019b.

11 Siehe McCormick 1986, 100-111 zur Christianisierung kaiserlicher Siegesfeierlichkeiten. McCormick merkt an (ebd. 111), dass spezifisch christliche Siegesfeierlichkeiten sich lange Zeit unabhängig von säkularen Zeremonien herausbildeten; zu einer Verschränkung von Siegesfeierlichkeiten und li-
} 
sich die Parameter erneut: Herakleios war nicht nur der erste oströmische Kaiser seit Theodosios I., der das Heer persönlich in den Provinzen anführte, sondern auch der erste Kaiser seit über 200 Jahren, der persönlich für einen militärischen Triumph verantwortlich zeichnete und entsprechend als Sieger nach Konstantinopel zurückkehrte. ${ }^{12}$ Herakleios' Einzug in die Hauptstadt nach über vierjähriger Abwesenheit war ein Ereignis sondergleichen. ${ }^{13}$

Um Herakleios' Reintegration ins hauptstädtische Sozialgefüge nachzuvollziehen, müssen zuerst eine Reihe an Fragen zur Rekonstruktion des Ereignisses adressiert werden. Während die Heraclias des Georg von Pisidien, soweit erhalten, den kaiserlichen Einzug nur mit einigen sehr allgemein gehaltenen Versen thematisiert, ${ }^{14}$ bieten spätere Quellen detailliertere Berichte. Laut Theophanes sammelte sich die Bevölkerung, angeführt von Sergios und dem Augustus Herakleios Konstantin, Herakleios' ältestem Sohn, am asiatischen Ufer des Bosporus, in Hiereia, um den Kaiser in Empfang zu nehmen; unter Dankeshymnen begab man sich daraufhin gemeinsam

turgischen Prozessionen sei es vor allem ab dem späten 6. Jahrhundert gekommen. Diesen Umstand betont auch Pfeilschifter 2016, der zu dem Schluss kommt, dass der römische Triumph bis ins 6. Jahrhundert einen säkularen Charakter behalten habe. Pfeilschifters Bewertung liegt allerdings eine sehr enge Definition von Triumph zugrunde, siehe ebd. 457-465, bes. 461. Eine derartig strikte Trennung zwischen Triumph, Adventus, liturgischer Prozession etc. halte ich in der Analyse der spätantiken Evidenz nicht unbedingt für zielführend. Anstatt in Triumph und Nicht-Triumph zu unterteilen, erscheint es mir vielmehr sinnvoll zu beobachten, welche zeremoniellen Versatzstücke je nach Anlass in einer bestimmten Art kombiniert wurden. Als Siegesfeierlichkeit betrachte ich dabei für die Spätantike ganz allgemein die Inszenierung eines militärischen Erfolges. Auch Diefenbach 2019 zieht, wenn ich richtig sehe, keine derart strenge Differenzierung; ebd. 63-78 lenkt er den Fokus erneut auf den Umstand, dass Siegesfeierlichkeiten bereits unter Theodosios II. mit religiösen bzw. liturgischen Elementen angereichert werden konnten: Als in Konstantinopel die Nachricht von der Niederschlagung des Usurpators Johannes eintraf, brach Theodosios die Spiele im Hippodrom ab und zog gemeinsam mit der versammelten Bevölkerung in eine der städtischen Kirchen, um zu beten (Sokr. Hist. eccl. 7.23.11f.). Dass dem öffentlichen Auftreten des Kaisers nicht nur bei Siegesfeierlichkeiten ein triumphaler Charakter innewohnte, haben McCormick 1986, 21, 95 und Diefenbach 2019, $67 \mathrm{f}$. mit Anm. 15 betont.

12 Theodosios I. war mehrfach im Nachklang eines militärischen Erfolges in Konstantinopel eingezogen. 380, nur wenige Jahre nach seiner Erhebung, feierte er einen Sieg über die Goten (Zos. 4.33.1 gibt leider nur spärliche Informationen); 386 zog er in Folge des Sieges über die Greutungen unter dem König Odotheus gemeinsam mit seinem Sohn Arkadios in die neue Hauptstadt ein (Consularia Constantinopolitana ad a. 386; Marc. Com. Chron. ad a. 386); siehe McCormick 1986, 42f. und Diefenbach 2019, 69 Anm. 17. In diesen Zusammenhang ist auch die Errichtung der Theodosios-Säule auf dem Forum Tauri einzuordnen. Es bleibt zu betonen, dass bereits der Sieg von 386 nicht vom Kaiser persönlich, sondern von dessen Magister militum Promotus errungen worden war.

13 Während seiner Regierung muss Herakleios bereits mehrfach in die Hauptstadt eingezogen sein: nach seinem missglückten Feldzug von 613 und nach der Kampagne von 622/623; davon gibt es allerdings keine Zeugnisse. Allein die Rückkehr des Kaisers nach Konstantinopel in Folge seines Aufenthaltes in Caesarea fand knappe Erwähnung in Vit. Theod. Syk. 154: Der Text erwähnt, Herakleios' Cousin Niketas sei ihm aus der Stadt entgegengeritten, um ihn zu empfangen; siehe McCormick 1986, 71 Anm. 126.

14 Georg. Pis. Heracl. 1.210 - 218, fragm. 54. 
in die Stadt. ${ }^{15}$ Während Theophanes Herakleios' Einzug in die Hauptstadt nach dem Friedensschluss mit Seiroe verortet (entsprechend 628/629), schildert Nikephoros die Rückkehr erst in Folge des kaiserlichen Abstechers nach Jerusalem, der in der Forschung in der Regel in den März 630 datiert wird: ${ }^{16}$ Mit Spielen im Hippodrom, bei denen der begeisterten Bevölkerung vier Elefanten vorgeführt wurden, habe Herakleios seinen mehrtätigen Triumph gefeiert. ${ }^{17}$

Will man diese beiden Berichte miteinander vereinbaren, so liegt die einfachste Lösung in der Annahme, dass Theophanes und Nikephoros sich auf zwei unterschiedliche Ereignisse beziehen: ${ }^{18}$ Entlang dieser These ließen sich nicht nur die konfligierenden Datierungen vereinbaren - Theophanes beschreibt einen Einzug vor, Nikephoros einen Einzug nach der Restitutio Crucis -, sondern auch der Umstand, dass die Berichte inhaltlich keinerlei Überschneidungen aufweisen. Diese Lösung halte ich allerdings für unbefriedigend. Meiner Ansicht nach beziehen sich Theophanes und Nikephoros auf dasselbe Ereignis, das in den Herbst des Jahres $628 \mathrm{zu}$ datieren ist. ${ }^{19}$ Angesichts der andauernden Bedeutung Konstantinopels für die Sicherung monarchischer Herrschaft scheint es plausibel, dass Herakleios nach seinem Erfolg im Osten schnellstmöglich in die Hauptstadt zurückkehrte; nachdem er die kaiserliche Autorität über den militärischen Sektor gefestigt hatte, galt es nun, dem hauptstädtischen Umfeld die nötige Aufmerksamkeit zukommen zu lassen. Die Feierlichkeiten mit militärischem Charakter (Präsentation der Kriegselefanten etc.), wie Nikephoros sie schildert, scheinen eine direkte Reaktion auf die Beendigung des Krieges im Jahr 628 zu sein; nach der Restitutio Crucis Jahre später hätte eine derartige Inszenierung kaum mehr Sinn ergeben. ${ }^{20}$ Die Tatsache, dass die beiden Zeugnisse sich

15 Theoph. Conf. AM 6119 (De Boor 328); vgl. Sebeos 39 (Thomson/Howard-Johnston I, 86). Theophanes' Bericht geht aller Wahrscheinlichkeit nach auf nicht erhaltene Verse des Georg von Pisidien zurück. Pertusi 1959, 292, 307 geht davon aus, dass er Teil des dritten Akroasis der Heraclias war; vgl. Mango/Scott 1997, 457 f.; siehe auch Meier 2015, 187. Ein Teil des Berichtes wurde oben bereits diskutiert S. $239 \mathrm{f}$.

16 Zur Datierung der Restitutio Crucis siehe unten S. 264 Anm. 43. Nik. Brev. 18 beendet seinen Bericht der Restitutio Crucis indes mit dem Zusatz, dass dies in der zweiten Indiktion (628/9) geschehen sei; darauf basiert der Eintrag in der Suda (Adler II, 582). Folgt man der fundierten Annahme, dass die Restitutio Crucis am 21. März 630 vollzogen wurde, kann diese Angabe nicht stimmen; doch anstatt hier einen Fehler bei der Indiktions-Zahl zu vermuten, könnte man die zweite Indiktion auch auf Herakleios' Einzug in Konstantinopel beziehen, der (ohne weitere Datums-Angabe) in direkter Folge darauf (Brev. 19) behandelt wird.

17 Nik. Brev. 19.

18 Diese Lösung wählt Kaegi 2003, 185f., 215 ohne weitere Diskussion; vgl. Mango 1990, 186.

19 Von einer raschen Rückkehr nach Konstantinopel gehen auch Stratos 1968, 239f. und HowardJohnston 1999, 26 aus. Ein in Herakleios' Namen veröffentlichtes Gesetz vom 21. März 629 könnte als Indiz dafür gelesen werden, dass der Kaiser sich zu diesem Zeitpunkt in der Hauptstadt aufhielt, so etwa Pertusi 1959, 234 und Konidaris 1982, 58-60. Laut Zuckerman 2013, 203 zog Herakleios erst im September 629 in Konstantinopel ein.

20 Dazu kommt, dass Herakleios sich nach seinem Aufenthalt in Jerusalem nicht direkt wieder nach Konstantinopel begab, sondern sich im Osten religionspolitischen Angelegenheiten widmete; siehe 
inhaltlich kaum überschneiden, lässt sich aus dem Umstand erklären, dass Theophanes und Nikephoros (bzw. ihre Quellen) den Fokus ihres jeweiligen Berichtes auf unterschiedliche Aspekte von Herakleios’ Rückkehr lenken. Diese Beobachtung trägt nicht zuletzt auch zum Verständnis der Inszenierung bei, die sich aus zwei nur lose miteinander verbundenen Sequenzen zusammensetzte: Empfang und Einzug einerseits, Hippodromspiele andererseits.

Der Empfang in Hiereia stand in der Tradition des Adventus-Zeremoniells, des kaiserlichen Einzuges in eine Stadt, das keinen per se militärischen Hintergrund hatte. ${ }^{21}$ Wie bereits Justinians Einzug des Jahres 559 - nach einer persönlichen Inspektion der Langen Mauern in Thrakien kehrte der Kaiser nach Konstantinopel zurück $^{22}$ - wurde auch Herakleios' Adventus von 628 stattdessen explizit religiös aufgeladen: Die Sequenz, im Zuge derer die städtische Bevölkerung Herakleios in Empfang nahm und vom militärisch konnotierten Äußeren in den zivilen Raum der Hauptstadt überführte, wurde mit Elementen liturgischer Prozessionen angereichert (Olivenzweige und Lichter, Dankeshymnen an Gott), wie sie im städtischen Raum Konstantinopels auch unter Teilnahme der Kaiser bereits über Jahrhunderte praktiziert worden waren. ${ }^{23}$ Neben dem ältesten Sohn des Kaisers, Herakleios Konstantin, der mit seinem Kniefall vorm Vater die dynastische Komponente der herakleischen Herrschaft demonstrierte, kam dem Patriarchen Sergios dabei eine herausgehobene Stellung zu. Indem schließlich auch Vertretern der Bevölkerung eine aktive Funktion zugewiesen wurde, demonstrierte die Sequenz gleichsam die Einheit des hauptstäd-

Mango 1990, 186 und die ausführliche Rekonstruktion unten S. 283-286. Entsprechend erachte ich die Chronologie des Nikephoros für falsch; dass die relativen Datierungen im Breviarium mit Vorsicht zu genießen sind, wurde bereits betont.

21 Pfeilschifter 2016, $475 \mathrm{f}$. betont, dass das Adventus-Zeremoniell sich besonders dafür eignete, in einen spezifisch christlichen Kontext eingepasst zu werden; vgl. zu Herakleios’ Adventus MacCormack 1981, 86 - 89, die allerdings nicht zwischen den zwei Phasen des Zeremoniells (1. Einzug; 2. Feierlichkeiten in der Stadt) unterscheidet. Zum Adventus allgemein siehe MacCormack 1972.

22 Ein ausführlicher Bericht dieses Einzuges findet sich in De cerim. 1 App. (Reiske 497 f.): Nachdem er die Stadt durch das Charision-Tor betreten hatte, begab sich Justinian zum Gebet in die Apostel-Kirche; auf der Mese erwarteten ihn Vertreter der Bevölkerung mit einem Kerzen-Spalier. Als der Kaiser den Palast betrat, wurde er mit triumphalen Akklamationen empfangen; siehe dazu McCormick 1986, 67; Leppin 2011, 321f. Der Unterschied zum Einzug von 628 besteht darin, dass das Treffen mit der hauptstädtischen Bevölkerung sich bei Herakleios' Einzug außerhalb der Stadt vollzog, sodass das Element des Überführens vom militärisch konnotierten Äußeren ins zivile Innere der Stadt noch stärker betont wurde. Hinsichtlich Justinians Einzug ist bemerkenswert, dass Theoph. Conf. AM 6051 (De Boor 234) zwar dessen Aktivität an den Langen Mauern, nicht aber die Details seiner Rückkehr erwähnt, wie sie das Zeremonienbuch wiedergibt; ähnlich wie bei Herakleios' Rückkehr sieht man also auch hier, dass verschiedene Überlieferungslinien den Fokus auf jeweils spezifische Aspekte des Geschehens lenken können.

23 McCormick 1986, 72; zur Herausbildung eines städtischen Zeremoniells und den Positionierungsund Repräsentationsmöglichkeiten des Kaisers innerhalb dieses Zeremoniells siehe Diefenbach 1996, bes. 43 - 52. Darüber, auf welchem Wege genau Herakleios sich in die Stadt begab, ob er etwa auf dem Weg in Kirchen Halt machte, geben die Quellen leider keine Auskunft. 
tischen Sozialgefüges: Herakleios’ Rückkehr wurde zum Moment städtischer Selbstvergewisserung. ${ }^{24}$

Das vorige Kapitel hat deutlich gemacht, wie der Krieg gegen die Perser im Allgemeinen und Herakleios’ Aktivität als Feldherr im Speziellen im hauptstädtischen Diskurs in einen religiösen Deutungszusammenhang eingepasst wurden. Diese Deutung konnte auch auf den Moment des Sieges übertragen werden: Theophanes - aller Wahrscheinlichkeit nach in Rückgriff auf Georg von Pisidien - beschreibt Herakleios' Rückkehr analog zum siebten Tag der göttlichen Schöpfung, dem Tag der Rast. ${ }^{25}$ In der Gestaltung von Herakleios' Einzug, soweit dieser sich aus Theophanes' Chronographie rekonstruieren lässt, war die religiöse Deutung zumindest in Grundzügen bereits praktisch angelegt. Was Georg von Pisidien kurz darauf in der Heraclias in Worte fasste - die Transformation vom schwitzenden Kaiser zum erhabenen Lichtwesen -, äußerte sich also bereits im Zeremoniell, im Zuge dessen der kriegführende Kaiser nach langer Abwesenheit in das Beziehungsgeflecht der Hauptstadt reintegriert wurde.

Innerhalb der Stadtmauern entfaltete sich daraufhin eine Sequenz, die sich - zumindest soweit sich dies aus Nikephoros' Bericht erschließen lässt - aus einem anderen Referenzrahmen speiste. Anstelle des religiösen Charakters überwogen nun Versatzstücke, die einer säkularen Triumphalpraxis entstammten, wie sie sich im konstantinopolitaner Kontext ab dem 4. Jahrhundert herausgebildet hatte. Die andächtige Stimmung, welche beim Aufeinandertreffen in Hiereia geherrscht hatte, wich nun einer typisch triumphalistischen Konfrontation: Mit Akklamationen begrüßten die Städter ihren Kaiser, der seinerseits Geldspenden verteilte und die Rückerstattung des Kirchenvermögens anordnete, das er zur Finanzierung des Krieges eingezogen hatte. ${ }^{26}$ Mittelpunkt der mehrtätigen Feierlichkeiten war der Hippodrom, der sich in den Jahrhunderten hauptstädtischer Monarchie als Kristallisationspunkt der Repräsentation kaiserlicher Sieghaftigkeit herausgestellt hatte. ${ }^{27}$ Über die Ausgestaltung der Spiele gibt Nikephoros nur unzureichend Auskunft. Es scheint jedoch plausibel, dass Herakleios gemäß der Tradition hauptstädtischer Siegesfeierlichkeiten - im Kathisma thronte, wo

24 Vgl. Diefenbach 1996, 49f., der in Bezug auf das 5. Jahrhundert den Adventus (sowohl den des Kaisers als auch das Empfangen von Reliquien) als identitätsstiftendes Moment für die städtische Gemeinschaft beschreibt.

25 Siehe dazu oben S. 240.

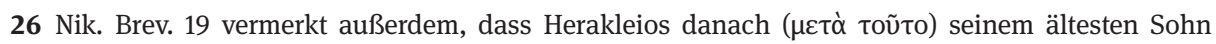
Herakleios Konstantin den Konsulat übertragen und Heraklonas, seinen Sohn aus der Ehe mit Martina, zum Caesar erhoben habe. Diese Erhebung fand nachweisbar 632 statt; siehe Mango/Scott 1997, 433 Anm. 2. Dass Nikephoros die Erhebung in direkte Verbindung mit den Siegesfeierlichkeiten setzt, könnte als Argument gegen meine Datierung der Siegesfeierlichkeiten ins Jahr 628 genutzt werden. Dennoch halte ich an der These fest, da Nikephoros wiederholt Ungenauigkeiten in der relativen Chronologie aufweist. Nach der Notiz von der Erhebung seiner Söhne durch Herakleios fährt Brev. 20 mit dem Bericht über die Eroberungen der Araber fort.

27 Auf die andauernde Bedeutung des Hippodroms habe ich bereits im Zusammenhang mit den erweiterten Krönungsritualen im frühen 7. Jahrhundert hingewiesen; dazu siehe oben S. $122 \mathrm{f}$. 
er die Huldigungen der Bevölkerung entgegennahm und die Spiele überwachte. Aus der Position des Feldherrn rückte er nun wieder in die typische Rolle der hauptstädtischen Kaiser: die des entrückten Siegers. Die vier Elefanten, die durch den Hippodrom geführt wurden, scheinen als Zurschaustellung von Beute indes im Vergleich zu dem spektakulärsten Triumph des 6. Jahrhunderts, dem Vandalentriumph unter Justinian, eher mager. Nach dem Sieg über die Perser - oder genauer gesagt: dem Friedensvertrag mit Chosroes' Nachfolger Kavadh Seiroe - ließen sich in Konstantinopel kaum Spolien vorzeigen. Während Justinian nach einem Erfolg gegen die Perser, errungen von seinen Generälen, im Stadtbild durch mehrere Reiterstatuen als Sieger verewigt worden war, ${ }^{28}$ blieb dergleichen unter Herakleios offenbar aus. ${ }^{29}$

Für Herakleios’ Rückkehr nach langjähriger Abwesenheit, mit einem Persersieg im Rücken, gab es im Konstantinopel des frühen 7. Jahrhunderts keinen Präzedenzfall. Die Strukturen, die die kaiserliche Repräsentation im öffentlichen Raum ebenso wie die Interaktion mit der Bevölkerung bedingten, waren durch Jahrhunderte sesshafter Kaiser geformt worden. Als die Position des Kaisers und die des Feldherrn unter Herakleios wieder in einer Person zusammenfielen, bestand die Herausforderung darin, diese Personalunion im Zeremoniell nicht nur sichtbar, sondern auch im Sinne einer Stabilisierung von Herrschaft nutzbar zu machen. Seine Wiedereingliederung in die Hauptstadt erfolgte durch ein hybrides Ritual, das die zwei Hauptsequenzen - Empfang/Einzug und Siegesfeier, jeweils gespeist aus distinkten Referenzrahmen - nur lose aneinanderreihte, anstatt sie organisch zu verschränken. Während Georg von Pisidien den Kaiser im panegyrischen Diskurs zum Feldherrn des kosmischen Geburtstages hochloben konnte, ${ }^{30}$ war Herakleios' praktischer Handlungsspielraum im normativ regulierten Umfeld der Hauptstadt weiterhin beschränkt. Die traditionell anmutenden Feierlichkeiten im Hippodrom kamen dem Bedürfnis des städtischen Umfeldes nach derartigen Inszenierungen nach; dabei entsteht der Eindruck, dass Herakleios seinen persönlich erfochtenen, militärischen Erfolg in Konstantinopel nur in Maßen ausleben konnte, was nicht zuletzt daran gelegen haben mag, dass die Strukturen einer hauptstädtischen Monarchie kaum Platz für den kriegführenden Kaiser boten. Einige Jahre später sollte Herakleios jedoch einen weiteren Triumph feiern - in einem Umfeld, das weit weniger als die Hauptstadt von Verhaltenserwartungen an den Kaiser geformt war. ${ }^{31}$

28 Dazu siehe oben S. 69 Anm. 179.

29 Vgl. McCormick 1986, 71f. und Pfeilschifter 2013, 475 zu Herakleios’ Rückkehr; letzterer misst allerdings der Adventus-Sequenz wesentlich größere Bedeutung zu als den Feierlichkeiten innerhalb der Stadt.

30 Dazu siehe oben S. 240 - 242. Hierin zeigt sich erneut der Wert der Panegyrik, die zu einem gewissen Grad im Diskurs kompensiert, was in der Praxis nur schwerlich umsetzbar war.

31 In diesem Zusammenhang bedanke ich mich für Anregungen von Johannes Wienand, der seine Arbeit zu Herakleios bislang noch nicht veröffentlicht hat. 


\subsubsection{Herakleios in Jerusalem - die Restitutio Crucis}

Während Herakleios in heimatliches Gebiet zurückkehrte, nahmen die Unruhen um die Besetzung des persischen Thrones eine neue Wendung: Nur acht Monate nach seiner Erhebung verstarb Seiroe und wurde von seinem minderjährigen Sohn Ardashir beerbt. ${ }^{32}$ Die Regierung in Ctesiphon hatte sich bereits zuvor bei der Kontrolle des versprengten persischen Heeres als quasi handlungsunfähig erwiesen; die Reichweite der Zentralmacht war massiv geschwächt. Dass sich dies unter Ardashir grundlegend ändern würde, war kaum abzusehen. Wollte Herakleios seine Anliegen - die endgültige Räumung der römischen Ostprovinzen durch die Besatzer - umgesetzt sehen und weitere militärische Konfrontation vermeiden, musste er sich auf eine Kooperation mit Shahrbaraz einlassen, der auf Seiten der Perser über die entscheidenden Ressourcen verfügte. Gesandtschaften zwischen Herakleios und dem General wurden ausgetauscht; beide zeigten sich für eine Zusammenarbeit offen und die persischen Truppen begannen tatsächlich mit dem Rückzug. ${ }^{33}$ In diesem Zusammenhang machte Herakleios sich erneut auf den Weg in den Osten.

Im Kapitel 4 wurden die Gründe für Herakleios’ Bruch mit etablierter monarchischer Verhaltenspraxis herausgearbeitet. Dass er als erster Kaiser seit über zweihundert Jahren Konstantinopel verließ, um an der Spitze der römischen Truppen in den Krieg zu ziehen, resultierte aus zwei miteinander verschränkten Entwicklungen: der außenpolitischen Bedrohung durch die Perser einerseits und dem Umstand andererseits, dass es im frühen 7. Jahrhundert verstärkt zu Unruhen und Ermächtigungsversuchen aus dem militärischen Sektor kam. Das hauptstädtische Umfeld bot dem sesshaften Kaiser offenbar nicht mehr die nötigen Ressourcen, um interne Konkurrenz einzuhegen. Um seine Herrschaft zu sichern, war Herakleios darum bemüht, die kaiserliche Autorität über den militärischen Sektor - und damit einhergehend auch die Stabilität seiner Position in Konstantinopel - zu sichern. Als die Perser 628 tatsächlich bezwungen werden konnten, sanktionierte der Erfolg Herakleios' transgressive Maßnahme gegenüber dem hauptstädtischen Umfeld. Doch obwohl der akute militärische Konflikt vorerst beigelegt war, blieb der Kaiser auch nach seiner triumphalen Rückkehr nicht in Konstantinopel.

Dass Herakleios die Hauptstadt erneut verließ, zieht zwei Schlussfolgerungen nach sich: einerseits in Hinblick auf die Möglichkeit dieser Maßnahme, andererseits in Hinblick auf die zugrundeliegende Intention. Herakleios' Abkehr von Konstantinopel war in den 620er Jahren gegenüber der dortigen Öffentlichkeit mit der Notwendigkeit seines persönlichen Engagements im Perserkrieg plausibilisiert worden; eine derartige Rechtfertigung gab es nach dem Friedensschluss nicht mehr. Herakleios indes hatte mit seiner Politik einen Paradigmenwechsel eingeleitet und dem hauptstädti-

$32 \mathrm{Zu}$ der sassanidischen Thronfolge siehe Bonner 2019, 313-317.

33 Zum Tod des Seiroe siehe etwas Sebeos 40 (Thomson/Howard-Johnston I, 87 f.) mit Kommentar bei Thomson/Howard-Johnston 1999 II, 222f. und Chron. 1234, 103 (Chabot I, 186); vgl. Flusin 1992 II, 289; Howard-Johnston 1999, 27 f.; Kaegi 2003, 184 f. 
schen Umfeld ein erweitertes Maß an Handlungsspielraum abgerungen; die enge physische Bindung des Monarchen an Konstantinopel, die das 5. und 6. Jahrhundert geprägt hatte, war gelockert und wich langsam aber sicher neuen Standards. Der Kaiser konnte es sich leisten, der Hauptstadt erneut den Rücken zuzukehren. Doch warum machte Herakleios von diesem erweiterten Handlungsspielraum Gebrauch, anstatt sich nach seinem Triumph in der Hauptstadt zur Ruhe zu setzen? Geht man davon aus, dass die grundsätzliche Motivation hinter politischen Entscheidungen des Kaisers in Machterhalt und Sicherung der Herrschaft lag - welche Folgen ein Akzeptanzentzug haben konnte, hatten die gewaltsamen Machtwechsel von 602 und 610 allzu deutlich gezeigt -, eröffnet sich folgende Erklärung: Selbst der Sieg über die Perser konnte Herakleios nicht gegen potentielle Kritiker und Herausforderer immunisieren; er musste sich weiterhin um die Sicherung seiner Position bemühen. ${ }^{34}$

Nach ersten Annäherungen zwischen Herakleios und Shahrbaraz kam es im Sommer des Jahres 629 zu einem persönlichen Treffen der beiden Männer in Arabissos im Anti-Taurus. Bei den dort stattfindenden Verhandlungen konnte eine formale Einigung erreicht werden: Herakleios würde Shahrbaraz bei dessen Griff nach dem persischen Thron unterstützen; Shahrbaraz seinerseits willigte ein, alle Gebiete diesseits des Euphrats zu räumen. ${ }^{35}$ Wie bereits einige Jahre zuvor, als es um eine römische Allianz mit dem türkischen Khagan gegangen war, unterfütterten die beiden Machthaber ihren Pakt auch nun mit der Aussicht auf eine familiäre Verbindung: Shahrbaraz' Sohn Niketas wurde in den Rang eines Patrikios erhoben und seine Tochter Nike mit einem von Herakleios' Söhnen aus zweiter Ehe, Theodosios, verlobt. ${ }^{36}$ Abgesehen von der Gebietsfrage erwies sich in Arabissos jedoch ein weiteres römisches Anliegen als zentral: die Forderung nach der Rückgabe des Heiligen Kreuzes, welches nach der Eroberung Jerusalems 614 von Shahrbaraz nach Ctesiphon verschleppt worden war.

Die Eroberung Jerusalems durch die Perser und die Deportation der Kreuzreliquie aus der Anastasis-Kirche nach Ctesiphon hatten Schockwellen durch den gesamten christlichen Mittelmeerraum gesandt. Welches Schicksal genau der umkämpften Reliquie in persischen Händen widerfuhr, ist angesichts einer legendenhaften Aus-

34 Dass selbst ein prestigeträchtiger Sieg über die Perser den Kaiser in Konstantinopel nicht grundsätzlich absichern konnte, zeigt bereits die Regierung Justinians: Nur wenige Jahre, nachdem er den Sieg Belisars über die Perser von 530 in der Hauptstadt hatte auf die eigene Person beziehen können, brach der Nika-Aufstand aus (532), der ihn beinahe den Thron kostete.

35 Siehe Sebeos 40 (Thomson/Howard-Johnston I, 87f.) mit Kommentar bei Thomson/HowardJohnston 1999 II, 223f. (ebd. zur Grenzziehung entlang des Euphrats) und für die Datierung Chron. 724 in Palmer 1993, 18, wo auch berichtet wird, dass die beiden Männer anlässlich des Paktes eine der Eirene geweihte Kirche errichteten.

36 Nik. Brev. 17 ist die einzige Quelle für diese familiäre Bindung; vgl. Mango 1985, 105f. Im Gegensatz zu Sebeos 40 (Thomson/Howard-Johnston I, 87 f.) geht hier die Initiative für ein Treffen von einem unterwürfigen Shahrbaraz aus. Zum Treffen in Arabissos siehe Mango 1985, 110-112; Flusin 1992 II, 288-291; vgl. auch Stratos 1968, 245-248; Kaegi 2003, 187-189 zuletzt Booth 2019, 781-784, 823 auch zu den Gründen für die Ortswahl. 
schmückung durch die Quellen kaum zu rekonstruieren. ${ }^{37}$ Im Zusammenhang mit der byzantinischen Offensive gegen die persischen Aggressoren ab 622 scheint die Rückgewinnung des Heiligen Kreuzes den öffentlichen Diskurs noch nicht bestimmt zu haben; ${ }^{38}$ erst nachdem Herakleios die Perser hatte bezwingen können, trat das Kreuz wieder auf die öffentliche Agenda. Wann genau die Reliquie zur konkreten Verhandlungssache wurde - ob bereits im Frühjahr des Jahres 628 oder erst im Sommer 629, im Zuge des Treffens zwischen Herakleios und Shahrbaraz -, lässt sich indes angesichts einer teils diffusen Überlieferung schwer bestimmen. ${ }^{39}$ Das innenpolitische Chaos, in dem das persische Reich nach der Ermordung des Chosroes II. versank, machte eine rasche Rückerstattung jedenfalls vorerst nicht möglich. Erst mit der Allianz zwischen Herakleios und Shahrbaraz geriet die Angelegenheit in Bewegung.

Mit römischen Hilfstruppen konnte Shahrbaraz tatsächlich Ctesiphon einnehmen und den minderjährigen Vertreter der sassanidischen Dynastie, den Großkönig Ardashir, überwältigen. ${ }^{40}$ Auch Shahrbaraz hielt seinen Teil der Abmachung ein: Das Heilige Kreuz wurde dem römischen General David übergeben, der es im nordsyrischen Hierapolis wiederum Herakleios persönlich aushändigte. ${ }^{41}$ Aufregung und Euphorie griffen um sich, als Herakleios sich mit der Reliquie und großem Gefolge in

37 Zum Kreuz in Persien siehe Payne 2015, 177-180. Mir geht es an dieser Stelle nicht um die Frage, ob es sich bei dem Objekt, das Herakleios übergeben wurde, tatsächlich um die Reliquie aus der Anastasis-Kirche handelte; entscheidend ist vielmehr, dass die Zeitgenossen daran glaubten, dass es sich so verhielt; vgl. dazu die kritische Bewertung bei Zuckerman 2013, bes. 216-218.

38 Keine der Quellen, die Herakleios' Konter-Offensive vor dem Sieg über die Perser thematisiert, erwähnt das Kreuz; siehe Drijvers 2002, 182.

39 Laut Nik. Brev. 15 forderte Herakleios die Kreuz-Reliquie bereits bei den Verhandlungen mit Seiroe zurück; die Notiz bei Theoph. Conf. AM 6118 (De Boor 327), Seiroe habe Herakleios die Kreuzreliquie ausgehändigt, ist offenkundig falsch. Bei Sebeos 40 (Thomson/Howard-Johnston I, 88) wird die Rückgabe des Kreuzes zwischen Herakleios und Shahrbaraz verhandelt; ähnlich in Chron. 1234, 103 (Chabot I, 186).

40 Gemäß al-Tabari wurde der junge Ardashir am 27. April 630 ermordet; die Eroberung Ctesiphons durch Shahrbaraz und die Rückgabe des Kreuzes erfolgten allerdings schon früher; siehe Flusin 1992 II, 297, 306-309.

41 Ant. Strateg. (Conybeare 516); Anon. Guidi (Nöldeke 31f.); Chron. Seert (Scher 556); Mich. Syr. 11.7 (Chabot II, 427); die Angabe bei Theoph. Conf. AM 6118 (De Boor 327), dass das Kreuz bereits durch Seiroe zurückgegeben wurde, ist nicht authentisch; siehe dazu Flusin 1992 II, 295-297 und Stratos 1968, 248-250, 384-387. Chron. 1234, 103 (Chabot I, 186) beschreibt die Ankunft der Reliquie in Hierapolis besonders detailliert: „Heraclius came out from Mabbugh to greet the Cross on its arrival and he took possession of it with due solemnity" (übers. in Palmer 1993, 142). Das Empfangen der Reliquie durch Herakleios erinnert an die Reliquientranslationen nach Konstantinopel, bei denen das heilige Objekt von Kaiser und Bevölkerung in die Stadt überführt wurde; dazu siehe Diefenbach 2002. Zuletzt haben Klein 2001, Zuckerman 2013 (besonders ausführlich) und Booth 2014, 155f. dafür argumentiert, dass das Kreuz zuerst nach Konstantinopel gebracht wurde, wo es am 14. Sept. 629 in der Hagia Sophia erhöht wurde, bevor Herakleios mit der Reliquie nach Jerusalem aufbrach; damit folgen sie in Teilen Theoph. Conf. AM 6120 (De Boor 328). Man würde allerdings meinen, dass etwa Georg. Pis. eine längere Präsenz des Kreuzes in der Hauptstadt, zumindest in seinem Gedicht In Restitutionem S. Crucis, kommentiert hätte. Ich halte diese These daher nicht für plausibel. 
Richtung Jerusalem in Bewegung setzte. ${ }^{42}$ Die christliche Bevölkerung Palästinas war sich der Außerordentlichkeit dessen bewusst, was sich im Frühjahr des Jahres 630 vor ihren Augen abspielte: Die bedeutendste christliche Reliquie, die von ihrer legendären Auffindung durch Konstantins Mutter Helena bis zum Raub durch die Perser in der Jerusalemer Grabeskirche aufbewahrt worden war, fand nun - nach beinahe 15-jährigem babylonischem Exil - an ihren angestammten Ort zurück. Und mehr noch: Mit Herakleios betrat zum ersten Mal überhaupt ein christlicher Kaiser persönlich die Heilige Stadt; am 21. März 630 zog er mit dem Heiligen Kreuz in Jerusalem ein. ${ }^{43}$ Der anonyme Autor der Translatio corporis Sancti Anastasii Persae, aller Wahrscheinlichkeit nach selbst ein Augenzeuge, bringt den epochalen Charakter dieses Ereignisses besonders gut zum Ausdruck. ${ }^{44}$

„Denn es geschah etwas, das noch nie zuvor geschehen war. Keiner der christlichen Kaiser ist nämlich seit Menschengedenken je nach Jerusalem gekommen. Allein unser sanftmütigster und

42 Theoph Conf. AM 6120 (De Boor 328) und Eutychios (Breydy 108f.) berichten, Herakleios habe auf seinem Weg in Tiberias Halt gemacht und dort Mitglieder der jüdischen Gemeinde getroffen; nach versöhnlichen Gesten sollten die Spannungen zwischen jüdischer und christlicher Bevölkerung später allerdings erneut eskalieren; zu der Rekonstruktion von Herakleios' Itinerar nach der Übergabe des Kreuzes siehe auch Flusin 1992 II, 309-311.

43 Vor allem das Jahr der Restitutio Crucis ist umstritten: 628, 629, 630 und 631 stehen zur Debatte, wobei in der Forschung in der Regel der 21. März 630 akzeptiert wird. Eine besonders eingehende Rekonstruktion findet sich bei Flusin 1992 II, 293-309; siehe außerdem Baynes 1912a; Frolow 1953; Stratos 1968, 384-387; Pertusi 1959, 235f.; Grumel 1966. Speck 2000 datiert die Rückführung des Kreuzes bereits ins Jahr 628 (mit Verweis auf seine ausführlichere Untersuchung in ders. 1988, 327378), was allerdings der Logik des Ereignisverlaufes und auch der Evidenz der Quellen widerspricht. Vgl. außerdem Zuckerman 2013 (bes. 197 f.), der sich mit elaborierter Argumentation und Berücksichtigung aller Quellen dafür ausspricht, dass das Kreuz zweimal nach Jerusalem gebracht wurde: die erste Restitutio am 21. März 629, daraufhin Präsentation in Konstantinopel, dann erneute Rückführung nach Jerusalem am 30. März 630. Kern dieser Argumentation ist allerdings, dass Shahrbaraz Herakleios eine (gefälschte) Kreuzreliquie übergab, noch bevor er von Ägypten nach Persien zurückkehrte, um die Herrschaft in Ctesiphon zu übernehmen. Ich halte dies für zu konstruiert. Die meiner Ansicht nach überzeugende Datierung auf den 21. März 630 leitet sich aus folgenden Quellen ab: Die Transl. Anast. Pers. 1 gibt für Herakleios' Einzug in Jerusalem die dritte Indiktion (1. Sept. 629 - 31. Aug. 630) und sein 20. Regierungsjahr an (Okt. 629-630); Ant. Strateg. (Conybeare 516) nennt als Datum den 21. März, allerdings ist hier die Jahresangabe problematisch: Es wird zwar ebenfalls die dritte Indiktion, allerdings das 21. Regierungsjahr des Herakeios genannt, also 631. Der 21. März 630 wird durch Georg. Pis. Rest. Cruc. 104-116 untermauert, wo erwähnt wird, dass die Nachricht von der Rückerstattung am Feiertag des Lazarus in Konstantinopel eingetrafen - im Jahr 630 fiel dieser Feiertag auf den 31. März (abhängig von Ostern, 8. April 630): Die Reisezeit von zehn Tagen zwischen Jerusalem und Konstantinopel ist für einen Eilboten durchaus realistisch. In den Jahren 628 und 631 lag Ostern derart früh, dass eine Ankunft der Nachricht in der Hauptstadt am Feiertag des Lazarus nicht mit der Rückerstattung am 21. März überein gebracht werden kann; höchstens 629 steht damit noch zur Debatte (Ostern 16. April).

44 Der Text entstand kurz nach der Translatio der Gebeine des Heiligen Anastasios in ein nahe Jerusalem gelegenes Kloster; siehe dazu Flusin 1992 I, $95 \mathrm{f}$. 
über alle Maßen frommer Kaiser wohnte uns bei zusammen mit dem lebensstiftenden Kreuz des Heilands in der dritten Indiktion und dem zwanzigsten Jahr seiner Herrschaft.“ ${ }^{*} 45$

Im Zuge der Christianisierung römischer Monarchie rückte Jerusalem als der Ort von Tod und Auferstehung Christi zunehmend in den Fokus kaiserlicher Politik. Mit dem Bau der Anastasis-Kirche über Golgatha und dem Grab Christi hatte bereits Konstantin I. das „neue Jerusalem (...) gegenüber dem altberühmten“, dem Jüdischen, an das der leere Tempelberg stets gemahnte, begründet. ${ }^{46}$ Die Anastasis-Kirche beherbergte nicht zuletzt auch die Überreste des Kreuzes, um dessen Auffindung sich mehrere Legenden rankten: Gemäß eines Überlieferungsstranges zeichnete Helena, die Mutter Konstantins, persönlich dafür verantwortlich. ${ }^{47}$ Auch im 5. und 6. Jahrhundert rissen kaiserliche Zuwendungen an Jerusalem nicht ab: Unter Justinian gipfelte derartiges Engagement im monumentalen Ausbau des Stadtzentrums, das mit der Nea-Kirche einen weiteren, symbolträchtigen Kultort gewann. ${ }^{48}$ Doch während Mitglieder der kaiserlichen Familie teilweise gar längerfristig in Jerusalem residierten, hatte bis ins Jahr 630 - wie der Autor der Translatio ganz treffend anmerkt - kein christlicher Kaiser persönlich den Fuß in die Heilige Stadt gesetzt; Herakleios war der erste. „Größte Freude und unbeschreiblicher Frohsinn ergriff die fernsten Winkel der Erde“449 - so die Reaktionen gemäß der Translatio.

Die spektakuläre Restitutio Crucis, die nicht nur Zeitgenossen in ihren Bann zog, ist der in der Forschung wohl meistbeachtete Aspekt von Herakleios' Herrschaft. Um nachzuvollziehen, welches politische Ziel der Kaiser mit seiner Reise nach Jerusalem verfolgte, werde ich mich sowohl um die Rekonstruktion des Ereignisses bemühen als auch die Frage adressieren, wie die Restitutio in verschiedenen Kontexten kommuniziert und gedeutet wurde. Dabei komme ich nicht umhin, auch die bisherige Forschung einer Revision zu unterziehen.

Wie bereits die Rückkehr des Herakleios nach Konstantinopel, so wurde auch der kaiserliche Einzug in Jerusalem - folgt man dem Bericht des Sebeos ${ }^{50}$ - als AdventusRitual vollzogen. ${ }^{51}$ Gemeinsam mit dem römischen Heer und dem kaiserlichen Gefolge

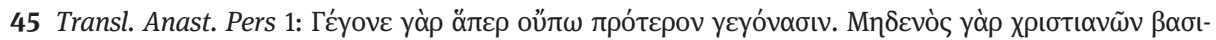

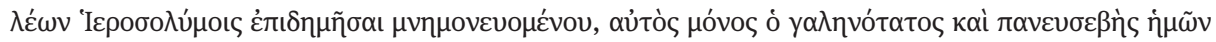

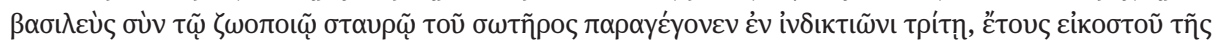

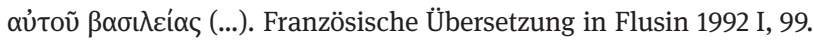

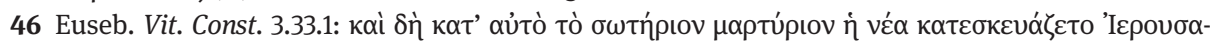

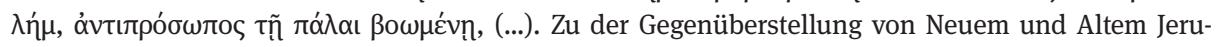
salem, wie sie sich im Bau der Anastasis-Kirche äußert, siehe Ousterhout 1990; Wilken 1992, 82-100. 47 Zur Auffindung des Kreuzes und der legendarischen Ausgestaltung siehe ausführlich Borgehammar 1991; Drijvers 1992; zusammenfassend Drijvers 2002, 179-181.

48 Diesen Prozess betrachtet Trampedach 2001 und ders. (im Druck); ders. 2015 zur Nea-Kirche Justinians; siehe allgemein auch die Beiträge des Sammelbandes Wienand/Klein (im Druck).

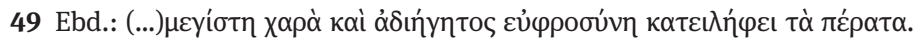

50 Sebeos 41 (Thomson/Howard-Johnston I, 90).

51 Vgl. Drijvers 2002, 185f.; Booth 2013a, 9 f. 
näherten Herakleios und seine Ehefrau Martina sich der Heiligen Stadt; ${ }^{52}$ die Bewohner Jerusalems empfingen das kaiserliche Paar und das Kreuz voller Ehrfurcht. So überwältigt sei die Menschenmenge gewesen, dass vor lauter Emotionen noch nicht einmal die liturgischen Hymnen gesungen werden konnten. ${ }^{53}$ Herakleios verteilte Almosen an die Menschenmenge ebenso wie an die Kirche; neben der Kreuzreliquie erstattete er auch weitere heilige Objekte zurück, die Jahre zuvor angesichts der persischen Eroberung in Sicherheit gebracht worden waren. ${ }^{54}$ In der Stadt traf Herakleios auf Modestos, der anstelle des im Exil verstorbenen Patriarchen Zacharias der Jerusalemer Kirche vorstand. Als der Kaiser das Kreuz dem versammelten Klerus präsentierte, konnte vor aller Augen die Unversehrtheit des Reliquiars und seines kostbaren Inhaltes bestätigt werden. ${ }^{55}$ Mit einer derartigen Inszenierung wurde nicht nur die Rückerstattung in die Anastasis-Kirche besiegelt, sondern auch die Authentizität der Reliquie - und nicht zuletzt die Validität von Herakleios' Restitution - nach den ungewissen Jahren in Persien öffentlich sanktioniert. ${ }^{56}$

Während die griechischen bzw. nahöstlichen Quellen keine weiteren Details zu Herakleios' Einzug in Jerusalem preisgeben, beruft sich die Forschung gerne auf eine lateinische Überlieferungstradition, ${ }^{57}$ die zuletzt von Stephan Borgehammar einer eingehenden Analyse und historischen Kontextualisierung unterzogen wurde. Als älteste Evidenz für diese lateinische Tradition identifiziert Borgehammar zwei liturgische Texte, die Reversio Sanctae Crucis und die Exaltatio Sanctae Crucis, die mit dem

52 Die Präsenz Martinas wird Ant. Strateg. (Conybeare, 516) entnommen; laut Sebeos 41 (Thomson/ Howard-Johnston I, 90) befanden sich auch die „Prinzen“ in Herakleios’ Gefolge. Dabei handelte es sich wohl um Kinder von Herakleios und Martina; Herakleios’ältester Sohn, der Augustus Herakleios Konstantin, war sicherlich als Vertreter des Vaters in Konstantinopel geblieben.

53 Das Weinen und Beten beim Einzug in Jerusalem schildert auch Georg. Pis. Rest. Cruc. 27-29. 54 Sebeos 41 (Thomson/Howard-Johnston I, 90).

55 Bereits der zeitgenössische Ant. Strateg. (Conybeare, 516) dokumentiert eine derartige Inszenierung; der Unversehrtheit der Reliquie widerspricht allerdings Ant. Strateg. (Conybeare 510 f.), wo von der Schändung des Kreuzes auf dem Weg nach Ctesiphon 614 berichtet wird. Die Unversehrtheit der Reliquie wird auch in der lateinischen Tradition betont (Exalt. S. Cruc. 4; ähnlich Revers. S. Cruc. 5), wo Chosroes das kostbare Reliquiar, das das Kreuz umschließt, auf seinem Thron als Rückenlehne nutzt. Noch ausführlicher ist Nik. Brev. 18, laut dem die Kleriker die Unversehrtheit des Siegels bestätigen, dann den Schlüssel des Reliquiars hervorholen, der in ihrem Besitz ist, und es vor aller Augen öffnen; siehe dazu Frolow 1953, 96 - 99; Flusin 1992 II, 311 f.; außerdem Zuckerman 2013, 217 f., der das Objekt, das Herakleios nach Jerusalem brachte, nicht für die 614 verschleppte Reliquie und die Inszenierung dementsprechend für eine Farce hält. Dass ich Zuckermans Argumentation nicht folge, habe ich bereits an anderer Stelle betont. Aus den Quellen wird deutlich, dass zeitgenössische Beobachter die Reliquie für authentisch hielten - und darum geht es letztendlich.

56 Mango 1992, 6 meint, dass diese Inszenierung dazu diente, zu zeigen, dass die Perser die Reliquie angemessen behandelt hätten - als Zeichen dafür, dass die Perser auf dem besten Weg seien, zum Christentum zu konvertieren; vgl. bereits ders. 1995, 105-118: Herakleios' dezidiertes Ziel sei es gewesen, die Perser, angefangen mit der Familie seines Verbündeten, des Generals Shahrbaraz, zu konvertieren.

57 So etwa Drijvers 2002, 187 f.; Kaegi 2003, 205f.; Greisiger 2014, 132-136; Meier 2019a, $1043 \mathrm{f}$. 
Fest der Kreuzerhöhung am 14. September in Verbindung stehen. ${ }^{58}$ Gemäß dieser Überlieferung nähert Herakleios sich, das Kreuz im Gepäck, Jerusalem vom Ölberg aus. Als er jedoch gedenkt, das Stadttor zu Pferd und in kaiserlichem Gewand zu durchqueren, ereignet sich ein Wunder: Die Steine des Tores fügen sich zusammen und versperren ihm den Weg. Der Grund für dieses Geschehen wird den Versammelten durch einen Engel offenbart: Während Herakleios seine kaiserlichen Insignien zur Schau stelle, sei Jesus Christus einst voller Demut auf einem Esel sitzend in Jerusalem eingezogen. Der Kaiser versteht den Wink, steigt vom Pferd, legt sein Ornat ab und nähert sich barfuß mit dem Kreuz in der Hand dem Tor; die Steine bewegen sich erneut und gewähren ihm diesmal den Durchgang. ${ }^{59}$ Borgehammar kommt in seiner eingehenden Analyse zu dem Schluss, dass der Ursprung der lateinischen Tradition spätestens in den 640er Jahren liegt und auf ein griechisches Original zurückgeht, das seinerseits zwischen 630 und 636 entstand. ${ }^{60}$ Folgt man Borgehammar, so scheint es in der Tat naheliegend, über die legendarische Ausschmückung Rückschlüsse nicht nur auf die unmittelbare Deutung der Restitutio Crucis, sondern auch auf das Ereignis selbst zu ziehen. Im Folgenden wird dieser Befund mit Fokus auf drei verschränkte Motive (Herakleios’ Akt der Demut, die Parallelisierung mit Christus und sein Einzug durch das Osttor) in einem breiten Kontext betrachtet.

Steckt in der Legende vom demütigen Herakleios ein wahrer Kern? Erwies der Kaiser dem Genius loci Jerusalems und der kostbaren Reliquie in seinen Händen die Ehre und entledigte sich beim Einzug in die Stadt tatsächlich seiner kaiserlichen Insignien? Dass ein römischer Kaiser sich öffentlich herabsetzte, um damit unter christlichen Vorzeichen seine Demut zu demonstrieren, erscheint vor dem Hintergrund monarchischer Herrschaftspraxis des 5. und 6. Jahrhunderts durchaus plausibel. Wenn die sesshaften Kaiser in Konstantinopel vor aller Augen ihre Insignien ablegten, sich gar aus dem geschützten Raum des Palastes herausbegaben, um sich unter die Menschen zu mischen, so demonstrierten sie damit nicht nur ihre Fröm-

58 Gemäß Borgehammar 2009, 148f., 160 gehen die beiden Texte auf eine gemeinsame Quelle zurück, haben aber keine Kenntnis voneinander. Die Herakleios-Überlieferung hat bereits Sommerlechner 2003 untersucht; ebd. 325-330 zum Fest der Kreuzerhöhung und den dazugehörigen liturgischen Texten. Die Reversio und Exaltatio Sanctae Crucis waren weit verbreitet (Borgehammar 2009, 146 nennt 200 - 300 Manuskriptbelege, die allerdings nicht weiter als bis ins 9. Jahrhundert zurückreichen) und fanden schließlich auch in die Legenda Aurea des Jacobus von Voragine Eingang; siehe dazu Sommerlechner 2003, 329f.

59 Rever. S. Cruc. 14-17; Exalt. S. Cruc. 17-21; Text bei Borgehammar 2009, 186-189, 198-201; Greisiger 2014, 132; Meier 2019a, $1043 \mathrm{f}$.

60 Borgehammar 2009, 148-160 mit ausführlicher Herleitung, zusammenfassend ebd. 157-160; Brandes 2002a, 35f. geht bereits von einer „totally unknown Eastern source” aus; dem folgt Greisiger 2014, 132f. Borgehammar 2009, 158f. weist zu Recht darauf hin, dass sich in Reversio und Exaltatio keine Spuren der Kritik an Herakleios finden, die in anderen lateinischen Quellen, wie etwa der Chronik des Fredegar, entstanden ca. 650, sehr prominent ist (Fredegar kritisiert explizit Herakleios' Verbindung zu seiner Nichte und seine Religionspolitik). Daher geht Borgehammar davon aus, dass diese Tradition zu einem Zeitpunkt ihren Ursprung nahm, als Herakleios noch auf der Höhe seines Erfolges und der Vorstoß der Araber noch nicht absehbar war. 
migkeit vor Gott, sondern stärkten auch die Bindung zur hauptstädtischen Bevölkerung. ${ }^{61}$ Der Geste kaiserlicher Demut indes war die Erhöhung inhärent; ein Gedanke, der bereits in der Passion und Auferstehung Christi angelegt war: In der stets kontrollierten öffentlichen Herabsetzung trat der Status des Souveräns umso deutlicher zutage. Dass im hauptstädtischen Kontext das Spannungsverhältnis zwischen Erniedrigung und Erhöhung auch in Hinblick auf Herakleios' Repräsentation eine Rolle spielte (in leicht abgewandelter Form), wurde im vorigen Kapitel herausgearbeitet. Doch wie verhielt es sich in Jerusalem? Inszenierte Herakleios sich bei seinem Einzug tatsächlich als demütiger Kaiser? Weder in den zeitgenössischen Texten noch in der späteren armenischen oder griechischen Überlieferung, die ich oben bereits zu Rate gezogen habe, finden sich Hinweise darauf. ${ }^{62}$

Einen Anhaltspunkt zur mutmaßlichen Demut des Kaisers bietet allein eines der wenigen bildlichen Zeugnisse, die mit Herakleios in Verbindung gebracht werden können. Der Türsturz einer Kirche im armenischen Mren, deren Bau anhand der Stifterinschrift auf 639/640 zu datieren ist, stellt - so die Deutung von Christina Maranci - die aus der Reversio bekannte Szene kaiserlicher Demut dar: ${ }^{63}$ Eine Figur in einfachem Gewand, gerade vom Pferd abgestiegen und vor einem Stabkreuz niederkniend, wird von Maranci als Herakleios in Jerusalem identifiziert. ${ }^{64}$ Dass die Kirche tatsächlich mit dem Kaiser in Verbindung steht, zeigt die Stifterinschrift, die vor einer Reihe armenischer Adliger den „siegreichen Kaiser Herakleios“ aufführt. Dennoch sollte die Deutung mit einer gewissen Vorsicht behandelt werden, da der Türsturz keine erklärende Beischrift trägt. ${ }^{65}$ Eine Interpretation der Darstellung, die den

61 Zur Funktion kaiserlicher Demut siehe Diefenbach 1996, 2002; zuletzt ders. 2019, 63 - 78; außerdem Meier 2007b und Kelly 2013; vgl. auch Greisiger 2014, 135.

62 Die Quellen wurden oben bereits genannt; dazu kommt noch ein Gedicht des Georg von Pisidien, welches das Eintreffen der freudigen Nachricht von der Restitutio Crucis in Konstantinopel verarbeitet, das ich im Folgenden genauer analysieren werde. Ant. Strateg. (Conybeare 516) weist auf Herakleios' gesetzeswidrige Verbindung zu seiner Nichte Martina hin; laut dem Text habe Herakleios bei seinem Besuch in Jerusalem Kritik der Kirchenoberen gefürchtet. Dass Herakleios in diesem Zusammenhang einen Akt der Buße bzw. Demut vollzog, erwähnt der Text allerdings nicht.

63 Maranci 2008/2009, 167-173; ihr folgt Borgehammar 2009, 166-168. Dass das Relief Herakleios' Restitutio Crucis darstellt, hat bereits Thierry 1997 angenommen, allerdings noch nicht in Verbindung mit der lateinischen Tradition.

64 Die Darstellung ist grob symmetrisch aufgebaut: Der als Herakleios interpretierten Figur links entspricht eine ähnlich große Figur, die von rechts kommend ebenfalls vor dem Kreuz niederkniet und durch ein Weihrauchgefäß in der Hand als Kleriker ausgezeichnet ist; in ihm erkennt Maranci den späteren Patriarchen Modestos. Das Stabkreuz in der Mitte wird von einer wesentlich kleineren Person getragen, die nicht näher identifiziert wird. Dem Pferd links entspricht rechts ein stilisierter Baum auf einem Hügel; siehe Abbildungen in Maranci 2008/2009.

65 Maranci 2008/2009, 170 beschreibt die Darstellung zu Recht als hapax. Die bildlichen Darstellungen, die zum Vergleich herangezogen werden könnten, datieren allesamt wesentlich später und stammen aus dem westlichen Mittelmeerraum (dazu ebd. 173). Alternative Interpretationen des Türsturzes (Darstellung armenischer Magnaten anstelle des Kaisers) präsentiert Maranci 2008/2009, 168 f. 
armenischen Kontext stärker in den Fokus rückt, erscheint durchaus auch plausibel. ${ }^{66}$

Folgt man indes Marancis Identifizierung, so lässt dies folgende Schlüsse zu: $\mathrm{Ob}$ Herakleios den Akt der Demut tatsächlich in eventu vollzog, ist nicht mehr zu bestimmen; dass die Berichte von vermutlichen Augenzeugen wie Antiochos Strategos und dem Autor der Translatio diesen Aspekt nicht erwähnen, könnte man eher als Argument dagegen anbringen. Sicher ist alleine, dass sich post eventum eine Deutung verbreitete, die die Demut des Kaisers ins Zentrum der Restitutio Crucis stellte. Diese Deutung wurde zwar weit gestreut - geht man tatsächlich davon aus, dass die lateinische Tradition und die Kirche in Mren auf dasselbe Narrativ zurückgehen -, schlug allerdings nur in wenigen Kommunikationskontexten Wurzeln: Während das Motiv das liturgische Gedenken an Herakleios im Westen bestimmte, ${ }^{67}$ findet sich in Konstantinopel keinerlei Spur davon, obwohl kaiserliche Demut dort durchaus als Repräsentationsmodus bekannt war. ${ }^{68}$

Es bleibt zuletzt auf Evidenz hinzuweisen, die nahelegen könnte, dass im Nahen Osten - also in dem Raum, in dem Borgehammar die Entstehung der Legende vermutet - die Idee des demütigen Kaisers zumindest latent fortlebte. Die Berichte vom Einzug des Kalifen Umar in Jerusalem 638 betonen seine einfache Kleidung, sodass man geneigt ist, hierin eine Herakleios-Imitatio zu vermuten. ${ }^{69}$ Für eine enge Verbindung zwischen Herakleios' Aktivität im Heiligen Land und der kurz darauf einsetzenden arabischen Expansion und Eroberung Jerusalems hat zuletzt Mischa Meier mit Nachdruck argumentiert. ${ }^{70}$ Die Apokalypse des Pseudo-Methodios aus dem späten 7. Jahrhundert schließlich kulminiert in der Prophezeiung vom letzten römischen Kaiser, der

66 Siehe Thierry 1997, die in den Reliefs der Kirche das Verdienst armenischer Adliger, unter anderem des David Saharuni, dokumentiert sieht. Darüber hinaus sei darauf hinzuweisen, dass armenische Texte vermerken, Herakleios sei mit dem Kreuz durch Armenien gezogen, bevor er sich nach Jerusalem begeben habe; siehe Flusin 1992 II, $30 \mathrm{f} \mathrm{f.} \mathrm{Die} \mathrm{Darstellung} \mathrm{könnte} \mathrm{also} \mathrm{durchaus} \mathrm{auch} \mathrm{eine} \mathrm{lokale}$ Tradition wiedergeben.

67 Dass das Gedenken an Herakleios im Westen keineswegs durchwegs positiv war, zeigt die Chronik des Fredegar (65), die ein sehr ambivalentes Bild des Kaisers zeichnet; zu Fredegar und seinem Bericht über Herakleios siehe zuletzt Esders 2009 und ders. 2018, bes. 134-137, 145-135. In der Kritik stand vor allem die Religionspolitik des Kaisers, dessen Monotheletismus im Westen auf Widerstand stieß. Das Schisma wurde auf dem dritten Konzil von Konstantinopel 680/681 beigelegt, der Monotheletismus verbannt. Danach scheint einer positiven Herakleios-Rezeption im Westen nichts mehr im Wege gestanden zu haben; vor allem Kreuzfahrer beriefen sich implizit wie explizit auf ihn; siehe dazu etwa Greisiger (im Druck).

68 Borgehammar 2009, 167 bringt diesen Befund auf den Punkt: „For the fact that some images take hold in some places but not in others, while other images fail to take hold at all - that is what creates the phenomenon we call history ..."

$69 \mathrm{Zu}$ Umar in Jerusalem siehe Theoph. Conf. AM 6127 (De Boor 339); Chron. 1234, 120 (Chabot I, 199f.) und Mich. Syr. 11.7 (Chabot II, 425f.); siehe Stratos 1972, 81f., 221 mit weiteren Quellen.

70 Meier 2019a, 1045-1048; Meier geht gar von einem „messianischen Konkurrenzverhältnis“ (Zitat ebd. 1047) zwischen Kaiser und Kalif, konkret zwischen Herakleios und Umar, aus; siehe auch Meier 2020. 
seine Krone in Jerusalem ablegt. ${ }^{71}$ Obwohl außer Frage steht, dass die apokalyptische Tradition von Herakleios' Abstecher nach Jerusalem beeinflusst wurde, bleibt zu betonen, dass das Motiv des Kaisers, der in Jerusalem abdankt, bereits älter sein könnte. Es ist also zumindest in Betracht zu ziehen, dass die Apokalypse sich auch aus anderen Quellen denn aus Herakleios' Ablegen der Insignien speisen konnte. ${ }^{72}$

Abgesehen von der Zuschaustellung von Demut gebührt auch dem Umstand Aufmerksamkeit, dass die lateinische Legende eine Reihe gar expliziter Parallelen zwischen Herakleios und Christus zieht. Wie einst der Heiland näherte sich demgemäß auch der Kaiser Jerusalem vom Ölberg aus; ${ }^{73}$ der Empfang der Bevölkerung mit Palmzweigen und Lichtern, wie ihn die Reversio nachvollzieht, gemahnt an den biblischen Palmsonntag. ${ }^{74}$ Und tatsächlich findet sich dieses Motiv im Zusammenhang mit der Restitutio Crucis auch in Konstantinopel: In dem Gedicht, das Georg von Pisidien verfasste, als die frohe Nachricht von Herakleios' Rückerstattung des Kreuzes in Konstantinopel eintraf, ${ }^{75}$ ruft der Poet den Ort der Kreuzigung Christi auf zu frohlocken: Dem Kaiser solle Golgatha Beifall klatschen: „Und wenn deine Steine keine Stimme haben, dann bereite neue Palmzweige vor, um dem neuen Sieger entgegen-

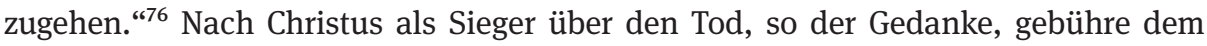
Kaiser als Sieger über Persien die Huldigung mit Palmzweigen. Hält man die Notiz aus der Reversio, Herakleios sei über den Ölberg in Jerusalem eingezogen, für authentisch, so lässt sich gar die These aufstellen, dass es sich bei der Christus-Parallelisierung nicht nur um eine nachträgliche legendarische bzw. panegyrische Deutung handelt, sondern dass Herakleios selbst sich mit seinem Einzug in Jerusalem dezidiert in die Tradition Christi stellte. ${ }^{77}$ Es bleibt allerdings zu erwähnen, dass die sonstigen Quellen keinen klaren Angaben zum kaiserlichen Itinerar machen. ${ }^{78}$

71 Zur Apokalypse des Ps.-Methodios siehe Reinink 1988, 1993.

72 Eine eingehende Analyse der relevanten apokalyptischen Tradition mit Diskussion der Datierungsfragen bietet Greisiger 2014, 172-180. Greisiger kommt indes zu dem Schluss, dass Herakleios' ostentative Demut, wie sie sich auch in der lateinischen Tradition äußert, die Entwicklung der apokalyptischen Tradition bedingte; siehe bes. 177-180. Ebd. 159-166 dazu, wie Herakleios Präsenz aus jüdischer Sicht verarbeitet wurde. Die Überlieferungstraditionen des apokalyptischen Schriftgutes sind derart komplex, dass ich sie hier nicht im Detail nachvollziehen kann; meine Argumentation kann auf eine detaillierte Berücksichtigung der Evidenz verzichten.

73 Dass Jesus sich vom Ölberg her Jerusalem näherte, halten fest: Mt 21.1-12; Mk 11.1-19; Lk 19.37-48. 74 Mt 21.5-7; Mk 11.8-10; Lk 19.36-40; Joh 12.12-18; dazu Greisiger 2014, 134. Zuletzt hat Christian Rollinger in seiner bislang unveröffentlichten Habilitation interessante Gedanken hinsichtlich einer möglichen Christus-Imitatio bei der Restitutio Crucis formuliert.

75 Diesen Kontext gibt Georg. Pis. Rest. Cruc. 104-115. Die Nachricht traf am Feiertag des Lazarus in Konstantinopel ein.

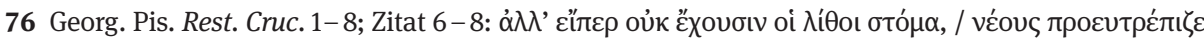

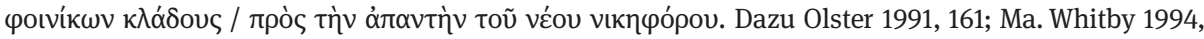
215; dies. 2002, 161; Meier 2015, 186; ders. 2017, 540.

77 So etwa Greisiger 2014, 134-136, 139.

78 Laut Theoph Conf. AM 6120 (De Boor 328) und Eutychios (Breydy 108f.) machte Herakleios auf dem Weg von Syrien nach Jerusalem in Tiberias am See Genezareth halt. Von dort aus hätte er dem Jordan 
Doch wie ist dieser Verweis auf Christus - ob bereits in eventu angelegt oder nicht - zu verstehen? Angesichts der generellen Tendenz der spätantiken Gesellschaft, die eigene Lebenswelt im Rahmen biblischer Exempla und Typologien zu begreifen und zu beschreiben, ist die Parallelisierung zwischen dem Einzug Christi in Jerusalem und dem des Herakleios nicht per se überraschend. Die imitatio Christi bzw. Dei, die Gestaltung der weltlichen Herrschaft nach himmlischem Vorbild, war seit Konstantin I. ein wiederkehrendes Motiv sowohl in der Rede über den Kaiser als auch in dessen Herrschaftspraxis und Selbstdarstellung. Wie mit Verweis auf Passagen aus Georg von Pisidien bereits im Kapitel 5 besprochen wurde, wurde auch Herakleios als Kaiser bereits vor seinem Sieg über die Perser bisweilen mit Christus überblendet. ${ }^{79}$ In diesem Zusammenhang hat sich in der Forschung zuletzt die Ansicht durchgesetzt, in Herakleios' Herrschaft offenbare sich eine distinkte, neuartige Herrschaftskonzeption, ein ,messianisches Kaisertum' mit eschatologischer Stoßrichtung; die Stilisierung als endzeitliche Erlöserfigur habe der Kaiser durch die Annäherung an den Messias Christus selbst gezielt befördert. ${ }^{80}$ Cyril Mango beschreibt die Restitutio Crucis gar als „a deliberatly apocalyptic act” ${ }^{81}$ Doch war Herakleios’ Einzug tatsächlich als Prolog zum Weltende konzipiert? Wie problematisch es sein kann, undifferenziert von einem eschatologischen Deutungsrahmen auszugehen, wurde bereits an anderer Stelle betont. ${ }^{82}$ Insofern lohnt es sich, die Evidenz, die von den Befürwortern einer eschatologischen/apokalyptischen Deutung der Restitutio Crucis angeführt wird, erneut zu beleuchten.

Gemäß dem Bericht des Antiochos Strategos zog Herakleios nicht etwa am Palmsonntag, sondern am 21. März in Jerusalem ein. ${ }^{83}$ Auch dabei handelte es sich um ein symbolträchtiges Datum: In der chronographischen Tradition, wie sie sich etwa in der hauptstädtischen Osterchronik äußert, stand der 21. März für die Erschaffung der Gestirne, also für den Beginn der Zeit. ${ }^{84}$ Geht man davon aus, dass Herakleios den Tag ganz bewusst wählte, lässt sich dies tatsächlich als ein starkes Statement lesen jedoch nicht unbedingt als ein apokalyptisches. Darin offenbart sich darin vielmehr der Gedanke, dass Herakleios' Wiedergewinnung der Ostprovinzen den Beginn einer neuen Zeit markierte, wie er sich bereits im Kaiserlob des Georg von Pisidien äußerte.

nach Süden folgen können, um dann von Osten her nach Jerusalem aufzusteigen; genauso hätte er aber auch den westlichen Weg wählen können.

79 Siehe dazu auch Meier 2015.

80 So vor allem Meier 2017, 540 - 543; bereits ders. 2015, 186-189; wesentlich ausführlicher und stets aus der Perspektive nahöstlicher Apokalyptik Greisiger 2014, 132-180; vgl. auch Shoemaker 2018, 76. 81 Mango 1980, 205; eine Erläuterung dessen, was genau an der Restitutio Crucis apokalyptisch ist, bleibt Mango allerdings schuldig; vgl. auch Drijvers 2002, 186-188; Shoemaker 2018, 76.

82 Siehe oben Kap. 5.5.

83 Das genaue Datum findet sich bei Ant. Strateg. (Conybeare 516). Geht man vom Jahr 630 aus, so zog Herakleios eineinhalb Wochen vor dem Palmsonntag in Jerusalem ein: Ostern fiel im Jahr 630 auf den 8. April; Palmsonntag (Sonntag vor Ostern) war demnach der 1. April.

84 Chron. Pasch. (Dindorf 26f.); dazu Flusin 1992 II, 314; Drijvers 2002, 186f.; Booth 2013a, 8f. und Zuckerman 2013, $203 \mathrm{f}$. 
Dieser Renovatio-Gedanke verweist gerade nicht auf ein wie auch immer geartetes Eschaton, sondern eröffnet einen positiven Blick in die Zukunft; ${ }^{85}$ Herakleios erscheint dabei als Agent eines neuen, heilvollen Zeitalters: Nach der Wiederherstellung der weltlichen Ordnung durch den Sieg über die Perser markierte er mit der Rückerstattung des Kreuzes an seinen angestammten Platz in der Anastasis-Kirche - so ließe sich diese Geste deuten - die Wiederherstellung der himmlischen Ordnung. ${ }^{86}$

Bei der Interpretation der Restitutio Crucis wurden neben den literarischen Quellen zuletzt wiederholt auch architektonische Hinterlassenschaften in die Diskussion einbezogen. Herakleios' Präsenz in der Heiligen Stadt könnte sich - so wird in der Forschung wiederholt gemutmaßt - in einem Ausbau des Tempelberges niedergeschlagen haben; als Evidenz für diese These dienen das Goldene Tor in der OstMauer des Tempelberges sowie die Struktur, die als muslimischer Felsendom bekannt ist. Der Bau des Goldenen Tores ist weder literarisch noch epigraphisch belegt; die Datierungen, die vom späten 6. Jahrhundert bis in früh-umayyadische Zeit rangieren, basieren auf architektonischen Merkmalen sowie der erhaltenen Baudekoration. ${ }^{87}$ Während eine Verbindung des Tores zu den muslimischen Bauten naheliegt, die in Folge der arabischen Eroberung auf dem Tempelberg entstanden, ${ }^{88}$ hat zuletzt eine alternative Hypothese Anklang gefunden: nämlich dass der Bau während des kurzen römischen ,Interregnums‘ 628-636 entstand; und mehr noch: dass das Tor dezidiert Herakleios' Einzug in die Heilige Stadt kommemorierte, der - folgt man der lateinischen Tradition, die ich oben besprochen habe - von Osten her erfolgte. ${ }^{89}$ Der Felsendom dagegen ist in seiner erhaltenen Form ein eindeutig muslimischer Bau; $;^{90}$ der oktagonale Grundriss indes gemahnt an spätantik-byzantinische Kirchen im Heiligen

85 Vgl. dazu oben S. 248-251.

86 Vgl. Mango 1992, 6: „The return of the Cross was meant to be a cosmic event.” Dass die Zeitgenossen sich der Bedeutung des 21. März im Speziellen bewusst waren, wird indes in keiner Quelle explizit. Da die letzten Folios des einzig erhaltenen Manuskripts der Osterchronik beschädigt sind, bleibt die These, dass der Text durch die göttliche Erschaffung der Gestirne am 21. März einerseits und Herakleios’ Restitutio Crucis am 21. März andererseits gerahmt wurde, zwar verlockend, aber nicht belegbar; vgl. Whitby/Whitby 1989, xif.

87 Siehe die ausführliche Beschreibung des Befundes bei Mango 1992 mit Diskussion der älteren Literatur.

88 Dass bereits der Kalif Umar auf dem Tempelberg Baumaßnahmen durchführen ließ, vermerkt etwa Theoph. Conf. AM 6135 (De Boor 342); dazu siehe Mango 1992, $1 \mathrm{f}$.

89 Peters 1983, 124-127; Peters stellt hier außerdem die gewagte These auf, dass das Osttor zur Zeit des Herakleios nicht auf den Tempelberg, sondern direkt in die Stadt führte; erst bei einer späteren Erweiterung der Tempel-Plattform nach Norden sei das Tor in die Umfassungsmauer des Tempelberges integriert worden. Für eine Zuschreibung des Osttores an Herakleios plädieren auch Mango 1992, bes. 6f.; Greisiger 2014, 147 f.; ebd. 136 weist Greisiger darauf hin, dass das Osttor im Mittelalter mit Herkleios' Einzug in Verbindung gebracht wurde.

90 Der Felsendom in seiner heute noch erhaltenen Form entstand - so der weitgehende Konsens der Forschung - im späten 7. Jahrhundert unter dem Kalifen 'Abd al-Malik; siehe Peters 1983, 131-133 und der Sammelband von Raby/Johns 1992. 
Land. ${ }^{91}$ Dieser Befund hat Francis E. Peters zu der Vermutung bewogen, dass der muslimische Bau nicht nur einen lokalen, christlichen Architekturtyp kopiert, sondern dass dem Felsendom die Baustruktur einer christlichen Kirche im wahrsten Sinne des Wortes zugrunde liegt - einer christlichen Kirche, deren Grundriss auf Herakleios' Initiative hin gelegt worden war. ${ }^{92}$ Angesichts des Umstandes, dass Jerusalem letztendlich nicht einmal ein Jahrzehnt in römischer Hand blieb, wäre ein Ausbau des Tempelberges gemäß diesem Gedankengang bei der Ankunft der Araber nicht sonderlich weit gediehen gewesen.

Um die Implikationen nachvollziehen zu können, die die These von einer herakleischen Bauinitiative mit sich bringt, ist ein Blick auf die Entwicklung und Bedeutung des Jerusalemer Tempelberges zu werfen. Nachdem die Römer den jüdischen Tempel 70 n. Chr. zerstört hatten, ließ Kaiser Hadrian auf dem Plateau in Folge des BarKochba-Aufstandes einen Jupiter-Tempel errichten; mit der fortschreitenden Christianisierung ab dem 4. Jahrhundert wurde der pagane Kultort jedoch aufgegeben. Aus christlicher Sicht avancierte der brach liegende Tempelberg in der Spätantike zum Mahnmal dafür, dass der Neue Bund mit der Anastasis-Kirche als kultischem Zentrum den Alten Bund, das Judentum, abgelöst hatte. ${ }^{93}$ Justinian ließ den Tempelberg bei seinem großangelegten Ausbau Jerusalems demonstrativ unberührt. ${ }^{94}$ Ein herakleisches Bauprogramm an und auf dem Tempelberg ließe sich dahingehend interpretieren, dass der Kaiser den Ort, an dem unter persischer Hoheit zumindest zeitweise der jüdische Kult wieder aufgenommen worden war, nun explizit dem Christentum aneignete, die Trennung von Altem und Neuen Bund aufhob und das Judentum symbolisch dem Christentum einverleibte. ${ }^{95}$ Folgt man der Zuschreibung, so eröffnen sich auch hier eschatologische Implikationen: Nicht nur die Konvertierung der Juden stand aus christlicher Sicht mit einem messianischen Zeitalter in Verbindung; ${ }^{96}$ auch der Bau eines neuen Tempels verwies sowohl in der jüdischen wie der christlichen

91 Zu nennen wären die Theotokos-Kirche auf dem Berg Garizim, die unter Kaiser Zenon an der Stelle des samaritanischen Tempels errichtet wurde, nachdem der Aufstand der Samaritaner niedergeschlagen worden war; außerdem die Kathisma-Kirche aus dem 6. Jahrhundert nahe Bethlehem; siehe Peters 1983, 127 f.; Greisiger 2014, $148 \mathrm{f}$.

92 Peters 1983; ihm folgt Sivan 2008, 48f. Dass Herakleios seinen Einzug in Jerusalem architektonisch kommemorierte, halte ich - angesichts der römisch-imperialen Tradition, kaiserliche Präsenz durch Bauinitiativen zu verewigen - prinzipiell für plausibel; vgl. Mango 1992, 6.

93 Greisiger 2014, 145f. In dem Brachliegen des Tempelberges bewahrheitete sich außerdem das Herrenwort: „Hier wird nicht ein Stein auf dem anderen gelassen werden, der nicht abgebrochen werden wird. “ Siehe Mt 24.2; Mk 13.2; Lk 21.6. Zum Ausbau eines neuen Jerusalems siehe Wilken 1992, 85-100.

94 Siehe Trampedach 2015; die berühmte Mosaik-Karte von Madaba aus der zweiten Hälfte des 6. Jahrhunderts versinnbildlicht diesen Zustand: Während sie die justinianischen Bauten, die NeaKirche und den Cardo Maximus deutlich wiedergibt, fehlt der Tempelberg in der Darstellung.

95 So Greisiger 2014, 145-150. Tatsächlich belegen einige Quellen, dass die jüdische Bevölkerung nach 628 verstärkt in den kaiserlichen Fokus rückte; gar von Zwangstaufen ist die Rede, siehe Greisiger 2014, 97-106; vgl. Drijvers 2002, 188-190; dazu siehe unten S. 287.

96 Greisiger 2014, 97-106. 
Vorstellungswelt auf eine kommende Heilszeit. ${ }^{97}$ So verlockend die Idee vom Ausbau des Tempelberges durch Herakleios und deren weitreichende Implikationen auch sind, so bleibt doch festzuhalten, dass es sich dabei um eine Hypothese handelt, die weder durch literarische noch durch archäologische Evidenz angemessen untermauert werden kann. ${ }^{98}$

Die Interpretation der Restitutio Crucis führt schließlich zu einem Aspekt, der sich in der rezenten Forschung - nicht zuletzt bei den Befürworten einer eschatologischen/ messianischen Deutung - geradezu als Allgemeinplatz verfestigt hat: Mit der Rückerstattung des Kreuzes habe Herakleios sich in die Tradition des alttestamentarischen Königs David gestellt, der seinerzeit die Bundeslade, das zentrale Kultobjekt des Judentums, nach Jerusalem gebracht hatte; und mehr noch: Der Bezug auf König David, auf den Urvater des Messias, ${ }^{99}$ sei unter Herakleios zum Schlüsselmoment kaiserlicher Repräsentation avanciert. ${ }^{100}$ Georg von Pisidien vergleicht in seinem Gedicht zur Restitutio Crucis in der Tat die Kreuzreliquie mit der Bundeslade - ausgehend von dem Umstand, dass beide Kultobjekte sich zeitweise in den Händen barbarischer Feinde befanden: Die Bundeslade war von den Philistern geraubt worden, ${ }^{101}$ das Kreuz von den Persern. Für den Dichter erweist sich das Kreuz als „neue Bundeslade“ (vé $\alpha$ кґ

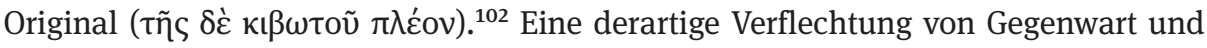
biblischer Vergangenheit, die sich auf das jüdische Erbe beruft, um die eigene Gegenwart mit Sinnbezügen aufzuladen, und im gleichen Zuge die Überlegenheit des

97 Bardill 2006, 342; siehe McKelvey 1969 zu Vorstellungen vom neuen/himmlischen Tempel im Alten und Neuen Testament. Greisiger 2014, 159-166 zeigt anhand von jüdischen Quellen, dass Herakleios' spektakuläre Präsenz in Jerusalem nicht ignoriert werden konnte, dass indes auf jüdischer Seite eine Gegendeutung etabliert wurde, „die zugleich das Gewicht, das er dem Ereignis beimaß, erkennen lässt, und präzise dessen imperial-propagandistische Intention zu treffen und außer Kraft zu setzen vermochte“ (Zitat ebd. 160).

98 Keine einzige literarische Quelle (weder zeitgenössisch noch später) dokumentiert römische bzw. herakleische Bauaktivität am bzw. auf dem Tempelberg. Eine eingehende (und unvoreingenommene) archäologische Untersuchung, die zur genaueren Datierung der Baustrukturen auf dem Tempelberg beitragen könnte, ist angesichts des weiterhin umstrittenen Status des Areals kaum möglich. Vgl. auch Howard-Johnston (im Druck), der in Hinblick auf einen herakleischen Ausbau Jerusalems noch weitreichendere Thesen aufstellt.

99 Die Idee, dass der Messias von David abstamme, entspringt einer Prophezeiung in 2. Sam 7.14-16; gemäß den Stammbäumen in Mt 1.1-17 und Lk 3.23-38 stammt Jesus von David ab.

100 Wander 1973,103f.; ders. 1975; Spain Alexander 1977; Trilling 1978, 250 f.; Ludwig 1991, 95; Drijvers 2002, 184 f.; Brandes 2002a, 19; Ludwig 2003; bes. 373-377; Borgehammer 2009, 161-163; Tsamadga 2010, 30 -33; Greisiger 2014, 139-145; Meier 2015, 187-189; ders. 2017, 541-543; ders. 2019 a, 1044. 1011 Sam 5.

102 Georg. Pis. Rest. Cruc. 73-77. Siehe dazu Pertusi 1959, 238; Borgehammar 2009, 162. Ludwig 1991, $97 \mathrm{f}$. sieht außerdem in Rest. Cruc. 71f., wo Herakleios bei der Rückerstattung des Kreuzes mit den Engeln tanzt, einen Reflex von 2 Sam 6.5, 14-15, wo David bei seinem Einzug in Jerusalem tanzt; vgl. die kritischen Anmerkungen dazu bei Ma. Whitby 2002, 162 Anm. 30. 
christlichen Kontextes betont, ist in der Spätantike durchaus typisch; ${ }^{103}$ auch für die typologische Verbindung zwischen Bundeslade und Kreuzreliquie finden sich weitere Belege. ${ }^{104}$ Dabei bleibt indes zu betonen, dass bei Georg der direkte Vergleich zwischen Herakleios und David, dem Restitutor der Bundeslade, gerade nicht gezogen wird. Diese Beobachtung dient als Anlass, die mutmaßliche David-Imitatio unter Herakleios einer Revision zu unterziehen.

Die David-Erzählung des Alten Testaments scheint in der Tat die ideale Vergleichsfolie und Projektionsfläche für die Herausforderungen, derer sich Herakleios im Laufe seiner Regierung stellen musste: Von Gott begünstigt kam David an die Macht, nachdem er sich gegen die herrschende Dynastie des Königs Saul hatte behaupten können; er zog in den Krieg, besiegte einen übermächtigen, nichtgläubigen Feind (den Philister Goliath), einigte sein Reich und brachte - wie bereits erwähnt mit der Bundeslade den zentralen Kultgegenstand seiner Glaubensgemeinschaft nach Jerusalem. David begründete eine bedeutende Herrscherfamilie, versündigte sich allerdings, als er die illegitime Verbindung mit Bathseba einging. ${ }^{105}$ Mit dem Verweis auf den alttestamentarischen König ließen sich potentiell kritische Aspekte von Herakleios' Herrschaft - die Umstände seiner Krönung, das persönliche Engagement im Krieg gegen die Perser und nicht zuletzt seine familiäre Situation - in einen autoritativen Referenzrahmen einordnen und damit sanktionieren. ${ }^{106}$ Die Überblendung von Herakleios und Christus, aus der der Kaiser als messianische Heilsfigur hervortritt, fände in der Annäherung an Christi Vorfahren David eine weitere Ausdrucksform. ${ }^{107}$ Die zentrale Frage ist indes, ob diese Verbindung, die aus der Sicht der Forschung so naheliegend scheint, auch von Herakleios selbst bzw. seinen Zeitgenossen gezogen wurde. Ist David tatsächlich die Schlüsselfigur, die den Weg zum Verständnis politischer Prozesse und Diskurse des 7. Jahrhunderts eröffnet? Lassen sich politische Maßnahmen wie etwa Herakleios’ persönliche Rückführung des Kreuzes tatsächlich

103 Siehe Viermann (im Druck) zu dem Motiv des Übertreffens des alttestamentarischen Königs Salomon; Rapp 2010 unterzieht die Modi, anhand derer eine christliche Gegenwart zum Alten Testament in Beziehung gesetzt werden konnte, einer eingehenden Untersuchung.

104 Ludwig 1991, 98-100; Greisiger 2014, 140f. Die Verbindung von Bundeslade und Kreuz war allerdings nicht exklusiv; in Anth. Palat. 1.121, einem Bau-Epigramm in der Blachernenkirche, verfasst von Georg von Pisidien, wird der Vergleich zwischen Bundeslade und der Theotokos gezogen; zu den Epigrammen siehe oben S. $255 \mathrm{f}$.

105 Spain Alexander 1977, 226- 231 zeigt ausführlich die Parallelen auf; vgl. Greisiger 2014, 139. Seit der Christianisierung römischer Monarchie wurde David in der Rede über den Kaiser wiederholt als Referenz bemüht. Allerdings handelte es sich bei der überschaubaren Anzahl an Beispielen - so hat zuletzt Ueli Zahnd (2008, 74-80 mit Beispielen) betont - um Zuschreibungen von Seiten kirchlicher Würdenträger und nicht etwa um kaiserliche Selbstbeschreibungen. Besonders prominent ist der David-Bezug im späten 4. Jahrhundert in der Auseinandersetzung zwischen Ambrosius, dem Bischof von Mailand, und Theodosios I.; dazu siehe Leppin 2007. Zu dem Apsis-Mosaik im Katharinen-Kloster auf dem Sinai, das Justinian und David in Verbindung setzt, siehe Tsamakda 2010, 25-30.

106 Ludwig 2003, 370 - 377 sieht David als Referenzpunkt für den „guten Usurpator“, als den sich Herakleios zu stilisieren suche.

107 Ludwig 2003, bes. 369, 376; Meier 2015, 187-189. 
mit dem Verweis darauf erklären, dass der römische Kaiser sich in die Tradition des alttestamentarischen Königs stellte?

Nachdem bereits zuvor zwischen kaiserlicher Repräsentation und Fremdzuschreibung unterschieden und die Notwendigkeit betont wurde, den kommunikativen Zusammenhang bei der Analyse der Quellen einzubeziehen, sollen diese methodischen Prämissen auch hier das Vorgehen leiten. Der einzige Beleg dafür, dass Herakleios selbst eine Beziehung zu dem alttestamentarischen König herstellte, ist der Umstand, dass er seinem Sohn, der laut Theophanes Confessor am 7. November 630 zur Welt kam, als der Kaiser mit seiner Frau Martina nach der Restitutio Crucis weiterhin im Osten weilte, den Namen David gab; dieser Schritt ist insofern bemerkenswert, als der Name David nicht zum Standardrepertoire der Nomenklatur römischer/ christlicher Kaiser gehörte. ${ }^{108}$ Als ein weiteres Indiz für Herakleios’ Angleichung an David wird in der Forschung der Umstand angeführt, dass der Kaiser spätestens 629 anstelle der traditionell römischen Titulatur den Titel pistos en Christo basileus annahm und damit - so die Hypothese - auf den alttestamentarischen basileus David ebenso wie auf die baslieia Christi, Davids Nachfahren, verwies. Darauf, dass sich für die Änderung der Titulatur durchaus auch andere, naheliegendere Erklärungen anbringen lassen, habe ich bereits an anderer Stelle hingewiesen. ${ }^{109}$

Besondere Aufmerksamkeit kommt in der Forschung schließlich den sogenannten ,David-Plates' zu, einem Set von neun dekorativen Silberschalen, die in einem Hort auf Zypern gefunden wurden und Szenen aus dem Leben König Davids darstellen. ${ }^{110}$ Ausgehend davon, dass die Kontrollstempel eine Fertigung zwischen 613 und 629/30 belegen, wurde dafür plädiert, dass die Schalen nach bzw. in Reaktion auf Herakleios’ Triumph über die Perser entstanden: ${ }^{111}$ Als Objekte imperialer Repräsentation, eventuell gar vom Kaiser persönlich als Geschenk für einen Vertreter der oströmischen Elite in Auftrag gegeben, würdigten sie Herakleios' Verdienst. ${ }^{112}$ Ob die David-Dar-

108 Theoph. Conf. AM 6122 (De Boor 335); vgl. Mango/Scott 1997, 466 Anm. 6; Greisiger 2014, 141 f. 638 wurde David zum Caesar gekrönt (De cerim. 2.27). Es bleibt allerdings folgende Anmerkung: Hätte sich Herakleios tatsächlich als neuen David verstanden, wäre es wohl passender gewesen, seinen Sohn Salomon zu nennen.

109 Siehe oben S. $234 \mathrm{f}$.

110 Die größte Schale rekapituliert in drei Szenen den Kampf Davids gegen Goliath; die kleineren bilden ab, wie David nach seinem Sieg in die königliche Familie des Saul aufgenommen wurde; die Szenen entstammen der Erzählung in 2 Sam 16-18.

111 Siehe Spain Alexander 1977, bes. 236; Mundell-Mango 1994, 122-131. Eine Interpretation der Schalen bieten auch Wander 1973 und Trilling 1978, der sie hinsichtlich ihrer Bildsprache mit den Gedichten des Georg von Pisidien vergleicht. Dass die Szenen am Hofe des Königs Saul sich an zeitgenössischer kaiserlicher Repräsentation orientieren, spricht nicht unbedingt dafür, dass hier eine typologische Verbindung gezogen wird; bei der Darstellung alttestamentarischer Könige bediente sich die bildliche Kunst in anachronistischer Manier stets der aktuellen Kaiserikonographie als Chiffre für Herrscherwürde; siehe Tsamakda 2010, 29.

112 So Spain Alexander 1972, 237; Greisiger 2014, 139; Meier 2015, 188. Tsamakda 2010, 32f. hingegen weist die These zurück, dass die David-Plates mit Largitio-Schalen in Verbindung zu bringen sind, die von den Kaisern zu bestimmten Anlässen ausgegeben wurden. 
stellungen auf den Silberschalen tatsächlich auf kaiserliche Initiative hin rezente politische Entwicklungen kommentieren, ist jedoch erneut nicht mit Sicherheit zu belegen; auch hier sind alternative Deutungen möglich. In der Spätantike waren derartige Silberschalen durchaus gängig: Während sie in der Regel mythologische Szenen darstellten, könnte man in den David-Plates schichtweg den Versuch eines aristokratischen Milieus sehen, christliche Themen in diese Darstellungsform zu integrieren. ${ }^{113}$ Die gesicherte Evidenz dafür, dass Herakleios sich in seinem Handeln auf David bezog, bzw. sich dergestalt repräsentierte, ist demnach dürftig.

Wie sieht es nun mit Fremdzuschreibungen aus? Der einzige Beleg dafür, dass Herakleios' Handeln im hauptstädtischen Umfeld mit Bezug auf König David gedeutet wurde, findet sich in der bereits besprochenen Predigt des Theodor Synkellos, die vor dem Friedensschluss mit Persien entstand. ${ }^{114}$ Im erhaltenen Oeuvre des Georg von Pisidien dagegen ist der vermeintlich naheliegende David-Bezug überraschend unterrepräsentiert - und das trotz der offensichtlichen Vorliebe des Dichters für historische wie biblische Analogien; David tritt bei Georg wenn überhaupt als Psalmist, nicht etwa als Herrscher-Typos auf. ${ }^{115}$ Allein in Georgs nicht erhaltenen Versen ließen sich Belege für eine kaiserliche David-Mimesis vermuten. Die Chronik des Theophanes Confessor aus dem 9. Jahrhundert, die erwiesenermaßen Georg von Pisidien als Quelle nutzte, gibt in der Tat eine legendenhafte Erzählung wieder, die an Davids Kampf gegen Goliath erinnert: ${ }^{116}$ Bei einem Scharmützel mit den Truppen des Shahrbaraz soll der Kaiser eigenhändig einen riesenhaften Perser besiegt haben; die Parallele zum alttestamentarischen König wird jedoch erneut nicht explizit gemacht. ${ }^{117}$

113 Siehe Leader 2000 und Zahnd 2008, 82, der die Frage nach dem Fundkontext auf Zypern aufwirft und anstelle des kaiserlichen Palastes für „das häusliche Umfeld eines reichen Bürgers“ als Kontext der Schalen plädiert; siehe auch Tsamakda 2010, 30-33, die zwar den Thesen Leaders folgt, aber dennoch einen Bezug zum Perserkrieg herstellt.

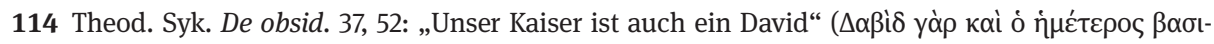
$\lambda \varepsilon \dot{c}()$. In der Predigt dient der David-Bezug einerseits dazu, Konstantinopel als das eigentliche Jerusalem zu etablieren, andererseits steht David als Chiffre für den frommen, siegreichen und von Gott begünstigten Herrscher; durch die Erweiterung auf Salomon kommt schließlich auch eine dynastische Komponente ins Spiel; siehe dazu oben S. 224. Vgl. Ludwig 1991, 95-97 zu der Predigt und $94-104$ zu den David-Bezügen unter Herakleios.

115 Siehe Ma. Whitby 1994, 218f.; Tsamakda 2010, 24f. In Exped. Pers. 2.113-115 lässt Georg Herakleios in einer Rede an seine Soldaten einen davidischen Psalm paraphrasieren, um den Kampf gegen die Perser mit einer religiösen Motivation zu untermauern; siehe außerdem die David-Verweise in Hex. 51-56, 90 f. (David als Psalmist) und In Alyp. 117f., die allerdings nicht in Bezug zu Herakleios stehen. Ein weiterer David-Verweis findet sich in der nach 628 entstandenen Geschichte des Theophylakt Simokattes (4.16): Die triumphale Rede des Bischof Dometianos nach der Rückgewinnung von Martyropolis von den Persern unter Maurikios bezieht sich in ihrem Lob Gottes auf David, allerdings auch hier ohne direkte Analogie zu Herakleios; zu dieser Rede siehe unten S. 298.

1161 Sam 17.

117 Theoph. Conf. AM 6116 (De Boor 314); besonders wenn Theophanes bemerkt, der Kaiser kämpfe in

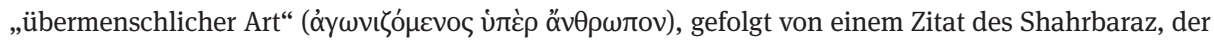
Herakleios für dessen mutigen Einsatz im Kampf lobt, fühlt man sich nicht etwa an David, sondern an 
Belege dafür, dass Herakleios in Analogie zu König David wahrgenommen wurde, finden sich indes in westlichen Quellen: Im bereits besprochenen Sermo de Exaltatione Sanctae Crucis, dessen Entstehung in die 640er-Jahre angesetzt wird, kommt es zum Zweikampf zwischen Herakleios und dem Sohn des Perserkönigs; Herakleios ruft Gott, „der du deinem Diener David den Sieg über Goliath gegeben hast“, um Hilfe an und gewinnt das Duell. ${ }^{118}$ Die fränkische Chronik des Fredegar aus den 650er Jahren wird noch deutlicher: Herakleios habe sich „wie ein zweiter David“ der Herausforderung des Zweikampfes gestellt. ${ }^{119}$ Anstatt davon auszugehen, dass die lateinischen Quellen den David-Verweis aus einer griechischen Tradition übernahmen, ${ }^{120}$ hat Ueli Zahnd zuletzt dafür argumentiert - meiner Ansicht nach überzeugend -, dass es vielmehr westliche Chronisten waren, die den legendarischen Stoff von Herakleios' Zweikampf aufnahmen und „die Parallelen zwischen Herakleios und David als erste explizit ausarbeiteten“. ${ }^{121}$

Allein folgende Überlegung ließe sich anstellen: In Hinblick auf die lateinische Herakleios-Tradition wurde bereits darauf hingewiesen, dass Motive wie das der kaiserlichen Humilitas in manchen Umfeldern Wurzeln schlugen, in anderen nicht. Ebenso könnte es sich mit dem David-Motiv verhalten haben. Folgt man der Hypothese, dass Herakleios einen Bezug auf König David selbst förderte - eine Hypothese, für die zumindest die Namensgebung seines Sohnes spräche - und sich mit seiner Restitutio Crucis gar an David orientierte, dann fand diese Intention in den Deutungen

Georg von Pisidiens Darstellung des Kaisers erinnert, wie ich sie im vorigen Kapitel herausgearbeitet habe. $\mathrm{Zu}$ impliziten David-Bezügen bei Theophanes und Nikephoros siehe Ludwig 1991, 100-102. Greisiger 2014, 142 meint, dass „die Gleichsetzung des Kaisers mit König David nach einigen Jahren offenbar so geläufig geworden [ist]“, dass auch seine Ehe mit Martina mit Verweis auf die Beziehung zwischen David und Bathseba kritisiert wurde; etwa Nik. Brev. 20 als Paraphrase des davidischen Psalms 51.5.

118 Exalt. S. Cruc. 9: donasti uictoriam seruo tuo Dauid aduersus Goliath. Interessant ist hier, dass die Reversio Sanctae Crucis, die gemäß Borgehammar auf dieselbe Quelle wie der Sermo zurückgeht, David nicht anführt; siehe dazu Borgehammar 2009, 161-163, 166.

119 Fred. Chron. 64: Hier verabredet sich Herakleios mit dem Großkönig persönlich zum Duell; dieser schickt jedoch einen General an seiner Stelle in den Kampf. Der Bericht vom Zweikampf zwischen Herakleios und dem persischen General Razates findet sich in leicht abgewandelter Form auch in Nik. Brev. 14 - allerdings ohne den expliziten David-Vergleich. Zur dem Zweikampf-Motiv siehe Speck 1988, 138f., 141-144; Speck geht davon aus, dass dieses Motiv aus einem nicht erhaltenen Herakleios-Roman stammt.

120 So mit Bezug auf Fredegar etwa Wander 1975.

121 Zahnd 2008, 82f.; Zitat ebd. 85. Im Westen habe die David-Imitatio im 8. Jahrhundert eine eigene Qualität erreicht, sei gar in eine „sakral-davidische Herrscheridee“ gemündet (ebd. 85), als sich etwa Pippin der Jüngere 754 von Papst Stephan zum König habe salben lassen (König David war durch Samuel gesalbt worden); durch die Salbung, die im oströmischen Reich erst im 13. Jahrhundert zum Einsatz kam, wurde die Kirche als zentrale Legitimationsinstanz anerkannt. Im 8. Jahrhundert häuften sich dann allerdings auch in Byzanz die David-Bezüge; siehe ebd. 83 - 87 und auch Ludwig 2003, 371373 zu Kaiser Basileios I. 
des Ereignisses durch seine Zeitgenossen kaum Widerhall. ${ }^{122}$ Doch warum schlug Herakleios' mutmaßliche David-Imitatio weder im christlichen Umfeld des Heiligen Landes noch in Konstantinopel Wurzeln? Ich sehe dafür keinen wirklich triftigen Grund, zumal Kaiser vor Herakleios durchaus im positiven Sinne mit David verbunden worden waren. ${ }^{123}$ Die Vermutung, dass die Eroberungen der Araber und das Scheitern der kaiserlichen Religionspolitik Herakleios' David-Imitatio ab absurdum führte und dieses Bild daher aus den Quellen verschwand, ${ }^{124}$ befriedigt nur bedingt: Es gibt eine ganze Reihe an Quellen, die den triumphalen Status quo der Jahre 628-634 wiedergeben; doch auch hier keine Spur von David. ${ }^{125}$ Es bleibt allein festzuhalten, dass die Forschung meiner Ansicht nach dazu tendiert, die Wirkmächtigkeit König Davids als Referenzpunkt kaiserlicher Selbstdarstellung und kaiserlichen Handelns unter Herakleios zu überschätzen. Dass der David-Vergleich in griechischen Quellen in Bezug auf Herakleios' Sieg über die Perser nicht explizit gezogen wird, selbst wenn er geradezu auf der Hand zu liegen scheint, mag schlichtweg daran liegen, dass dieses Motiv nie mit entsprechender Vehemenz kommuniziert wurde.

Bislang wurde vor allem dazu gemahnt, bei der Interpretation der Restitutio Crucis keine voreiligen Schlüsse zu ziehen. Das Ergebnis ist eher ernüchternd, da die gängigen Thesen - sei es die David-Mimesis oder der Ausbau des Tempelberges - aus dieser Perspektive einer ausreichenden Quellen-Basis ermangeln. Dabei sollte man allerdings nicht aus dem Auge verlieren, dass es durchaus Evidenz gibt, die einen Eindruck davon vermittelt, wie die Rückerstattung der Kreuzreliquie von Zeitgenossen wahrgenommen wurde; neben den Texten aus dem Umfeld Jerusalems, die ich oben bereits ausgewertet habe, gebührt dem Gedicht des Georg von Pisdien eine eingehendere Betrachtung.

Als die Nachricht von der Restitutio Crucis am Feiertag des Lazarus in Konstantinopel eintraf, fasste Georg von Pisidien die frohe Nachricht in Worte, die gleichsam

122 Vgl. allerdings Greisiger 2014, 151-156, der Evidenz dafür aufbringt, dass die „(Selbst-)Stilisierung des Kaisers als neuer David gerade im Nahen Osten sehr genau registriert wurde“ (Zitat ebd. 151); ich halte diese Evidenz allerdings für alles andere als eindeutig. Greisiger vermutet ebd., dass sich Herakleios mit der David-Stilisierung auch an jüdische Kontexte gerichtet haben könnte.

123 Siehe etwa das Kontakion „Auf Erdbeben und Brände“, das von Romanos Melodos in Zusammenhang mit der Einweihung von Justinians Hagia Sophia 537 komponiert und vor der hauptstädtischen Gemeinde vorgetragen wurde. In Strophe 18 wendet sich Justinian an Gott und bittet ihn, ihm wie David über Goliath den Sieg zu bescheren; siehe dazu Viermann (im Druck).

124 So Ludwig 2003, 376 und ähnlich Zahnd 2008, 83.

125 Greisiger 2014, 144 sieht den Grund dafür, dass die griechischen Quellen geradezu darum bemüht sind, Herakleios' David-Typologie zu verschleiern, darin, dass sie den Kaiser ,in eine heikle Nähe zu jenem davidischen Messias [rückte], den die Juden erwarteten“. Auch diese Erklärung leuchtet mir nicht ein, da ich bezweifle, dass das hauptstädtische Umfeld sich der jüdischen Aktivitäten in Jerusalem bewusst war. Ma. Whitby 1994, 219 schlägt als Grund dafür, dass Georg von Pisidien die DavidTypologie in Bezug auf Herakleios nicht bemüht, den Umstand vor, dass das eigenhändige Töten eines Gegners nicht in das Bild passt, das Georg vom Kaiser habe zeichnen wollen. 
das Verdienst des Kaisers wie auch die Wirkmächtigkeit der Reliquie würdigen. ${ }^{126}$ Die Jerusalem-Episode wird als letzter Akt des erfolgreichen „Kampfes für den Frieden“

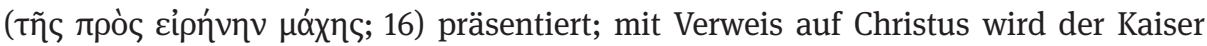
als „neuer Sieger“ ( nicht nur als Objekt, welches Herakleios aus der persischen Gefangenschaft an seinen angestammten Ort zurückbringt, sondern auch als wunderwirkende Waffe, mittels

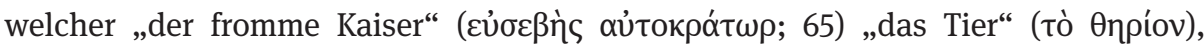
Chosroes, zur Stecke gebracht habe: „Er hat das Feuer niedergebrannt durch das entflammte Holz, das Chosroes als einfaches Holz gering schätzte, das er jedoch als eine Lanze in seinem Herz wiederfand. “128 Schließlich erhebt Georg die Reliquie gar zum Subjekt: Das Kreuz übergibt dem Kaiser die Feinde als „große Trophäe“ ( $\mu \varepsilon ́ \gamma \alpha$

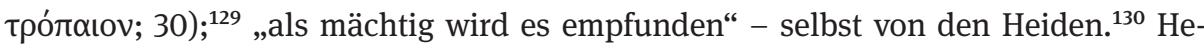
rakleios und die im Kreuz wirkende Macht werden dabei als Einheit beschrieben: „Nun hast du, oh Kaiser, die Macht der unter uns waltenden mystischen Kraft und es rühmt das ganze Land und die Stadt und der gesamte Kosmos in einem einzigen Zusammenklang die dir gegebene Gnade. “"131 Der kriegführende Kaiser der Expeditio Persica, dem die Rüstung besser stand als die Insignien kaiserlicher Hoheit, ${ }^{132}$ steht

126 Zum Eintreffen der Nachricht in Konstantinopel siehe Georg. Pis. Rest. Cruc. 104-116. Mischa Meier (2019, 1045 mit Anm. 109) sieht in dieser Passage Evidenz dafür, dass die Restitutio Crucis für Georg „ganz im Zeichen des unmittelbar drohenden Jüngsten Tages“ stand; diese These gründet auf den Versen 109-110: „Es gehört sich, so meine ich, dass der Auferstehung der Toten auch das erneute

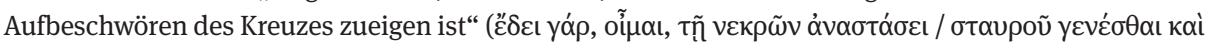
$\pi \alpha \dot{\lambda} \lambda \mathrm{v} \mu \eta v v \dot{\mu} \alpha \tau \alpha)$. Anstatt hierin einen expliziten Verweis auf den Jüngsten Tag zu sehen, sehe ich in darin eher ein Spiel mit dem Lazarus-Thema, das die letzten Verse des Gedichtes. bestimmt.

127 Dazu siehe oben S. 270.

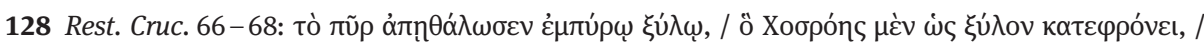

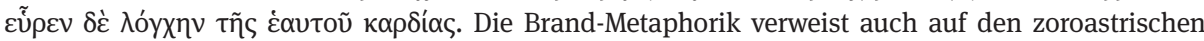
Feuerkult, auf den bereits in Rest. Cruc. 12-14 angespielt wurde. Zum Kreuz als Waffe vgl. bereits ebd. 19-24: Hier wird Herakleios als Held im Stile des Jason dargestellt, der das Goldene Vlies zurückgewann. Neben der Polemik gegen die Perser findet sich auch Polemik gegen die Juden, denen Georg zuruft, sie sollten endlich vom Irrglauben der Väter ablassen (ebd. 25f.).

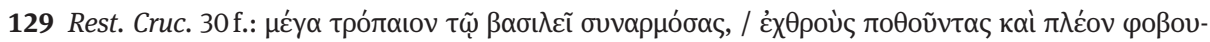
нદ́vous. Zu diesen Versen siehe Gigante 1975, $371 \mathrm{f}$.

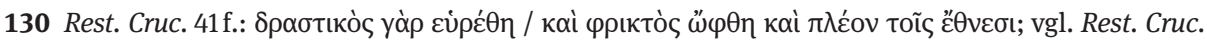
12-14. In ebd. 27-38 ist es das Kreuz selbst, das aufgrund der Sündhaftigkeit der Christen seine Heimat verließ, um sich schließlich zur Rückkehr zu entscheiden. Die Idee, dass Gott mit dem Verlust der Kreuzreliquie die Sündhaftigkeit der Christen strafte, findet sich auch in anderen zeitgenössischen Texten; siehe Booth 2013, 11 f. Booth (ebd., 10-14) weist außerdem auf alternative Deutungen der Restitutio Crucis hin: In einem Gedicht des Sophronios, des späteren Patriarchen von Jerusalem, das ebenfalls kurz nach dem Ereignis komponiert worden zu sein scheint, kommt Herakleios keine tragende Rolle zu.

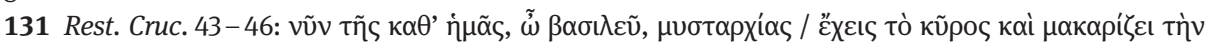

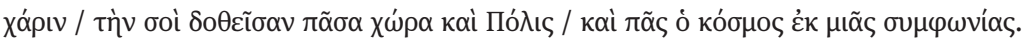

132 Georg. Pis. Exped. Pers. 3.112-115; zu der Weiterentwicklung des Bildes vom ,schwitzende Kaiser nach dem Sieg über die Perser siehe oben S. 236-238. 
nach seinem Sieg über dem Chaos der sich bekriegenden Völker: „Du selbst aber schweigst, der du die Krone und das Szepter trägst, wie ein Richter in Mitten der Ringer; gegen viele hast du gerungen, nun aber beendest du den Kampf.“133

Das Kernstück des Gedichtes nimmt nicht etwa der alttestamentarische König David ein, ${ }^{134}$ sondern ein römischer Kaiser: Konstantin der Große, der gemäß Georg

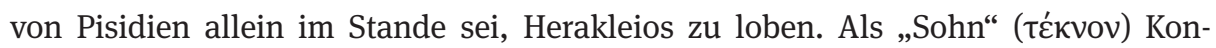
stantins erweist sich Herakleios, da er das in Aufruhr geratene römische Reich wieder in Ordnung gebracht habe. ${ }^{135}$ Die Leistung Konstantins, die Auffindung der Kreuzreliquie, ${ }^{136}$ wird von Herakleios indes noch überboten:

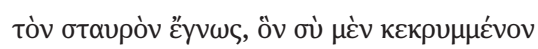

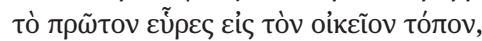

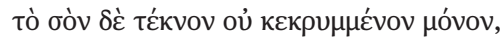

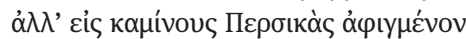

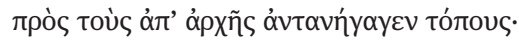

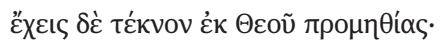

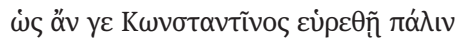

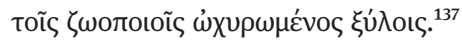

Du hast das Kreuz erkannt, das du zuerst gefunden hast, als es versteckt war an seinem angestammten Platz; dieses aber hat dein Sohn nicht nur, nachdem es versteckt wurde, sondern nachdem es in die persischen Feueröfen gelangt war, an seine ursprünglichen Orte zurückgebracht.

Du aber hast aufgrund der Vorsehung Gottes ein Kind. Als ein neuer Konstantin möge er befunden werden, gestärkt durch die lebensspendenden Hölzer.

Anstatt in eine alttestamentarische Genealogie ordnet der Dichter Herakleios und dessen Restitutio Crucis also in eine christlich-imperiale Tradition ein. ${ }^{138}$ Die kaiserliche Mühe um das Kreuz wird in Konstantinopel, in der Stadt Konstantins, also nicht etwa als David-Imitatio, sondern ganz explizit als Konstantin-Imitatio dargestellt. Im vorigen Kapitel habe ich durch den Vergleich zwischen der kaiserlichen Siegesdepesche von 628 und der Adaption des Georg von Pisidien gezeigt, dass der Dichter bei seiner Modellierung der kaiserlichen Imago durchaus eigene Impulse setzte; in diesem Fall ist die Depesche, die Herakleios von Jerusalem nach Konstantinopel sandte, ${ }^{139}$ nicht erhalten, ein direkter Abgleich also nicht möglich. Dass Georg sich mit dem Konstantin-Motiv durchaus an kaiserlicher Repräsentation orientierte, zeigt der Umstand, dass Herakleios mehrere seiner Söhne, angefangen mit dem 612 geborenen

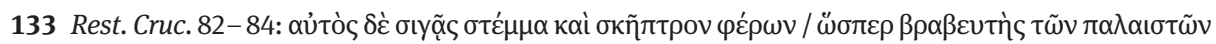

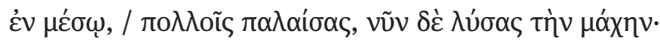

134 Booth 2013, 10 schreibt in Bezug auf Georgs Gedicht: „The emperor is also a new David, restoring to Jerusalem a powerful relic.” Derartige Aussagen sind irreführend, da das Gedicht den Kaiser gerade nicht als neuen David darstellt.

135 Rest. Cruc. 50 f.: „Applaudiere deinem Sohn, wie er deinen geretteten Besitz zeigt, den er als einen

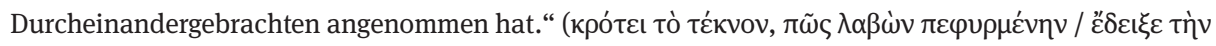

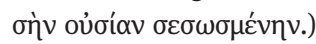

136 Die Auffindung der Kreuzreliquie, die in der Regel Konstantins Mutter Helena zugeschrieben wird, gebührt bei Georg von Pisidien Konstantin selbst.

137 Rest. Cruc. 56-63.

$138 \mathrm{Zu}$ dieser Tradition siehe Spain Alexander 1977, 225f.; Ludwig 1991, 98; Drijvers 2002, 181-184.

139 Dass es eine Depesche gab, zeigt Georg. Pis. Rest. Cruc. 103-114. 
Herakleios Konstantin, nach seinem großen Vorgänger benannte. ${ }^{140}$ Herakleios war nicht der erste Kaiser, der Konstantin als Vorbild evozierte bzw. derart dargestellt wurde; der Fokus auf die Kreuzreliquie, die Herakleios in eine direkte Beziehung zum ersten christlichen Kaiser setzte, brachte allerdings eine neue Ebene in diese Verbindung ein. ${ }^{141}$

Wie ist die Restitutio Crucis nun zu bewerten? Grundsätzlich folge ich der These, dass Herakleios mit der persönlichen Rückerstattung der Kreuzreliquie sein Profil als christlicher Kaiser zu schärfen gedachte. ${ }^{142}$ Damit adressierte er nicht nur die Hauptstadt, deren Akzeptanz er nach wie vor bedurfte, sondern auch die Bevölkerung der rückgewonnenen Ostprovinzen, wo die Wiederkehr der römischen Zentralmacht keineswegs nur positiv aufgenommen wurde. Nachdem Herakleios in Folge seiner siegreichen Rückkehr nach Konstantinopel kaum hatte Spolien vorzeigen können, erhob er das wiedergewonnene Kreuz - nicht zuletzt durch seine persönliche Rückerstattung nach Jerusalem - zur zentralen Trophäe für den kaiserlichen Triumph, bedeutsamer als jede Kriegsbeute. Seinen Einzug in Jerusalem konnte der Kaiser in einen vollumfassend christlichen Deutungszusammenhang stellen. Die Heilige Stadt bot Herakleios eine Bühne, die er flexibler bespielen konnte als das von gewachsenen Verhaltenserwartungen geprägte hauptstädtische Umfeld; die Ausstrahlung des Ereignisses indes reichte bis nach Konstantinopel, wie das Gedicht des Georg von Pisidien zeigt.

Der Überblick über die erhaltene Evidenz spricht dafür, dass sich in Bezug auf die Restitutio Crucis keine autoritative Deutung etablierte; abgesehen von dem Konsens, dass es sich bei Herakleios' Einzug um ein Ereignis sondergleichen handelte, war die Interpretation dessen, was sich im Frühjahr 630 im Heiligen Land abspielte, fragmentiert und stark vom jeweiligen Kommunikationskontext geprägt. Während sich im Westen eine lateinische Tradition herausbildete, die einen demütigen Herakleios Jahrhunderte später zu einem der Vorbilder der Kreuzfahrer-Bewegung werden ließ, ${ }^{143}$ fand in Konstantinopel vor allem die Verbindung zum ersten christlichen Kaiser

140 Spain Alexander 1977, 226 Anm. 50 weist außerdem darauf hin, dass mehrere Inschriften in Kleinasien sowohl Herakleios als auch seine Söhne als „Neuer Konstantin“ betiteln; Drijvers 2002, 181f. Der konstantinische Slogan en touto nika tauchte außerdem auf Münzen von Herakleios Konstantin oder Konstans II. auf; siehe dazu Greisiger 2014, 135 Anm. 248.

$141 \mathrm{Zu}$ Konstantin als Referenzpunkt siehe den Sammelband zu „New Constantines“ (Magdalino 1994); bes. Haldon 1994 mit Blick auf das gesamte 7. Jahrhundert. Drijvers 2002, 181 f. weist darauf hin, dass das Interesse an Konstantin im frühen 7. Jahrhundert offenbar anstieg: Mehrere Konstantins-Viten, in denen die Auffindung des Kreuzes einen wichtigen Platz einnehmen, stammen aus dieser Zeit.

142 Flusin 1992 II, 313: „Il était donc important, pour Héraclius, de se faire reconnâitre par une geste spectaculaire comme l'empereur chrétien, chef à la fois de l'État et de la chrétienté. C'est cette reconaissance qu'il cherche à obtenir en restaurant la Croix à Jérusalem.“ Zur Bewertung der Restitutio Crucis in der Forschung siehe außerdem Spain Alexander 1977, 225: Mit dem Akt habe sich Herakleios Kritikern entgegengestellt, die seine illegitime Ehe mit Martina anklagten; siehe bereits Frolow 1953, 101-105; vgl. Ant. Strateg. (Conybeare 516).

143 Siehe z. B. Regan 2003, 77; Paul 2012, 187-199; Greisiger (im Druck). 
Konstantin, hergestellt durch die Sorge um die Kreuzreliquie, Resonanz. Im nahöstlichen Raum setzten sich im Laufe des Jahrhunderts - vor allem auch unter dem Eindruck der arabischen Eroberungen, die die Gegend nur einige Jahre nach dem kaiserlichen Einzug in Jerusalem heimsuchten - eschatologische Deutungen durch; ob diese tatsächlich bereits in eventu von Herakleios angelegt waren, lässt sich nicht mehr mit Sicherheit feststellen. Was sich indes in Bezug auf die rückgewonnenen Ostprovinzen plausibel machen lässt, ist die These, dass Herakleios' Restitutio Crucis in engem Zusammenhang mit dem Versuch stand, die dogmatischen Streitigkeiten zu schlichten, welche seit Jahrhunderten die Christenheit spalteten; ${ }^{144}$ diesen Schlichtungsversuch werde ich nun einer genaueren Betrachtung unterziehen.

\subsubsection{Religionspolitik}

Nach seinem Aufenthalt in Jerusalem kehrte Herakleios nicht direkt nach Konstantinopel zurück, sondern bewegte sich in Richtung Nordosten, nach Syrien bzw. Mesopotamien; es galt einerseits, die Sicherung der römisch-persischen Grenzlinie zu überwachen, und andererseits, die Lage innerhalb der zurückgewonnenen Provinzen zu konsolidieren. ${ }^{145}$ Währenddessen kamen die politischen Geschicke Ctesiphons nicht zur Ruhe: Nur 40 Tage, nachdem Herakleios' Verbündeter Shahrbaraz im April 630 den jungen Ardashir hatte ermorden lassen und selbst zum Großkönig gekrönt worden war, erlag er selbst einem Attentat. ${ }^{146}$ Boran, eine Tochter des Chosroes II., die Shahrbaraz nach seiner Einnahme Ctesiphons geheiratet hatte, übernahm an dessen Stelle die Regierung. Sich ihrer schwachen Position bewusst, schickte sie im Sommer 630 eine Gesandtschaft zu Herakleios, angeführt durch den nestorianischen Katholikos Ishoyahb, um ihre Kompromissbereitschaft $\mathrm{zu}$ demonstrieren. ${ }^{147}$ Herakleios seinerseits befand sich nun erneut in der überlegenen Verhandlungsposition und wusste diese zu nutzen: Während im Zuge des Paktes mit Shahrbaraz der Euphrat als Grenze zwischen Rom und Persien festgelegt worden war, blieb Boran nichts anderes übrig, als nun einer Verschiebung weiter nach Osten zuzustimmen. Man einigte sich auf die für Rom äußerst günstige Linie des Jahres 591, die Maurikios durch die Unterstützung des Chosroes II. gegen den Usurpator Baram Chobin hatte erwirken können: Strategisch wichtige Gebiete Transkaukasiens fielen erneut an Rom. Damit

144 Frolow 1953, 101-105 und Stratos 1968, 251f. sehen die Restitutio Crucis als Vorspiel, das einen fruchtbaren Boden zur kaiserlichen Schlichtungspolitik bereiten sollte.

$145 \mathrm{Zu}$ der Sicherung der Grenzen siehe Transl. Anast. Pers. 1 (ebd. 3 verfolgt den Weg des Herakleios bis nach Konstantina am Euphrat) und Sebeos 41 (Thomson/Howard-Johnston I, 90 f.).

146 Bonner 2019, 315.

147 Tod des Shahrbaraz: Sebeos 40 (Thomson/Howard-Johnston I, 89); zur Delegation siehe Anon. Guidi (Nöldeke 32f.), Chron. Seert (Scher 557 f.); vgl. Flusin 1992 II, 320 - 322, außerdem Stratos 1968, 255f. und Kaegi 2003, 212f.; zur Regierung der Boran siehe Bonner 2019, 317. 
war es Herakleios schließlich gelungen, den Status quo der Jahre vor dem Ausbruch des Krieges unter Phokas wiederherzustellen. ${ }^{48}$

Nicht nur realpolitische Fragen nach Truppenstationierungen und Grenzziehungen bestimmten Herakleios' Aktivitäten in den Jahren nach dem Friedensschluss; ab etwa 630 begann er auch verstärkt, sich auf dem kirchen- bzw. religionspolitischen Feld zu betätigen. In dem Moment, als die Perser abgezogen waren, galt es, die Bevölkerung der ehemals besetzten Gebiete wieder auf eine Linie mit Konstantinopel zu bringen. Vor allem religiös begründete Unstimmigkeiten verhinderten eine Annäherung und den nachhaltigen Wiederaufbau von administrativen Strukturen im Sinne der Zentralmacht; dies hatte sich bereits in Edessa gezeigt, wo der lokale Bischof aufgrund religiöser Differenzen die Kommunion mit Herakleios verweigerte. ${ }^{149}$ Nach der Beruhigung des Verhältnisses zum Nachbarn Persien hatte nun religiöse Einigung höchste Priorität - eine Einigung, die nicht nur im obigen Sinne pragmatisch motiviert war, sondern gleichsam auch vor dem Hintergrund des Ideals einer im christlichen Glauben geeinten Ökumene stand. Sich auf die theologische Expertise des Patriarchen Sergios berufend, hatte der Kaiser die Einigung der Kirche bereits vor 628 auf seine Agenda gesetzt; ${ }^{150}$ nach der Rückgewinnung der Ostprovinzen verfolgte er dieses Ziel jedoch mit einer gesteigerten Vehemenz.

Eine derartige Zielsetzung war gewiss keine leichte. Das Zerwürfnis zwischen den verschiedenen christlichen Gemeinden der Levante und Ägyptens konnte auf eine mehrere Jahrhunderte alte Geschichte zurückblicken. Nach dem Konzil von Chalkedon vom Jahr 451, im Zuge dessen die dyophysitische Lehre - die Lehre von den zwei Naturen Christi - im Glaubensbekenntnis festgelegt worden war, hatten sich Syrien und Ägypten als Zentren einer miaphysitischen Opposition herauskristallisiert. ${ }^{151}$ Einigungsversuche von Seiten der Kaiser, welche sich zumindest ab Justin I. zu den Richtlinien des Konzils von Chalkedon bekannten, hatten die Kluft zwischen den Parteien eher vertieft als eingeebnet. Von einem Kompromiss war man auch im Jahr 628 weit entfernt. Die Rückgewinnung der Ostprovinzen durch Herakleios wurde von den dort ansässigen miaphysitischen Gemeinden nicht unbedingt positiv gesehen; mit der chalkedonensischen Zentralmacht in Konstantinopel verband man vor allem Repressionen, während die persischen Besatzer sich gegenüber den Miaphysiten tolerant gegeben hatten. ${ }^{152}$ Der enge Kontakt mit Persien nach 628 brachte nun auch

148 Die Einigung auf die Grenze von 591 ist in Sebeos 41 (Thomson/Howard-Johnston I, 90 f.) bezeugt. Zur Frage der Grenzziehung im Nachklang von Chosroes' Sturz siehe Howard-Johnston 1999, 27-29; zu der Verschiebung der Grenze unter Maurikios siehe Mi. Whitby 1988, 197-202, 304.

149 Dazu siehe oben S. 253.

150 Frendo 1988b, 16; Meyendorff 1989, 338f.

$151 \mathrm{Zu}$ der theologischen Kontroverse vor und im Anschluss an das Konzil von Chalkedon siehe Meyendorff 1989, 165-250; Lange 2012, 21-414; zu der Herausbildung der miaphysitischen Kirche siehe Frend 1972 und Menze 2008 für Syrien; Flusin 1992 II, 95-128 zum Verhältnis zwischen Chosroes II. und den christlichen Gemeinden in seinem Herrschaftsgebiet.

152 Siehe Stratos 1968, 283 - 286; zu den Miaphysiten unter persischer Vorherrschaft siehe Frend 1972, $336-339$. 
nestorianische Gemeinden wieder verstärkt mit ins Spiel: Auf persischem Boden hatte diese Spielart des Christentums, die bereits beim Konzil von Ephesos 431 als Häresie verurteilt worden war, ungestört ihre eigenen Strukturen ausbilden können. Dogmatisch standen die Nestorianer den Miaphysiten wiederum diametral entgegen: Während die Miaphysiten von einer - nämlich der göttlichen - Natur in Christus ausgingen, basierte die Lehre der Nestorianer auf einer deutlichen Trennung der menschlichen und göttlichen Naturen Christi, die über den chalkedonesischen Dyophysitismus noch hinausging. ${ }^{153}$

Viele Kaiser des 4. bis 6. Jahrhundert hatten sich in Hoffnung auf eine Kircheneinigung an christologischen Fragen bereits die Zähne ausgebissen - mit mehr oder weniger großem Schaden für die eigene Reputation. ${ }^{154}$ Doch davon ließ sich Herakleios in seinem ambitionierten Unterfangen nicht abschrecken. Nach der Restitutio Crucis begann er, mit einer Reihe hochrangiger Vertreter der verschiedenen christlichen Denominationen des Nahen Ostens ins Gespräch zu treten. Als Grundlage für die erhoffte Einigung propagierte er eine spezielle christologische Formel, gedeckt durch die theologische Expertise des Patriarchen Sergios von Konstantinopel; eine Formel, welche für alle konfligierenden Parteien gleichsam akzeptabel sein sollte: Anstatt weiter über ein oder zwei Naturen (physeis) Christi zu debattieren, lag ihr Kern in der Annahme einer einzigen göttlichen Energie (energeia) in Christus. Diese Formel war theologisch nicht innovativ; ihr Wert bestand vielmehr darin, dass sie sich einer Sprache bediente, die in der Vergangenheit von Kirchenvätern beider Seiten - sowohl Anhängern des Chalkedonense als auch dessen Gegnern - genutzt worden war. Konstantinopel setzte in seinem Ringen um Einigung also auf eine mutmaßlich gemeinsame Basis. ${ }^{155}$ Diese Lehre, wie sie sich im Laufe der 630er Jahre sukzessive herauskristallisierte, sollte unter dem Schlagwort Monoenergismus bzw. Monotheletismus in die theologischen Debatten eingehen. ${ }^{156}$

Im nordsyrischen Hierapolis, wo Herakleios zuvor bereits Station gemacht hatte, um die Kreuzreliquie in Empfang zu nehmen, traf er auf den einflussreichen mia-

$153 \mathrm{Zu}$ der nestorianischen Kirche in Persien siehe Lange 2012, 471-516; zu Christen in Persien siehe auch Schilling 2008 und Payne 2015.

154 Einen Überblick über die kaiserliche Religionspolitik bietet Lange 2012, 170 - 287; ebd. 288-363 zu Justinian; zu Letzterem auch Uthemann 1999; vgl. Meyendorf 1989, 28 - 38 zum Verhältnis von Kaiser und Kirche.

155 Vgl. Theoph. Conf. AM 6121 (De Boor 329f.). Zu dieser Formel siehe etwa Stratos 1968, 288 und Booth 2014, 188-200; zu den Vorläufern der Lehre von der mia energeia Lange 2012, 428- 446 und zu deren Vor- bzw. Ausarbeitung durch Sergios und Herakleios ebd. 534-552. Zu den theologischen Problemstellungen, die ich hier nicht weiter diskutieren werde, siehe Uthemann 1997 und Hovorun 2008; eine Zusammenstellung der relevanten Quellen zur monoenergetisch-monotheletischen Debatte bietet Winkelmann 1987; vgl. auch Winkelmann 2001.

$156 \mathrm{Zu}$ Beginn der 630er Jahre rankte sich die Debatte um die eine Energie; erst mit der Zeit trat der eine Wille in den Vordergrund, der dann auch den Namen des später verurteilten Dogmas prägte: Monotheletismus; siehe den Überblick über diesen Prozess bei Meyendorff 1989, 333-356 und Hovorun 2008, 55-72. 
physitischen Patriarchen von Antiochia, Athanasios den Kameltreiber, sowie eine Reihe von gleichgesinnten Bischöfen in dessen Gefolge. Obwohl beide Seiten nach mehrtägigen Gesprächen zu Glaubensfragen einen gewissen Grad an Kompromissbereitschaft gezeigt zu haben scheinen, bleibt unklar, ob es zu einer formalen Einigung kam. Athanasios jedenfalls starb kurz drauf, im Jahr $631 .^{157}$ Auch das bereits erwähnte Zusammentreffen mit dem Gesandten der persischen Königin Boran, dem nestorianischen Katholikos Ishoyahb, in Aleppo nutze Herakleios, um sein Einigungsprogramm voranzutreiben. Nachdem die beiden Männer sich gegenseitig ihre theologischen Positionen dargelegt hatten, zelebrierte Ishoyahb in Präsenz des Kaisers die Messe und gewährte ihm die Kommunion; Geschenke wurden ausgetauscht und Hochachtung bekundet, bevor Ishoyahb in seiner Funktion als Gesandter wieder nach Persien zurückkehrte. Die Formel von der einen Energie hatte hier offenbar Anklang gefunden. ${ }^{158}$ In Edessa begegnete Herakleios schließlich dem miaphysitischen Katholikos der armenischen Kirche, Ezr, der mit Aussicht auf großzügige Gegenleistungen die Einigungsformel akzeptierte. Auf einer Synode der armenischen Bischöfe in Theodosiopolis kurz darauf wurde gar die Union mit Konstantinopel bestätigt und das Chalkedonense anerkannt; doch es sollte nicht lange dauern, bis deutlich wurde, dass die Einigungsformel in Armenien nicht auf breitere Unterstützung hoffen konnte. Die Region kam weder administrativ noch kirchenpolitisch zur Ruhe, nachdem sie mit dem territorialen Zugeständnis von Boran größtenteils wieder unter römische Vorherrschaft gekommen war. ${ }^{159}$

Ägypten bereiste Herakleios nicht persönlich, installierte jedoch mit Kyros, dem ehemaligen Bischof von Phasis, einen engen Vertrauten als Patriarch von Alexandria. Neben kirchlicher Hoheit wurde diesem auch umfassende administrative Vollmacht übertragen. Seinem Konkurrenten, dem miaphysitischen Patriarchen Benjamin, der unter der persischen Besatzung uneingeschränkt sein Amt hatte ausüben können,

157 Das Treffen ist einerseits bei Theoph. Conf. AM 6121 (De Boor 329f.) überliefert, wo zumindest vordergründig eine Einigung auf die Lehre von der einen Energie erreicht wird - Herakleios soll Athanasios versprochen haben, ihn im Amt des Patriarchen von Antiochia zu bestätigen, wenn er sich zum Chalkedonense bekenne; andererseits bei Mich. Syr. 11.3 (Chabot II, 412), wo sich Athanasios nicht auf die Angebote des Herakleios einlässt, was zu Verfolgungen der Miaphysiten führt (ähnlich Chron. Seert [Scher 544]). Die Unterschiede spiegeln die Voreingenommenheit der jeweiligen Überlieferungstradition wieder: Theophanes steht für die Anhänger des Chalkedonense, Michael für die miaphysitische, d.h. jakobitische Kirche. Zu dem Treffen siehe Stratos 1968, 293-297; Frend 1972, 346f.; Flusin 1992 II, 321 mit Anm. 81 (zur Frage der Datierung); Kaegi 2003, 214; Lange 2012, 553 - 566 und Booth 2014, 202-204, der das Treffen auf den Winter 629/30 datiert, also vor den Abstecher nach Jerusalem, ausführlich dazu ebd. Anm. 63.

158 Chron. Seert (Scher 557-560); siehe dazu Flusin 1992 II, 319-327; Kaegi 2003, 212f.; Lange 2012, 566 - 570; Booth 2014, $201 \mathrm{f}$.

159 Sebeos 41 (Thomson/Howard-Johnston I, 91f.) und Narratio de rebus Armeniae (Garitte 287-311); siehe Stratos 1968, 291-293; Frend 1972, 345f.; Thomson/Howard-Johnston 1999 II, 228; Kaegi 2003, 214 f.; Lange 2012, 571-575; Booth 2014, 200. 
blieb nur die Flucht. ${ }^{160} 633$ fand sich auch in Alexandria eine Synode ägyptischer Bischöfe zusammen, auf der unter Kyros' Federführung entlang der Kompromissformel von der einen Energie eine Einigungs-Erklärung erarbeitet werden konnte. Miaphysitische Gläubige bis hin zu prominenten Bischöfen traten mit den Repräsentanten der hauptstädtischen Linie in Kommunion. ${ }^{161}$

Schließlich sahen sich auch jüdische Gemeinden von Herakleios’ Konsolidierungspolitik tangiert - hier kam allerdings eine härtere Linie zum Einsatz. Nach seiner Restitutio Crucis erneuerte der Kaiser den Beschluss, der Juden den Zutritt zur Heiligen Stadt und dem direkten Umland verbot. ${ }^{162}$ Im Jahr 632 erließ er für Afrika ein Edikt, welches die Zwangstaufe von Juden anordnete. Dass derartige Maßnahmen tatsächlich weiträumig Anwendung fanden, ist zwar zweifelhaft; die Jahre nach der Rückgewinnung der Ostprovinzen waren allerdings - so viel lässt sich sagen - geprägt von antisemitischen Ressentiments und gewaltsamen Ausfällen gegen jüdische Gemeinden. ${ }^{163}$

Die Kompromissformel von der einen Energie fand zumindest in manchen Kreisen Anklang. Nach der Wiederherstellung römischer Hoheit im Osten schien also auch Herakleios' nächstes Ziel, die Einigung der christlichen Kirchen, zu Beginn der 630er Jahre bisweilen zum Greifen nahe. Selbst der Papst Honorius, bei dem Sergios brieflich für die Initiative Konstantinopels geworben hatte, signalisierte 634 sein Einverständnis. ${ }^{164}$ Doch nach anfänglichen Teilerfolgen formierte sich schnell entschlossene Opposition gegen die hauptstädtische Initiative - und das von beiden Seiten: Auf

160 Theoph. Conf. AM 6121 (De Boor 330) und zu den Vollmachten des Kyros: Chron. 1234, 118 (Chabot I, 197) und Hist. Patr. Alex. (Evetts 489f.); PLRE IIIA, Cyrus 17 (377f.).

161 Siehe Stratos 1968, 297-299; Kaegi 2003, 216; zur Synode Frend 1972, 349f.; Lange 2012, 575-581; Booth 2014, 205-207; die Einigungserklärung ist erhalten, mit Übers. bei Allen 2009, 169-173.

162 Theoph. Conf. AM 6120 (De Boor 328).

163 Zum Taufedikt siehe Doctrina Iacobi in Dagron/Déroche 2010, 31f. und Mich. Syr. 11.4 (Chabot II, 414); Diskussion bei Olster 1994, bes. 85 f., 123, 162; Kaegi 2003, 216f.; Greisiger 2014, 97-106; außerdem Speck 1997b, bes. 441-467; vgl. zu der antisemitischen Stimmung auch Av. Cameron 1994. Sowohl Fredegar Chron. 65 als auch Hist. Patr. Alex. (Evetts 492) berichten, Herakleios sei durch Astrologie offenbart worden, dass sein Reich an ein beschnittenes Volk fallen werde, woraufhin er die Zwangstaufen der Juden angeordnet habe. Laut Fredegar (ebd.) forderte Herakleios den fränkischen König Dagobert auf, die Juden in seinem Reich taufen zu lassen; Dagobert sei der Aufforderung nachgekommen; Variationen dieser Legende finden sich auch in arabischen Quellen. Siehe dazu Esders 2009, 2018, der dafür argumentiert, dass die Legende ursprünglich in einem chalkedonensischen Milieu in Syrien/Palästina entstand, das Herakleios aufgrund von dessen Religionspolitik feindlich gesinnt war; die Legende sei dann über die Kontakte der pro-chalkonensichen Partei um Sophronios und Maximos Confessor nach Italien - ein Schlüsselereignis ist hier das Lateran-Konzil von 649 - und schließlich zu Fredegar gelangt (siehe Esders 2018, 144-153).

164 Stratos 1968, 301; Kaegi 2003, 269 und ausführlicher Zocca 1992, bes. 110 -123; Lange 2012, 597601; der Briefwechsel in dieser Angelegenheit zwischen Sergios und Honorius mit Übers. bei Allen 2009, 183-209. Honorius brachte dabei eine Variation der Kompromissformel ins Spiel, die Lehre vom einen Willen Christi (hen thelema), die dann 638 in einem kaiserlichen Edikt, der Ekthesis, aufgegriffen wurde. 
lokaler Ebene entzog sich das Gros der miaphysitischen Gemeinden mit ihren gewachsenen Strukturen einer nachhaltigen Annäherung an Konstantinopel; ${ }^{165}$ der vehementeste Widerstand, der auch den Fortlauf der dogmatischen Debatte in den nächsten Jahrzehnten entscheidend prägen sollte, ging allerdings von Seiten prominenter Anhänger des Konzils von Chalkedon aus. Als Zentrum dieser Opposition erwies sich das monastische Umfeld Palästinas, als ihre Galionsfigur ein gewisser Sophronios: In den Klöstern der judäischen Wüste als Schüler des Johannes Moschos sozialisiert, bereiste Sophronios nach der Einnahme Jerusalems durch die Perser 614 das westliche Mittelmeer bis nach Rom und gewann dabei eine ansehnliche Reputation als strikter Verfechter des Chalkedonense. Spätestens 633 erhob er sich offen gegen die durch Sergios und Kyros propagierte Kompromissformel von der einen Energie, die er als unzulässige Verwässerung der orthodoxen Lehre verstand. 634 wurde er zum Patriarchen von Jerusalem gewählt, von wo aus er seine Position weiter vehement vertrat, während Palästina sich bereits mit den ersten Angriffen der Araber konfrontiert sah. ${ }^{166}$ Sophronios' Schüler Maximos, dem seine späteren Aktivitäten den Beinahmen Confessor einbrachten, führte den Kampf seines Mentors nach dessen Tod im Jahr 638 noch über mehrere Jahrzehnte hinweg weiter. ${ }^{167}$ Herakleios' Bemühungen um eine religiöse Einigung der römischen Ostprovinzen wurde indes zu diesem Zeitpunkt bereits durch das sukzessive Vorrücken der Araber zunichte gemacht.

An dieser Stelle geht es nicht darum, die theologischen Feinheiten der Debatte nachzuvollziehen, die durch Herakleios' Aktivitäten in den Ostprovinzen losgetreten wurde; ${ }^{168}$ die nun folgende Analyse ist stattdessen von den Fragen geleitet, warum der Kaiser sich auf dem Feld der Kirchenpolitik betätigte, wie sein Engagement zu bewerten ist und wie es im hauptstädtischen Kontext kommuniziert wurde.

Mit der strukturellen wie organisatorischen Verschränkung von römischem Imperium und christlicher Kirche ab dem 4. Jahrhundert fiel die Sorge um die Herstellung und Wahrung christlicher Einheit in den kaiserlichen Zuständigkeitsbereich. Diese Sorge war nicht zuletzt machtpolitisch motiviert: Je prominenter christlicher Glaube und kirchliche Strukturen im Reichszusammenhang, umso wichtiger wurde auch der funktionale Zusammenhalt der Kirche für die Aufrechterhaltung der öffentlichen Ordnung und die Stabilität des politischen Systems. „A divided Church would also mean a divided empire”, fasst John Meyendorff die Bedeutung eines

165 Siehe Stratos 1968, 302-304. Es bleibt allerdings auch zu betonen, dass die Lehre vom Monoenergismus/Monotheletismus vor allem in chalkedonensischen Gemeinden Syriens und Palästinas angenommen und auch nach der arabischen Eroberung beibehalten wurde, siehe dazu Tannous 2014. $166 \mathrm{Zu}$ der Opposition des Sophronios siehe vor allem Allen 2009 (mit den maßgeblichen Quellen); Booth 2014, 209-224, 228-241 und ders. 2013, 16-26, wo er nachvollzieht, wie sich die palästinensische Kirche angesichts der Eroberung durch die Araber von der Idee des Römischen Reiches als entscheidenden Faktors der christlichen Heilsgeschichte lossagte und somit von Konstantinopel emanzipierte; vgl. auch Kaegi 2003, 269-271 und bes. Schönborn 1972 zu Sophronios.

$167 \mathrm{Zu}$ Maximos Confessor siehe Booth 2014, 269-328.

168 Siehe zur theologischen Debatte zuletzt Winkelmann 2001, 13-21; Hovorun 2008; Lange 2012. 
einheitlichen Glaubensbekenntnisses für die Integration des römischen Reiches zusammen. ${ }^{169}$ Bereits Konstantin bemühte sich aktiv um die Schlichtung dogmatischer Spaltungen: Um den Dissens beizulegen, der durch die Lehren des Presbyters Arius losgetreten worden war, rief der Kaiser 324 das erste ökumenische Konzil in Nikaia zusammen, dem er auch persönlich vorstand. ${ }^{170}$ Seit dem dritten ökumenischen Konzil von Chalkedon 451 unter Kaiser Markian wurde das Glaubensbekenntnis als kaiserliches Gesetz proklamiert: Die Sorge um den rechten Glauben bzw. die rechte Gottesverehrung fiel somit offiziell in den Rahmen kaiserlicher Gestaltungskompetenz. ${ }^{171}$ Die Definition und Durchsetzung von Orthodoxie, die sich im Verhältnis von Gottvater und Sohn verdichtete, avancierte zur ,Staatsangelegenheit‘. Dabei stand der pragmatischen Bemühung um Frieden und Einheit der Gedanke einer Einigung der Christenheit unter römischer Ägide als heilsgeschichtlichen Versprechen zur Seite. ${ }^{172}$ Römische Monarchen beanspruchten nicht nur Synodalgewalt, indem sie Bischöfe zusammenriefen, sondern auch die Autorität, sich auf inhaltlicher Ebene in Glaubensstreitigkeiten einzumischen, was auf Seiten der Kleriker nicht selten auf Kritik stieß; ${ }^{173}$ vor allem Justinian tat sich dahingehend hervor, dass er besonders intensiv in theologische Debatten eingriff. ${ }^{174}$ Gleichzeitig erwartete ab dem 5. Jahrhundert vor allem das Konstantinopolitaner Umfeld von den Kaisern, sich als Wahrer der (chalkedonensischen) Orthodoxie $\mathrm{zu}$ beweisen ${ }^{175}$ - eine Erwartung, die nicht selten in

169 Meyendorff 1989, 33; die Bedeutung der Einigkeit des Christentums für die Aufrechterhaltung öffentlicher Ordnung betont auch Wienand 2016b, bes. 95f. - bereits Konstantins kirchenpolitische Initiativen seien vor diesem Hintergrund zu lesen. Diefenbach 2012, 59-66 gibt einen ausführlichen Überblick über die Forschung zu der Interdependenz zwischen politischen Strukturen und christlicher Kirche im 4. Jahrhundert (mit entsprechenden Literaturverweisen); dabei identifiziert er zwei konträre Ansätze: einerseits die Annahme eines „umfassenden kaiserlichen Integrations- und Normierungswillens“, andererseits „die Betonung eines kaiserlichen Regierungsstils, der stärker an den Maßgaben eines situativen und pragmatischen Reagierens auf lokale Probleme orientiert ist“ (Zitat ebd. 66).

$170 \mathrm{Zu}$ Konstantin auf dem Konzil von Nikaia siehe Wienand 2012, 415-420; dort mit weiterer Literatur. Zuvor hatte sich Konstantin bereits darum bemüht, den Donatisten-Streit in Afrika zu schlichten; dazu siehe Wienand 2016b.

171 Siehe Meyendorff 1989, 28-38 zum Verhältnis von Kaiser und Kirche; ebd. 165-206 zum Konzil von Chalkedon und seinen Folgen.

172 Zum heilsgeschichtlichen Aspekt der Kircheneinigung siehe Greisiger 2014, 121.

173 Die starke Position des oströmischen Kaisers in Bezug auf innerkirchliche bzw. theologische Angelegenheiten wurde in der Forschung bisweilen mit dem Begriff des Caesaropapismus beschrieben; zur Begriffsgeschichte siehe Dagron 2003, 282-312, der sich allerdings von dem Begriff distanziert. Zum Kaiser als Priester siehe Treitinger 1956, 124-144; Höfert 2015, 139-145, $197-229$.

174 Zur Religions- bzw. Kirchenpolitik Justinians siehe Uthemann 1999. Der Codex Iustinianus beginnt mit einem formalen Glaubensbekenntnis; siehe dazu Speigl 1995. Eine systematische Untersuchung, die die Entwicklung der kaiserlichen Religions- und Kirchenpolitik vor dem Hintergrund der funktionalen Interdependenz von politischen und kirchlichen Prozessen - und nicht zuletzt die Rolle der Kaiser in dieser Entwicklung - von Konstantin bis ins 6. bzw. 7. Jahrhundert untersucht, ist meines Wissens ein Desiderat; auch die Studie von Meyendorff 1989 leistet dies nur in Ansätzen.

175 Diefenbach 1996, 58; Meier 2003c, 145, 147. Nach dem Tod des Zenon forderte die hauptstädtische Bevölkerung einen frommen und orthodoxen Kaiser, siehe De cerim. 1.92. 
Konflikt zu kaiserlichen Bemühungen trat, die Gemeinden, die das in Chalkedon definierte Dogma nicht anerkannten, in die reichsumfassende Kirche zu reintegrieren. Empfand das hauptstädtische Umfeld kaiserliche Maßnahmen in diesem Sinne als unzulässig, konnte es zu Akzeptanzentzug kommen, der die Stabilität der Regierung empfindlich schwächte. ${ }^{176}$

So sehr sich die römischen Kaiser auch um die Einigung der Christenheit bemühten, konnte doch kein umfänglicher Erfolg erzielt werden. Anstelle einer konfessionellen Einigung vertieften sich die Gräben zwischen den verschiedenen Denominationen. Mit der Festigung der jakobitischen und koptischen Kirche bildeten sich im Osten des römischen Reiches ab dem 6. Jahrhundert alternative Organisationsstrukturen heraus, was nicht zuletzt den Zugriff der Zentralmacht auf die jeweiligen Gebiete beeinträchtigte. ${ }^{177}$ Auf die Spaltungen bzw. die Abweichung von dem, was in Konstantinopel als orthodox angesehen wurde, reagierten die römischen Kaiser mal mit Gesprächs- und Kompromissbereitschaft, mal mit gewaltsamen Sanktionen; keine der beiden Herangehensweisen erwies sich als nachhaltig. Seit Justin II. sahen sich die miaphysitischen Gemeinden des Ostens mit zunehmend harschen Restriktionen und zeitweise gar Verfolgungen von Seiten der Zentralmacht konfrontiert. ${ }^{178}$ Dass auch Herakleios sich auf dem Feld der Kirchenpolitik engagierte, ist also zunächst nicht verwunderlich. Mit dem Sieg über die Perser im Rücken diente seine Initiative primär der Festigung römischer Herrschaftsstrukturen in den Ostprovinzen und wurde gleichzeitig - wie ich im Folgenden ausführen werde - in der Hauptstadt im Sinne einer Profilschärfung des Kaisers im sakralen Feld aufbereitet. ${ }^{179}$

Während seine Vorgänger gegenüber den Miaphysiten einen konfrontativen Kurs eingeschlagen hatten, war Herakleios' Politik auf der praktischen Ebene von Kompromissbereitschaft geprägt; zeitweise lässt sich unter seiner Regierung gar ein recht hohes Maß an Toleranz ${ }^{180}$ gegenüber den nahöstlichen Kirchenstrukturen, die sich weiterhin strikt vom Chalkedonense abgrenzten, beobachten: 615/616 bemühte sich

176 Zum „Kampf um den rechten Glauben“ aus der hauptstädtischen Perspektive siehe Pfeilschifter 2013, 313-329. Der Sturz des Kaisers Basiliskos erfolgte 476 nach kurzer Regierung nicht zuletzt aufgrund dessen religionspolitischer Positionierung zugunsten der miaphysitischen Denomination; siehe dazu Redies 1997; Kolditz 2013; Pfeilschifter 2013, 564-584.

177 Zu dieser Entwicklung siehe die Monographie von Frend 1972; Meyendorff 1989, 266-280; zur Herausbildung einer miaphysitischen Kirche in Syrien siehe Menze 2008; Wood 2011 (Letzterer vor allem mit Blick auf die politische Theologie des syrischen Raumes).

178 Zur Religionspolitik des Justin II. siehe Av. Cameron 1976c; zu den Verfolgungen des Miaphysiten und einer daraus resultierenden Stärkung des antichalkedonensischen Widerstandes siehe Frend 1972, $316-335$.

179 Vgl. dazu Frendo 1988b, 17 f., der hinter der Kirchenpolitik vor allem die Ambition des Sergios und eine ,arrogance of invincibility” sieht.

180 Den Begriff der Toleranz in Zusammenhang mit der Kirchen- bzw. Religionspolitik Konstantins diskutiert Wienand 2016b, bes. 78-84. Demnach bedeutet Toleranz, dass als normativ falsch beurteilte Praktiken/Überzeugungen geduldet werden. Im Falle der Bemühungen des Chalkedonensers Niketas um eine inner-miaphysitische Kircheneinigung trifft der Begriff demnach tatsächlich zu. 
Niketas, Herakleios' Cousin, in seiner Funktion als Praefectus Augustalis von Ägypten, eine inner-miaphysitische Spaltung beizulegen, indem er Vertreter der koptischen und der jakobitischen Kirche in Alexandria zu Gesprächen zusammenbrachte. Davon, dass Niketas' Initiative im kaiserlichen Sinne war, ist auszugehen. ${ }^{181}$ Bereits kurz nach Herakleios' erfolgreicher Usurpation lassen sich also von offizieller Seite Bemühungen nachvollziehen, die römischen Ostprovinzen, die von jahrelangen inneren Unruhen (Revolte der Herakleioi, gewaltsame Ausschreitungen innerhalb der Städte) destabilisiert waren, durch eine deeskalierende Kirchenpolitik zu befrieden. Nachdem die Einigungsbemühungen angesichts der persischen Okkupation vorerst hatten auf Eis gelegt werden müssen, nahm Herakleios das Unterfangen nach dem Friedensvertrag von 628 erneut auf: Indem er die eine göttliche Energie Christi, die weder den chalkedonensischen noch den miaphysitischen Glaubensgrundsätzen widersprach, ${ }^{182}$ ins Zentrum seiner interkonfessionellen Verhandlungen rückte, setzte er auf das Erreichen eines Minimalkonsenses. Anstatt mit kaiserlichen Edikten einen Kompromiss zu erzwingen, wie es seine Vorgänger bisweilen versucht hatten, setzte Herakleios ab 630 auf Gespräche auf lokaler Ebene mit den jeweils prominenten Gemeindevertretern; eine überregionale Synode wurde vorerst nicht einberufen. Nicht zuletzt das Prestige, das der Erfolg gegen die Perser und zuletzt die Restitutio Crucis ihm als christlichem Kaiser eingebracht hatte, mag die Basis dafür bereitet haben, dass sein persönliches Engagement zumindest vorübergehend auf fruchtbaren Boden fiel. ${ }^{183}$

Neben der Notwendigkeit, die wiedergewonnenen Ostprovinzen auf kirchenpolitischer Ebene in den Reichszusammenhang einzubinden, lässt sich Herakleios' Initiative auch vor dem Hintergrund sehen, dass sich in den Jahren zuvor ein anderer Monarch um die Einigung der Christenheit bemüht hatte: der persische Großkönig. Chosroes II. veranlasste und förderte nicht nur den Wiederaufbau Jerusalems nach der Eroberung durch seine eigenen Truppen, ${ }^{184}$ sondern berief auch - ganz im Stile der römischen Kaiser - die christlichen Bischöfe seines Einflussbereiches zu Synoden zusammen, um die innerchristlichen Streitigkeiten zu schlichten: Bereits 612 versammelte er zum Zweck der Kompromissfindung Vertreter der Miaphysiten und Nestorianer in Ctesiphon; die theologischen Debatten überwachte er persönlich. ${ }^{185}$ Während die nestorianische Kirche im persischen Kernland weiterhin die Oberhand behielt, konnten die Miaphysiten in den besetzten Gebieten ohne Restriktionen der

181 Siehe dazu Olster 1985; Frendo 1988b, 12, 17; Greisiger 2014, $122 \mathrm{f}$.

$182 \mathrm{Zu}$ der Lehre von der einen Energie vor dem 7. Jahrhundert bei miaphysitischen und chalkedonesischen Autoren siehe Lange 2015, 415-446.

183 Vgl. Frend 1972, 343; Frendo 1988b, 16 f.

184 Dass Chosroes' Engagement in den griechischen (romfreundlichen) Quellen verschwiegen wird, ist kaum verwunderlich; es lässt sich indes aus Quellen erschließen, die dem persischen Kulturraum näherstanden: Sebeos 34 (Thomson/Howard-Johnston I, 70); Anon. Guidi (Nöldeke 29); siehe dazu Payne 2015, 183, der auch die Vertreibung der Juden aus Jerusalem durch die Perser, wenige Jahre nach der Eroberung 614, als eine an christliche Kaiser gemahnende Praktik liest (ebd. 183f.).

185 Payne 2015, 185, 187 f.: Ein Kompromiss kam offenbar nicht zustande. 
Zentralmacht ihre Strukturen ausbauen; die chalkedonensischen Gemeinden hingegen, welche die kirchenpolitische Linie der römischen Zentrale verfolgten, waren nun der politischen Unterstützung beraubt. ${ }^{186}$ Als die benachbarte Großmacht Persien also nicht nur weite Teile des östlichen Mittelmeerraumes in ihren Besitz brachte, sondern sich auch ganz aktiv als alternativer Rahmen für die Aushandlung und Verbreitung des christlichen Glaubens anbot, wurde die organische und geradezu exklusive Verbindung, die das Christentum mit dem römischen Reich gebildet hatte, in Frage gestellt. ${ }^{187}$ Dass Herakleios die Einigungspolitik nach der Rückgewinnung der Ostprovinzen derart vehement und mit persönlichem Einsatz vorantrieb, ist nicht zuletzt vor diesem Hintergrund zu verstehen: Es galt, den Bewohnern der Provinzen nicht nur die politische Vorherrschaft des römischen Reiches, sondern auch die religiöse Autorität des römischen Kaisers als Oberhaupt des Christentums gegen potentielle Konkurrenten vor Augen zu führen. Für eine derartige Motivation spricht nicht zuletzt der Umstand, dass sich Herakleios auch ganz dezidiert um eine Einigung mit der nestorianischen Kirche bemühte, die nach der Emigration ihrer Vertreter nach Persien lange Zeit nicht vorrangig auf der Agenda römisch-imperialer Kirchenpolitik gestanden hatte.

Beim Blick auf die monoenergetische Einigungspolitik kommt regelmäßig die Frage auf, ob tatsächlich Herakleios selbst als treibende Kraft hinter dieser Initiative stand oder ob nicht vielmehr der konstantinopolitaner Patriarch Sergios, selbst ein gebürtiger Syrer, als Strippenzieher zu identifizieren ist. ${ }^{188}$ Die Quellen zeichnen meiner Ansicht nach ein recht deutliches Bild: Die offenbar reibungslos funktionierende Zusammenarbeit zwischen Kaiser und Patriarch, die bereits im vorigen Kapitel in Zusammenhang mit Herakleios' Abwesenheit von der Hauptstadt betont wurde, griff auch auf dem Feld der Kirchenpolitik. Während Sergios den monoenergetischen Kompromiss auf theologischer Ebene bereits über Jahrzehnte vorbereitet und beworben hatte, ${ }^{189}$ stand Herakleios nach der Rückgewinnung der Ostprovinzen der Einigungsbemühung sowohl operativ als auch repräsentativ vor. ${ }^{190}$ Eine derartige Symbiose von Patriarch und Kaiser in kirchenpolitischen Angelegenheiten war keinesfalls selbstverständlich; Justinian hatte, wenige Jahre vor seinem Tod, aufgrund der von ihm favorisierten Lehre des Aphtartodoketismus mit dem Patriarchen Euty-

186 Frend 1972, 336-339; Frendo 1988b, 11; Meyendorff 1989, 340f.; Flusin 1992 II, $95-128 \mathrm{zu}$ Chosroes II. und den Christen; Payne 2015, 181-188 zu den christlichen Gemeinden unter persischer Herrschaft.

187 Booth 2014 zeigt in seiner Monographie, wie sich die Vorstellung einer christlichen Ökumene vom römischen Imperium als politischem Rahmen löste; dies geschah nicht nur während der persischen Okkupation und später angesichts der arabischen Expansion, sondern verstärkt auch von Seiten der ultra-chalkedonensischen Opposition gegen Herakleios' Einigungspolitik, die sich um Sophronios von Jerusalem und Maximos Confessor gruppierte.

188 Van Dieten 1972, 24 Anm. 82; Frendo 1988b, 10.

$189 \mathrm{Zu}$ der theologischen Grundlage siehe Lange 2012, 540 - 553.

190 Vgl. Greisiger 2014, 124: „War Sergios der intellektuelle Architekt der angestrebten Einigung, so fungierte Herakleios als deren pragmatischer Organisator.“ 
chios einen erbitterten Zwist ausgetragen, der schließlich in der Exilierung des Patriarchen eskalierte. ${ }^{191}$ Im Gegensatz dazu scheint Herakleios Sergios' theologischen Eingaben gefolgt zu sein, was die Annahme eines herrschaftspragmatischen Ansatzes seiner Schlichtungsversuche noch untermauert; im Gegensatz zu Justinian war Herakleios kein Theologe.

Vergleicht man jedoch den kompromissorientierten Ansatz, mit dem Herakleios der Lage in den Ostprovinzen Herr zu werden versuchte, mit der Art und Weise, wie diese Initiative vor einem hauptstädtischen Publikum besprochen wurde, so offenbart sich eine deutliche Diskrepanz. Einen Einblick in den konstantinopolitaner Diskurs bietet wieder einmal Georg von Pisidien, dessen Gedicht Contra Severum kaum anders denn als Kommentar zur kaiserlichen Einigungspolitik gelesen werden kann: Anstelle von Kompromissbereitschaft herrscht hier eine konfrontative Rhetorik vor, die nicht selten in offene Polemik ausartet. ${ }^{192}$ Hinsichtlich der Datierung des Gedichtes ist sich die Forschung uneins. ${ }^{193}$ Während die Komposition bisweilen mit der Veröffentlichung der Ekthesis im Jahr 638 in Verbindung gebracht wird, eines kaiserlichen Ediktes, das die monoenergetisch-monotheletische Kontroverse $\mathrm{zu}$ schlichten gedachte, ${ }^{194}$ halte ich eine Datierung in die frühen 630er Jahre für wesentlich plausibler - in die Zeit, als Herakleios die konfessionelle Einigung persönlich in den Ostprovinzen durchzusetzen suchte. ${ }^{195}$ Die Charakteristika des Gedichtes, die allen voran ins Auge stechen, sind Folgende: Georg stellt Herakleios als kompetenten und autoritativen Agenten auf dem religiösen Feld in den Vordergrund; der vom Kaiser ausgefochtene Kampf gegen die Häretiker steht auf einer Ebene mit dem gegen die ungläubigen Perser.

Das vordergründige Ziel des Gedichtes ist es, die Überlegenheit und Wahrheit des chalkedonensischen Glaubensbekenntnisses gegenüber den Miaphysiten zu bezeugen. Georg richtet seine Kritik vorrangig an Severos, den 538 verstorbenen Bischof von

191 Dazu siehe Uthemann 1999, 79-82; Meier 2003a, 289-291.

192 Vgl. Frendo 1988b, 17. Anders Larison 2019, bes. 166 f., der allerdings nicht zwischen dem Diskurs, wie wir ihn in Georg von Pisidien sehen, und Herakleios’ praktischen Maßnahmen unterscheidet: Ausgehend von Contra Severum schließt er, dass Herakleios eine strikte anti-miaphysitische Politik vertreten habe: „the idea of 'conciliatory' religious policies under Heraclius is not tenable.” (Zitat ebd. 167).

193 Der Sieg über die Perser wird in Cont. Sev. 24-33 thematisiert, ebd. 34 der Tod Chosroes' als terminus post quem.

194 So etwa MacCoull 1998, 76-79, die meint, im Gedicht intertextuelle Referenzen zur Ekthesis erkennen zu können (nämlich die Nutzung des Begriffs ektheseis [Cont. Sev. 677]), die ich allerdings nicht für aussagekräftig genug halte, um eine Spätdatierung zu untermauern; auch Larison 2019, 169f. äußert sich dahingehend kritisch; zur Ekthesis siehe unten S. 312f.

195 So auch Frendo 1988b, 17; Tartaglia 1998, 22-25; Ma. Whitby 1998, 271; Howard-Johnston 2010, 23f. geht gar davon aus, dass das von Herakleios in Auftrag gegebene Gedicht noch 629 vollendet wurde, bevor der Kaiser erneut gen Osten aufbrach; seiner Ansicht nach sei es unwahrscheinlich, dass ein derartig polemisches Gedicht nach dem Beginn der Einigungsgespräche entstanden sei. Dass sich allerdings die praktische Kompromissbereitschaft einerseits und die diskursive Polemik andererseits keineswegs ausschließen, wird im Folgenden deutlich. 
Antiochia, eine zentrale Identifikationsfigur der syrisch-miaphysitischen Kirche. Den Hauptteil des Gedichtes, der mit Bezugnahme auf eine Reihe prominenter Kirchenväter das theologische Argument ausbreitet, unterziehe ich hier keiner eingehenden Analyse, ${ }^{196}$ sondern konzentriere mich stattdessen auf Proömium und Epilog, die

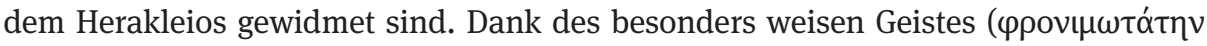

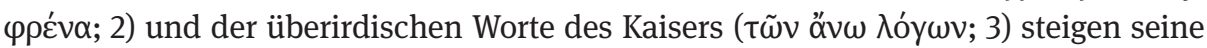

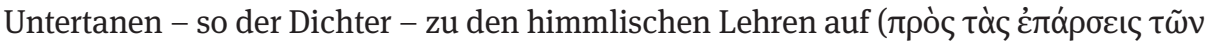

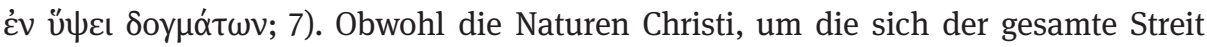
dreht, von den Menschen kaum zu erfassen seien, ${ }^{197}$ betont Georg von Pisidien die kaiserliche Kompetenz in dieser Angelegenheit. Zuerst blickt das Gedicht auf Hera-

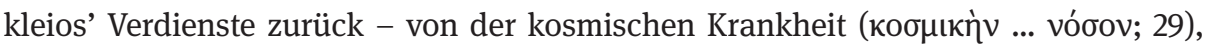
den Barbaren und Tyrannen, habe der Kaiser die Menschheit befreit ${ }^{198}$-, um dann auf dessen Nemesis, den inzwischen ermordeten Perserkönig Chosroes, überzuleiten: Dieser habe die Ordination von Bischöfen gefördert, die der Lehre des Severos folgten,

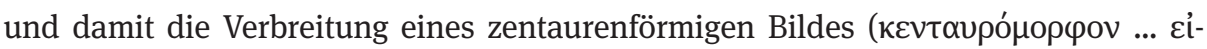
кóva; 43), des miaphysischen Irrglaubens, begünstigt - „unseren Glauben in Brand

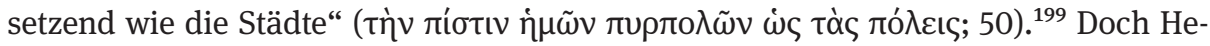

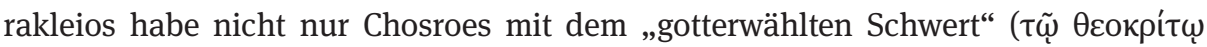
$\xi^{\prime}\left(\varphi \varepsilon \iota\right.$; 59) getötet, sondern auch den Aberglauben der Mager ausgemerzt. ${ }^{200}$ Die größte

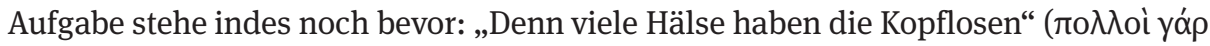

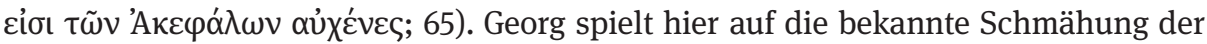
Miaphysiten als Akephaloi, als Kopflose, an, ${ }^{201}$ um dann unter Bezugnahme auf die bereits wohlbekannte Herakleios/Herakles-Analogie ${ }^{202}$ festzustellen, dass „unser

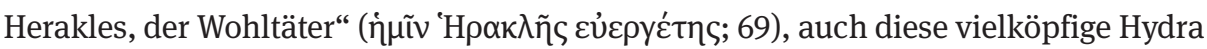
zur Strecke bringe: „Das tatkräftige und weise Feldherrentum wendet sich von den Barbaren hin zu den Schriften, damit derjenige, der die Barbaren überzeugt hat still zu halten, nun ebenso wie diese auch die Häresien vom Stillhalten überzeugt. “203 He-

196 Eingehende Interpretationen des Gedichtes, die auch die theologische Argumentation einschließen, finden sich bei MacCoull 1998 und Larison 2019; außerdem etwas knapper Tartaglia 1998, $22-25$.

197 Cont. Sev. 9-23.

198 Cont. Sev. 24-33.

199 Cont. Sev. 34-55.

200 Cont. Sev. 58-61. Ähnliches Lob auf Herakleios, das wohlbekannte Motive aufgreift, findet sich auch in Cont. Sev. 450-457; hier kommt auch das Epithet kosmorustes (dazu siehe oben S. 239 und Meier 2015, 185f.) erneut zum Einsatz; Herakleios wird außerdem analog zur mythologischen Figur des Orpheus gezeichnet; dazu MacCoull 1998, 75.

201 Diese Bezeichnung geht auf die Situation zurück, als sich die ulta-miaphysitischen Mönche Ägyptens von ihrem ,Oberhaupt', dem alexandrinischen Patriarchen Petros Mongos, lossagten, nachdem dieser Zenons Henotikon unterschrieben hatte; siehe Larison 2019, 175.

202 Dazu siehe oben S. 135 f.; zu dieser Stelle im Speziellen Meier 2015, $174 \mathrm{f}$.

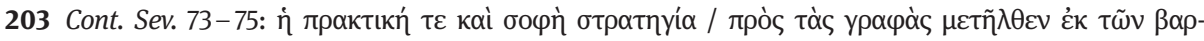

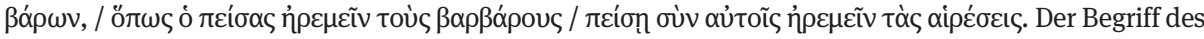
strategos bzw. der strategia in Bezug auf Herakleios ist zentral in Georgs Ouevre; siehe oben S. 194. 
rakleios' strategia, die er zuvor im Krieg gegen die Perser unter Beweis gestellt hat, richtet sich nun also auf die Auslegung der Heiligen Schriften. ${ }^{204}$ Als Basis dieses Unterfangens dient dem Kaiser die Inspiration durch den Heiligen Geist: „das Feuer

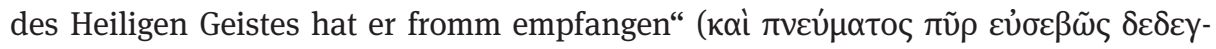

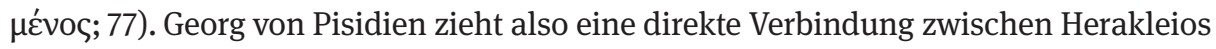
und der göttlichen Sphäre; eine Verbindung, die die theologische Initiative des Kaisers autorisiert: „Mit dieser Erkenntnis der Schriften eröffnet er [i.e. Herakleios] uns die von Gott geschriebenen Tafeln, die er in seinem Herzen trägt, nicht abgeschrieben aus Lehrbüchern, sondern vom göttlichen Finger eingeprägt. “205 In den Versen wird der Heilige Geist zum summachos des Kaisers, zum Kampfgefährten, „erst in Bezug auf die

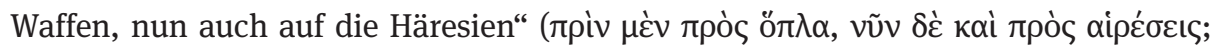
156f.). Das Gedicht schließt mit folgendem Bild: „So rennt Christus überall mit dir [i.e. Herakleios] gemeinsam; und überall zeigt er dich als den Sieger.“206

Liest man das Contra Severum als Sprechakt, der auf die spezifischen Anforderungen und Erwartungen des hauptstädtischen Umfeldes - genauer gesagt: weltlicher und kirchlicher Würdenträger ${ }^{207}$ - reagierte, so zeigt sich, dass religiöser Kompromiss, wie Herakleios ihn praktisch in den Ostprovinzen zu implementieren versuchte, im hauptstädtischen Umfeld nicht positiv konnotiert werden konnte; allein eine Rhetorik der Härte und Intoleranz versprachen offenbar vor einem derartigen Publikum eine kaiserliche Profilschärfung. ${ }^{208}$ Anstelle einer interkonfessionellen Einigung, wie sie der Kaiser in den Ostprovinzen durchzusetzen versuchte, stellt Georg von Pisidien Herakleios' Sieg über die Häresien in Aussicht - ein Sieg, der als logische Konsequenz aus dem bereits errungenen, gottgegebenen Triumph über die Perser resultiert. Die Konfrontation mit den Miaphysiten reduziert er dabei im Wesentlichen auf eine Polemik gegen den längst verstorbenen Bischof Severos als offensichtlichen Strohmann; auf eine differenzierte Bewertung der kirchenpolitischen Konstellation kommt es dem Dichter nicht an. ${ }^{209}$ Weder die Kompromissformel des Monoenergismus noch deren Entwickler, der Patriarch Sergios, werden in den Versen auch nur eines einzigen Wortes gewürdigt; die theologischen Details der interkonfessionellen Gespräche

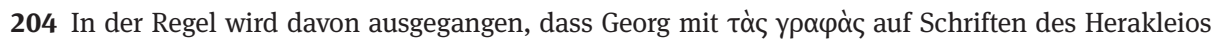
gegen die Miaphysiten anspielt (Tartaglia 1998, 23); mir scheint dagegen eher plausibel, dass er damit die Heilige Schrift oder die Schriften der Kirchenväter meint.

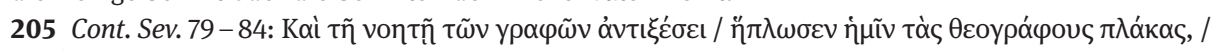

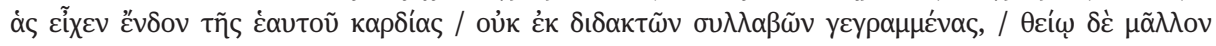

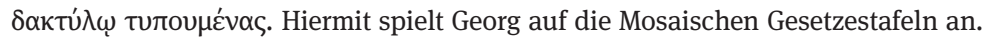

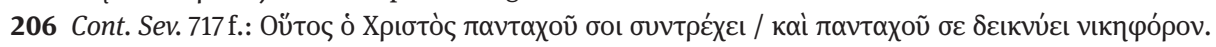
$207 \mathrm{Zu}$ Georgs Publikum siehe oben Kap. 5.1. Ich bezweifle, dass sich das Gedicht an miaphysitische Kreise richtete (davon geht etwa Tartaglia 1998, 23 aus); wie auch die anderen Gedichte Georgs, so richtete sich auch Contra Severum an ein hauptstädtisches Publikum.

208 Ähnliches hat Wienand 2016b, bes. 96 bereits in Bezug auf Konstantin beobachtet, wobei natürlich betont werden muss, dass die Umstände im frühen 4. Jahrhundert noch andere waren.

209 Allein in Cont. Sev. 706-712 könnte man einen Verweis auf Herakleios' Treffen mit Vertretern der miaphysitischen Kirchen vermuten; siehe dazu Kaegi 2000, 229f.; Larison 2019, 165. 
werden vernachlässigt. ${ }^{210}$ Dies ist besonders vor dem Hintergrund bemerkenswert, dass der Kleriker Georg damit seinen direkten Vorgesetzten, den Patriarchen, der in den früheren Gedichten oft als Protagonist glänzte, ausblendet; stattdessen stilisiert er Herakleios als Vorkämpfer und göttlich inspirierten Agenten der chalkedonensischen Orthodoxie. Dem Kaiser gesteht Georg eine direkte Verbindung zur göttlichen Erkenntnis zu; die Rolle der Kirche bzw. deren höchster Vertreter als zwischen himmlischer und irdischer Sphäre vermittelnde Instanz wird rundweg ausgespart. Bedenkt man das Ringen zwischen Kaiser und Kirche um die Deutungshoheit in theologischen und kirchenpolitischen Fragen, das die Verschränkung von römischer Monarchie und christlicher Kirche mit sich brachte, so ist diese Beobachtung bemerkenswert: Während Herakleios praktisch den theologischen Eingaben des Patriarchen Sergios folgte, erhob Georg ihn im Diskurs zur unangefochtenen religiösen Autorität, zum Eiferer für den rechten Glauben. ${ }^{211}$ Das Gedicht versucht, die Kirchenpolitik vor einem hauptstädtischen Publikum als weiteres Feld zu etablieren, auf dem Herakleios sich als - im chalkedonensischen Sinne - orthodoxer und sieghafter Kaiser profilieren kann; das Epithet des nikephoros, das der Dichter dem Kaiser bereits in den Versen auf die Restitutio Crucis antrug, ${ }^{212}$ kommt auch hier wieder zum Einsatz. ${ }^{213}$ Gleichzeitig schimmert im Contra Severum jedoch auch die hortative Qualität von Panegyrik durch: Georg machte mit seinem Gedicht eindrücklich klar, dass religiöser Kompromiss in der Hauptstadt keine akzeptable Option war.

Während Georgs Contra Severum unzweideutig einen Kommentar zu Herakleios' Kirchenpolitik abgibt, ist der Zusammenhang eines weiteren Textzeugnisses zwar nicht zweifelsfrei belegbar, zumindest aber plausibel: genauer gesagt des enkomiastischen Dialoges, der dem Geschichtswerk des Theophylakt Simokattes vorgeschaltet ist. Dieser Dialog wurde bereits in Bezug auf die konsequente Schmähung von Herakleios’ Vorgänger Phokas als Tyrann besprochen. Theophylakt Simokattes weiß vom Tode Chosroes'; das Geschichtswerk wurde also nach 628 vollendet. Den Dialog genauer zu datieren, ist aufgrund des Mangels an eindeutigen Hinweisen schwierig; eine Komposition in den frühen 630er Jahren wäre jedoch durchaus denkbar. ${ }^{214}$ Die bild-

210 Vgl. Tartaglia 1998, 24.

211 Soweit ich dies im Moment überblicken kann, ist die Art und Weise, wie Herakleios hier im Diskurs mit göttlicher Erkenntnis und theologischer Autorität ausgestattet wird, auch im Vergleich zu den vorigen Jahrhunderten bemerkenswert. Ohne diesem Aspekt einer genaueren Untersuchung widmen zu können, scheint mir, dass ähnlich starke Aussagen in Bezug auf Konstantin noch getätigt werden konnten, der als erster christlicher Kaiser über einen recht bereiten Handlungsspielraum verfügte. Seine Nachfolger konnten sich derartige Aussagen (bzw. Zuschreibungen) - angesichts der sukzessiven Festigung von Möglichkeiten und Grenzen kaiserlichen Handelns im kirchenpolitischen Sektor - kaum mehr leisten.

212 Rest. Cruc. 8.

213 Erst Jahre später, als Herakleios mit der Ekthesis einen Kommentar zur Einigungspolitik als kaiserliches Edikt proklamierte, sollte auch die hauptstädtische Öffentlichkeit mit Details der Kirchenpolitik konfrontiert werden; dazu siehe unten.

$214 \mathrm{Zu}$ den Datierungsfragen siehe oben S. 134 Anm. 254. 
hafte und metaphorische Sprache des Dialoges erschwert indes die Interpretation des Textes. Ein Aspekt, hinsichtlich dessen sich die Forschung kaum einig werden kann, ist die Frage, wer sich hinter dem „großen Hohepriester und Vorsitzenden der ge-

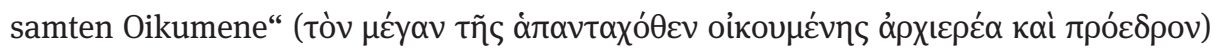
verbirgt, den eine der beiden Gesprächspartnerinnen, die personifizierte Philosophie, als ihren Retter identifiziert: Während ein Lager darin den Patriarchen Sergios erkennt, ${ }^{215}$ hält das andere nur die Identifikation mit Herakleios für plausibel. ${ }^{216}$

Dass ein römischer Kaiser in einer enkomiastischen Überhöhung als „Vorsitzender der gesamten Oikumene“ bezeichnet wird, verwundert kaum; was hingegen manchen Leser irritiert, ist das Epithet archiereus. Konnte der römische Kaiser tatsächlich als Hohepriester adressiert werden? Und mehr noch: Wenige Zeilen später beschreibt die

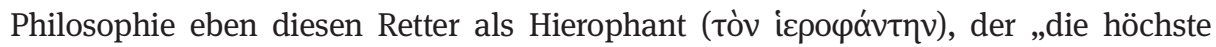

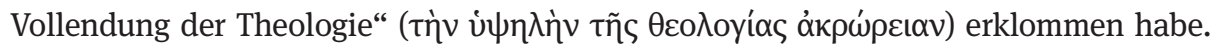
Dass römische Kaiser durchaus als Priester, als hiereus, bzw. als Hierophant angesprochen werden konnten, hat die Forschung bereits wiederholt betont: Diese Zuschreibung findet sich bei Euseb in Bezug auf Konstantin ${ }^{217}$ und in den Konzilsakten von Ephesos und Chalkedon in Bezug auf Theodosios II. bzw. Markian. ${ }^{218}$ Vor dem Hintergrund des Contra Severum, wo Georg von Pisidien Herakleios zum göttlich inspirierten Agenten der Orthodoxie macht, erscheint es nun auch kaum mehr weit hergeholt, den archiereus aus Theophylakts Dialog mit dem Kaiser zu identifizieren.

Um den semantischen Gehalt des Epithets archiereus bei Theophylakt zu verstehen, hilft ein Blick in den weiteren Text der Historien. Der Begriff archiereus kommt in dem Geschichtswerk ein weiteres Mal vor: in einer Predigt, die Theophylakt dem

215 So etwa Van Dieten 1972, 54f.; Schneider 1985, 240 f. Anm. 4; Whitby/Whitby 1986, 4 Anm. 9. Mi. Whitby 1988, 33 Anm. 20 unterscheidet textimmanent zwischen den Herakliden (i. e. Herakleios), die die Philosophie in den Kaiserpalast zurückgebracht hätten, und dem archiereus, der die Geschichte wiederbelebt habe.

216 Zur Identifizierung des archiereus mit Herakleios siehe Hunger 1978, 315; Frendo 1988a, $144 \mathrm{f}$. Anm. 11; Speck 1993, 212 mit Anm. 83; Meier 2015, 168 mit Anm. 8. Dafür, dass mit dem archiereus Herakleios gemeint ist, spricht auch der Umstand, dass die personifizierte Philosophie daraufhin ihre eigene Auferweckung mit der der mythischen Alkestis durch den „Übel abwehrenden Herakles“

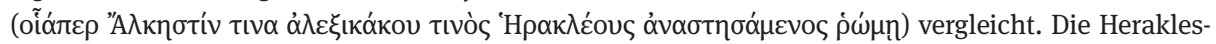
Analogie wurde zu Beginn des Dialoges bereits auf Herakleios bezogen; dass sie damit auf Sergios ausgeweitet würde (so etwa Whitby/Whitby 1986, 4 Anm. 10), halte ich für unwahrscheinlich; allgemein zur Herakles/Herakleios-Analogie, die sich nicht nur bei Theophylakt findet, siehe oben 135, 213, 239.

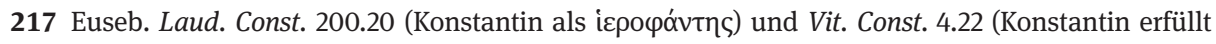

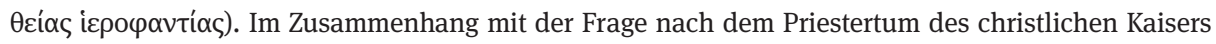

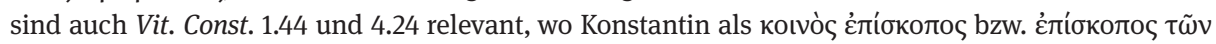
ÉkTós beschrieben wird; dazu Girardet 1980; Dagron 2003, 132-135; Höfert 2015, 139-141.

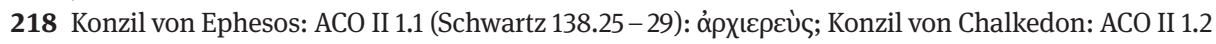
(Schwartz 157.29): ípévç. Höfert 2015, 199f. weist zu Recht darauf hin, dass das Priesterattribut nur eines von sehr vielen Epitheta ist, mit denen der jeweilige fromme Kaiser von den anwesenden Bischöfen gepriesen wird. 
Bischof Dometianos nach der Rückgabe der Stadt Martyropolis an die römischen Truppen im Jahr 590 in den Mund legt. ${ }^{219}$ In der Forschung wurde bereits mehrfach darauf verwiesen, dass der triumphalistische Duktus der Predigt viel eher in den Kontext von Herakleios' Sieg gegen die Perser (d.h. der Abfassungszeit der Historien) passt als in den längst vergangenen Perserkrieg unter Maurikios. ${ }^{20}$ Nachdem Theophylakts Dometianos zu Beginn seiner Rede die Kriegstrompeten des König David evoziert, ruft er dazu auf, Gott als den „obersten Feldherrn im Kriege“ (ả ... $\left.\dot{\varepsilon} v \pi 0 \lambda \varepsilon^{\prime} \mu о \iota \varsigma\right)$ zu preisen - Gott, „dessen Hohepriester in Ewigkeit nach der Ordnung des Melchisedek derjenige, der zur Rechten der Majestät sitzt, sowohl ist als auch genannt wird."221

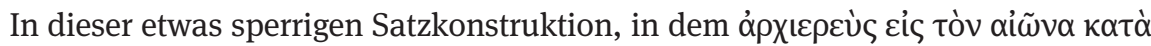

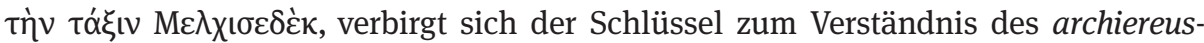
Begriffs. Im Alten Testament erwählt Gott den Melchisedek, den König von Salem, zum Priester, obwohl er nicht dem levitischen Amtspriestertum angehört. ${ }^{222}$ Mit dem oben zitierten Ausdruck greift Theophylakt wortwörtlich auf Stellen aus der Septuaginta und dem Neuen Testament zurück, in denen der Priesterkönig Melchisedek als Referenz angebracht wird. In Psalm 110 wendet Gott sich mit folgenden Worten an den König David: „Du bist der Oberpriester in Ewigkeit nach der Ordnung des Melchise-

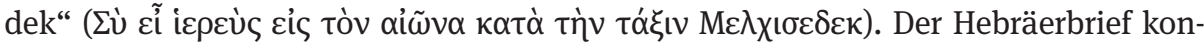
struiert ein Hohepriestertum Christi, das durch die Präfiguration des Melchisedek als unabhängig von der levitischen Linie und allein auf Gott rückführbar ist. „Christus wurde von Gott zum Hohepriester nach der Ordnung des Melchisedek ernannt“

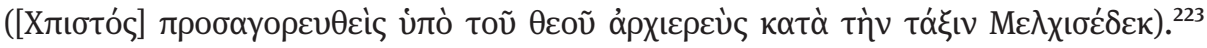
Byzantinische Texte schließlich nutzen die Figur des Melchisedek, um die ambivalente sakrale Position des römischen Kaisers zu beschreiben: Durch den Verweis auf

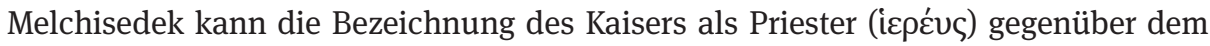
Klerus aufrecht gehalten werden, da dadurch der Kaiser eben nicht als amtlich ge-

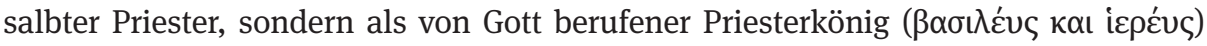
deklariert wird. ${ }^{224}$

$219 \mathrm{Zu}$ den Reden bei Theophylakt siehe Prinzig 1988, bes. 6-13; Efthymiadis 2010, 177-181.

220 Vgl. in diesem Sinne Whitby/Whitby 1986, 127 f. Anm. 65; Frendo 1988a, 152f.; Frendo 2001, 130; Howard-Johnston 2010, 145.

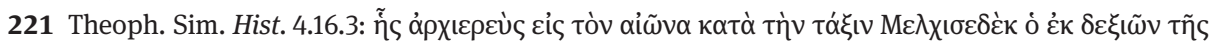

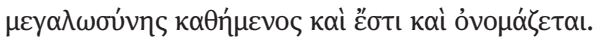

222 Gen $14.18-20$.

223 Auch hier (Hebr 7.1) wird die Doppel-Funktion des Melchisedek als König und Priester betont:

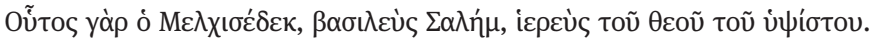

$224 \mathrm{Zu}$ der Figur des Melchisedek in der byzantinischen Kaiseridee vgl. Girardet 1980, bes. 575-579; Dagron 2003, 173-181 und neuerdings Höfert 2015, 141-143. In den ,Prozessakten` der Verhandlungen um Maximos Confessor in Konstantinopel 655 im Rahmen der monotheletischen Kontroverse unter Konstans II. wurde die Stellung des Kaisers anhand der Figur des Melchisedek diskutiert; siehe die Relatio motionis in: Allen 2002, 56 - 58 (= PG 90, 117); vgl. dazu Dagron 2003, 168 - 173 und Höfert 2015, 211-216. Bereits im späten 6. Jahrhundert beschreibt Venantius Fortunatus (Carm. 2.10) den fränki- 
Mit der typologischen Linie von Melchisedek über David und Christus konstruiert Theophylakt also einen archiereus als Priesterkönig, ausgestattet mit weltlicher wie geistlicher Autorität. Eine Identifizierung des archiereus im Dialog mit Herakleios gewinnt damit noch an Plausibilität. Während Herakleios sich in den Ostprovinzen persönlich um eine Kompromissfindung mit den nicht-chalkedonensischen Gemeinden bemühte, wurde in der Hauptstadt - so viel lässt sich aus den beiden hier besprochenen Quellen schließen - das Bild des Monarchen als kompetenter und göttlich sanktionierter Akteur auf dem religiösen Feld propagiert, als Priesterkönig; Herakleios' Repräsentation als frommer und siegreicher Kaiser gewann dadurch eine weitere wirkmächtige Facette.

Zuletzt möchte ich noch einmal auf die Frage nach der Intention der herakleischen Kirchenpolitik zurückkommen. Nachdem bisher vor allem die funktionale Reintegration der Ostprovinzen als Ziel der Einigungspolitik hervorgehoben wurde, sei zuletzt noch erwähnt, dass in der Forschung wiederholt auch die eschatologische Ebene der Annäherung an die nicht-chalkedonensischen Gemeinden ins Spiel gebracht wird: Die angestrebte Einigung aller Christen sei als ein Aspekt von Herakleios' Bemühungen $\mathrm{zu}$ verstehen, seine Herrschaft als messianisches Zeitalter $\mathrm{zu}$ stilisieren. ${ }^{225}$ Als Argument für diese These werden nicht nur die innerchristlichen Schlichtungsversuche angeführt, sondern auch der Umstand, dass Herakleios offenbar darum bemüht war, sowohl die Perser als auch die Juden zum Christentum zu konvertieren. Bereits in Hinblick auf Chosroes II. hatten sich Gerüchte verbreitet, der persische Großkönig habe sich zum Christentum bekannt. ${ }^{226}$ Mit dem Bündnisschluss zwischen Herakleios und dem persischen General Shahrbaraz 629 soll dann - dafür hat vor allem Cyril Mango plädiert - dessen Konvertierung und die seiner Familie einhergegangen sein. ${ }^{227}$ Gegen die Juden zeigte Herakleios dagegen eine härtere Hand: Die Quellen sprechen von repressiven Maßnahmen und Zwangstaufen. ${ }^{228}$ Doch stand dahinter tatsächlich die Idee der endzeitlichen Bekehrung der Völker aus der synoptischen Apokalypse?229 Ohne zu bezweifeln, dass Herakleios' Einigungspolitik sowohl die kompromissorientierte als auch die gewaltsame - in bestimmten Kontexten eschatologisch gedeutet werden konnte, gibt es doch meiner Ansicht nach erneut keine ausreichenden Belege dafür, dass eine derartige Deutung großflächig (vom Kaiser) propagiert wurde. Auch hier ließe sich eine herrschaftspragmatische Intention mutmaßen: Nachdem der jüdischen Bevölkerung Palästinas von den Per-

schen König Childebert als Melchisedech noster merito rex atque sacerdos / conplevit laicus religionis opus.

225 Greisiger 2014, 117-129.

226 Dazu Payne 2015, 164-166; zu der Legende von der Taufe des Chosroes II. siehe Schilling 2008, $235-277$.

227 Mango 1985, 105-117; ders. 1992, 6; siehe auch Greisiger 2013, 364; ders. 2014, 117-121; Payne 2015, 197.

228 Dazu siehe oben S. 273 Anm. 95.

229 Mt 24,14; Mk 13.10; dazu Greisiger 2014, 117. 
sern ein erweiterter Handlungsspielraum zuerkannt worden war und bisweilen gar der Neubau des jüdischen Tempels in greifbare Nähe gerückt war, lag es Herakleios daran, diese Gruppe in ihre Schranken zu weisen und die christliche (Deutungs-)Hoheit über Jerusalem und das Heilige Land zu verdeutlichen. Doch unabhängig davon, was Herakleios mit seinen Maßnahmen im religiösen Bereich intendierte, erwiesen sich seine Bemühungen in den Ostprovinzen schnell als vergebens.

\subsection{Im Angesicht der Niederlage}

\subsubsection{Das Vorrücken der Araber}

Nur wenige Jahre, nachdem es Herakleios gelungen war, die Ostprovinzen von den persischen Besatzern zu befreien und zumindest weitgehend $\mathrm{zu}$ befrieden, sah sich die Levante erneut feindlichen Angriffen ausgesetzt; die Phase, in der der Kaiser seinen Triumph über Persien voll auskosten konnte, währte nur wenige Jahre. Während die hauptstädtische Initiative noch darauf zielte, die Einigung des wieder hergestellten Reiches voranzutreiben, sollten die gerade zurückgewonnenen Regionen im Laufe des nächsten Jahrzehntes schrittweise erneut dem Zugriff Konstantinopels entgleiten. ${ }^{230}$ Die Bedrohung hatte nun ihren Ursprung auf der arabischen Halbinsel; ab dem Ende des Jahres 633 drangen bewaffnete Verbände von Süden her nach Palästina ein. ${ }^{231}$

Begegnungen der Römer mit arabischen Stämmen - sowohl friedlich als auch kriegerisch - waren in der Spätantike keine Seltenheit. ${ }^{232}$ Dass sich mit dem Fortschreiten der 630er Jahre eine Bedrohung von bislang unbekannter Qualität ergeben würde, war aus römischer Sicht zu Beginn des Jahrzehnts kaum absehbar. Während das römische Reich und Persien sich bekriegt hatten, waren die vereinzelten Stämme der arabischen Halbinsel durch das Wirken Mohammeds geeint worden - weitgehend unbeachtet von den beiden Großmächten. Nachdem Abu Bakr, der 632 die Nachfolge des verstorbenen Mohammed angetreten hatte, sich im innerarabischen Bürgerkrieg hatte behaupten können, richtete sich der Fokus nun auf die angrenzenden Gebiete

230 Die arabische Eroberung ist in der Forschung ausgiebig thematisiert. In dieser Arbeit geht es nicht darum, die Details des sukzessiven Vorrückens zu klären bzw. die Diskussionen der Forschungsliteratur nachzuvollziehen; ein grobes Bild ist für meine Zwecke ausreichend. Es sei vor allem auf die ausführlichen Darstellungen bei Stratos 1972, 40 -116; Lilie 1976; Donner 1981; Kaegi 1992 verwiesen; außerdem Kaegi 2003, 229-299; Howard-Johnston 2010, 461-489; Meier 2019a, 1035-1088. Shoemaker 2018 zum eschatologischen Hintergrund der arabischen Eroberungen. Zu der problematischen Quellenlage hinsichtlich der arabischen Eroberung siehe Thomson/Howard-Johnston 1999 II, 233 - 238 und Kaegi 1992, 1-18; die arabischen Quellen werden hier nicht explizit aufgeführt.

231 Laut Theoph. Conf. AM 6123 (De Boor 336) wurden die arabischen Einfälle dadurch ausgelöst, dass die Römer aufgrund akuten Geldmangels die Tribut-Zahlungen an die arabischen Stämme, die die Grenzregionen sicherten, nicht tätigen konnten; ähnlich Nik. Brev. 20.

232 Siehe Kaegi 1992, 52-55 zur römischen Allianz mit den Ghassaniden. 
Roms und Persiens und ihre reiche Infrastruktur. Die ersten Einfälle in römische Provinzen hatten den Charakter von Plünderungszügen mit dem Ziel der Beutegewinnung. ${ }^{233}$ Es zeigte sich allerdings schnell, dass das römische Heer, welches sich von den Strapazen des langwierigen Krieges gegen Persien noch nicht angemessen regeneriert hatte, den Aggressoren kaum standhalten konnte. Nachdem die Truppen des Statthalters von Palästina, Sergios, nahe Gaza im Februar 634 von den zahlenmäßig überlegenen arabischen Einheiten dezimiert worden waren, ${ }^{234}$ schickte Herakleios seinen Bruder Theodor mit rasch zusammengestellten Einheiten, um sich des Problems anzunehmen. Doch auch dieser wurde im Sommer 634 östlich des Jordans geschlagen. ${ }^{235}$ Damit war Palästina von römischer Verteidigung abgeschnitten und sah sich - zwanzig Jahre nach den traumatischen Erfahrungen der persischen Eroberung - schutzlos den feindlichen Plünderungen ausgesetzt. Allein befestigte Städte konnten noch gegen die Araber aushalten. Ein Erdbeben und das Auftauchen eines Kometen, der über mehrere Monate am Himmel sichtbar war, lösten zusätzlich Angst und Schrecken in der Bevölkerung aus. ${ }^{236}$ Im Winter 634 hatte sich die Situation bereits derart verschlechtert, dass die christliche Gemeinde anlässlich der Weihnachtsfeierlichkeiten den Weg zwischen Jerusalem und Bethlehem nicht mehr sicher zurücklegen konnte. ${ }^{237}$ Spätestens vor diesem Hintergrund wurde die Reliquie des Heiligen Kreuzes, die Herakleios im Jahr 630 nach Jerusalem rückerstattet hatte, nach Konstantinopel in Sicherheit gebracht. ${ }^{238}$

233 Lilie 1976, 34-41; zu der Entwicklung auf der arabischen Halbinsel siehe Howard-Johnston 2010, 445-465. Wiederholt wird in der Forschung darauf verwiesen, dass die frühen arabischen Eroberungen keinen religiösen Hintergrund hatten, etwa Stratos 1972, 43f., 119-122; für Howard-Johnston 2010, 470 - 473 ist der religiöse Faktor allerdings mit verantwortlich für den Erfolg der arabischen Expansion. Mischa Meier (2019, 1035-1088; 2020) hat zuletzt dafür argumentiert, das Ausgreifen der Araber sei eine Reaktion auf die allgemeinen Liturgisierungs-Tendenzen gewesen.

234 Theoph. Conf. AM 6121 (De Boor 336); Datum in Chron. 724 in Palmer 1993, 18; außerdem Chron. 1234, 108 (Chabot I, 189) und Mich. Syr. 11.4 (Chabot II, 413).

$235 \mathrm{Zu}$ dieser Schlacht siehe Theoph. Conf. AM 6125 (De Boor 337); Mich. Syr. 11.5 (Chabot II, 418); Chron. 1234, 110 (Chabot I, 190f.); Niederlage des Theodor auch bei Sebeos 42 (Thomson/HowardJohnston I, 96f.); zu dieser frühen Phase der Auseinandersetzungen siehe Kaegi 1992, 88-111; zur Schlacht von Gabitha/Adjnadayn und ihrer Abgrenzung zur späteren Schlacht am Yarmouk siehe auch Stratos 1972, 50-56

236 Ex eventu werden diese Phänomene in den Quellen als Vorzeichen der arabischen Eroberung interpretiert: Theoph. Conf. AM 6124 (De Boor 336); Mich. Syr. 11.4 (Chabot II, 414); Agapius (Vasiliev 454, 469); Chron. Seert (Scher 580); siehe mit weiteren Quellen Stratos 1972, $40 \mathrm{f}$.

237 Hoyland 1997, 70 f.; Booth 2013a, 20 f.

238 Laut Sebeos 41 (Thomson/Howard-Johnston I, 91), 42 (Thomson/Howard-Johnston I, 98) und Theoph. Conf AM 6125 (337) gelangte das Kreuz angesichts der arabischen Eroberung Palästinas nach Konstantinopel; laut Nik. Brev. 18 schickte Herakleios das Kreuz direkt nach seinem Besuch in Jerusalem in die Hauptstadt, wo es von dem Patriarchen Sergios in Blachernae empfangen und in der Hagia Sophia erhöht wurde. Nikephoros merkt an, dass dies in der zweiten Indiktion geschehen sei, die auf die Jahre 628/29 fällt, was der hier vorgeschlagenen Abfolge zuwiderlaufen würde. Zu dieser Problematik siehe Mango 1990, 185 und Zuckerman 2013, 204-206. Speck 2000 und Zuckerman 2013 gehen aufgrund einer alternativen Lesung des Chron. Pasch. davon aus, dass das Kreuz sich bereits im 
Während der letzten Jahre des Krieges zwischen Rom und Persien war Herakleios konstant als Oberbefehlshaber des römischen Heeres an den wichtigsten Kriegsschauplätzen präsent gewesen. Anfang der 630er Jahre hielt der Kaiser sich erneut im Osten des Reiches auf, wo er sich zuvor um die Einigung der christlichen Gemeinden bemüht hatte; doch anstatt die römischen Truppen persönlich anzuführen, delegierte er diese Aufgabe nun an Untergebene und koordinierte die Verteidigungsmaßnahmen von strategisch günstig gelegenen Zentren wie Emesa, Edessa bzw. Antiochia aus. ${ }^{239}$ Nachdem sein Bruder Theodor in Folge der verlorenen Schlacht des Sommers 634 offenbar in Ungnade gefallen war, bestimmte Herakleios einen seiner Schatzmeister, den Sakellarios Theodor, und den Armenier Baanes als Befehlshaber gegen die Araber. ${ }^{240}$ Doch auch dieses Gespann konnte trotz vereinzelter Erfolge das feindliche Vorrücken nicht aufhalten: Ab 635 musst sich Syrien dem Angriff stellen. Während die Araber zuvor nach den Plünderungen noch in die eigenen Gebiete zurückgekehrt waren, setzten sie sich nun auf römischem Territorium fest. Nach mehrmonatiger Blockade ergab sich Damaskus im Herbst 635 den Feinden; gegen die Entrichtung einer Steuer an die arabischen Besatzer wurden die Bewohner in Frieden gelassen. Weitere syrische Städte folgten diesem Beispiel. ${ }^{241}$

Von seinem Standort in Antiochia aus bemühte sich Herakleios, innerhalb kürzester Zeit eine Armee auszuheben, die zumindest zahlenmäßig den Arabern gewachsen war. Dieser heterogenen Truppe gelang es tatsächlich, die Feinde vorübergehend nach Süden zu drängen. Im Sommer 636 schließlich standen die beiden Heere sich östlich des Sees Genezareth gegenüber, in einer Gegend, die von den verzweigten Nebenflüssen des Jordan und tiefen Wadis geprägt ist. Nach vereinzelten Scharmützeln, die sich über Wochen hinzogen, kam es im August zur großen Feldschlacht am Fluss Yarmouk, bei der sich die Araber schnell als überlegen erwiesen. Ob aufgrund

September 629 in Konstantinopel befunden haben muss; ähnlich Klein 2001. Siehe Klein 2004, 34- 43 und ders. 2006, bes. 89-91 zum Fortleben der Kreuzreliquie in Konstantinopel. Teile des Kreuzes wurden bis zur Eroberung Konstantinopels durch die Kreuzfahrer 1204 in der Pharos-Kapelle im kaiserlichen Palast aufbewahrt.

239 Siehe Kaegi 2003, 23f.; für Emesa anstatt Edessa siehe Stratos 1972, 56.

240 Theoph. Conf. AM 6125 (De Boor 337); Chron. 1234, 110 (Chabot I, 191); laut Nik. Brev. 20 hatte Theodor die Ehe des Herakleios mit seiner Nichte Martina kritisiert und wurde deswegen unehrenhaft entlassen und in Konstantinopel festgesetzt; laut Mich. Syr. 11.6 (Chabot II, 420 f.) fungierte auch ein Sohn des Shahrbaraz als Befehlshaber für die Römer, der allerdings nach der Schlacht am Yarmouk versuchte, zu den Arabern überzulaufen; zum römischen Befehlshaber siehe Stratos 1972, 209. Manche Quellen erwähnen Theodor als Eunuch, siehe PLRE IIIB, Theodorus 164 qui et Trithyrius (1279f.); vgl. auch PLRE IIIA, Baanes (161).

241 Theoph. Conf. AM 6126 (De Boor 338); Chron. 1234, 111 (Chabot I, 191f.), 114f. (Chabot I, 194f.) und Mich. Syr. 11.6 (Chabot II, 421): Bei den syrischen Chronisten erfolgt die Einnahme der syrischen Städte nach der Schlacht am Yarmouk. Das erklärt sich dadurch, dass die arabischen Besatzer Teile Syriens zeitweise geräumt hatten und diese nach dem August 636 wieder einnahmen; siehe die Diskussion bei Stratos 1972, 59-62, 208f. Ob und inwiefern der fehlende Verteidigungswille einer Bevölkerung, die Konstantinopel bisweilen kritisch gegenüberstand, zu der raschen Invasion der Araber beigetragen hat, ist eine viel diskutierte Frage; siehe Stratos 1972, 66, 127-133 und Moorhead 1981. 
von schwierigen Wetterbedingungen, von Uneinigkeit innerhalb des römischen Heeres, der Desertation der ghassanidischen Föderaten oder schlichtweg aufgrund von militärischer Schwäche - das römische Heer erlitt eine vernichtende Niederlage. Nach der Schlacht am Yarmouk war die römische Verteidigung quasi handlungsunfähig. ${ }^{242}$ Herakleios verließ Antiochia und kehrte umgehend nach Konstantinopel zurück. ${ }^{243}$ Syrien, Palästina und Mesopotamien waren de facto verloren und wurden in den folgenden zwei Jahren sukzessive von den Arabern besetzt. ${ }^{244}$ Und diese waren gekommen, um zu bleiben; mit Umar, dem Nachfolger des 634 verstorbenen Abu Bakr, begab sich erstmals persönlich ein Kalif in die besetzten Gebiete. Nachdem Jerusalem sich 638 ergeben hatte, zog erneut ein Herrscher voller Ehrfurcht vor dem genius loci in die Heilige Stadt ein: Vom Ölberg kommend wurde Umar vom Patriarchen Sophronios in Empfang genommen. ${ }^{245}$

Nach der Sicherung Palästinas und Syriens wandten sich die Araber ab 639 auch nach Ägypten. Angesichts der unzureichenden Verteidigungslage schlug der Patriarch Kyros, ausgestattet mit umfassenden Vollmachten, gegenüber den Aggressoren den Weg der Diplomatie ein: Gegen jährliche Goldzahlungen sollte Ägypten von Plünderungen verschont bleiben. Kyros' Initiative stieß in Konstantinopel allerdings nicht auf Unterstützung. Im Gegenteil, Herakleios bezichtigte seinen einstmaligen Verbündeten des Hochverrats, zog ihn aus Alexandria ab und setzte stattdessen auf bewaffnete Konfrontation. ${ }^{246}$ Doch schnell zeigte sich, dass Kyros mit seinem Gespür richtig gelegen hatte. Trotz militärischer Verstärkung konnten die römischen Truppen Ägypten nicht halten; die vorwiegend miaphysitische Bevölkerung Ägyptens unter der Führung des exilierten Patriarchen Benjamin wiederum sah das Anrücken der Araber als Möglichkeit, sich von der Dominanz der Chalkedonenser zu befreien. ${ }^{247}$ In den folgenden drei Jahren sollte auch diese Provinz dem oströmischen Reich endgültig verloren gehen. ${ }^{248}$ Neben den römischen Süd-Ostprovinzen wurde auch Persien, das in-

242 Theoph. Conf. AM 6126 (De Boor 337f.) auch zur Revolte armenischer Kontingente, die den Baanes gar zum Kaiser ausriefen; Chron. 1234, 116 (Chabot I, 195f.) und Mich. Syr. 11.6 (Chabot II, 420 f.); siehe dazu Stratos 1972, 68-73; Donner 1981, 91-155; Kaegi 1992, 112-146 (auch zu der Frage nach dem zahlenmäßigen Umfang der Heere und der Verluste) und ders. 2003, 239-244.

243 Chron. 1234, 117 (Chabot I, 196f.) und Mich. Syr. 11.7; die syrischen Quellen zu Herakleios' Rückkehr sind auch in Hoyland 2011, 106-108 zusammengefasst. Vgl. Theoph. Conf. AM 6125 (De Boor 337), der die Rückkehr des Herakleios allerdings vor die Schlacht am Yarmouk ansetzt; siehe dazu Stratos 1972, 73 f.; Donner 1981, 145.

244 Stratos 1972, 74-86; Kaegi 1992, 147-180.

245 Zu Umar in Jerusalem siehe Theoph. Conf. AM 6127 (De Boor 339); Chron. 1234, 120 (Chabot I, 199f.) und Mich. Syr. 11.7 (Chabot II, 425f.); siehe Stratos 1972, 81f., 221 mit weiteren Quellen.

246 Theoph. Conf. AM 6126 (De Boor 338f.), Nik. Brev. 23; Chron. 1234, 118 (Chabot I, 197 f.) und Mich. Syr. 11.7 (Chabot II, 425); vgl. zu der Initiative des Kyros (auch aus Perspektive der arabischen Quellen) Kaegi 2003, 285-287 und Booth 2016.

247 So etwa Chron. 1234, 118 (Chabot I, 197f.).

248 Siehe Stratos 1972, 94-116 und zuletzt Booth 2013b, der dafür argumentiert, dass der arabische Vorstoß nicht nur über die Delta-Region erfolgte, sondern simultan auch von Mittelägypten her. Booth 
nenpolitisch seit der Ermordung Chosroes' II. nicht mehr zur Ruhe gekommen war, Opfer der arabischen Expansion. Während das oströmische Reich jedoch die Gebietsverluste verkraften und als politische Entität auf reduziertem Territorium fortbestehen konnte, versetzten die Niederlagen gegen die Araber dem sassanidischen Reich den Todesstoß; mit Yazdegerd III., einem Enkel des Chosroes II., starb 651 der letzte persische Großkönig. ${ }^{249}$

\subsubsection{Rückkehr nach Konstantinopel II}

Nachdem das römische Heer am Yarmouk vernichtend geschlagen worden war, kehrte Herakleios umgehend nach Konstantinopel zurück. Acht Jahre, nachdem er mit dem Triumph über die Perser im Rücken in die Stadt eingezogen war, waren die Voraussetzungen nun gänzlich andere. Dieses Unterkapitel befasst sich mit der Frage, wie der Kaiser mit militärischer Niederlage umging und welche direkten Auswirkungen das Debakel am Yarmouk auf seine Herrschaft zeitigte. Der Blick in die Forschungsliteratur offenbart eine recht einseitige Bewertung von Herakleios' späten Regierungsjahren: Führende Publikationen zeichnen - in Kontrast zum glorreichen Persersieger - ein Bild des Kaisers als gebrochener Mann, ein Bild von physischem und psychischem Niedergang, der spätestens dann einsetzte, als Herakleios' Restitutionswerk vor seinen Augen durch die Araber zunichte gemacht wurde. ${ }^{250}$ Dieser Stilisierung, die größtenteils auf der unkritischen Wiedergabe von tendenziösen Quellen basiert, soll im Folgenden eine alternative Bewertung entgegengehalten werden.

Die einzige Quelle, die Herakleios’ Rückkehr nach Konstantinopel in Folge der Schlacht am Yarmouk im Detail dokumentiert, ist das Breviarium des Nikephoros, verfasst um die Wende vom 8. zum 9. Jahrhundert. ${ }^{251}$ Der Text ist derart dicht an Informationen, dass sich eine vollständige Wiedergabe anbietet.

Zu dieser Zeit brach Herakleios nach Hause auf und richtete sich in dem Hiereia genannten Palast ein. Denn er hatte Angst davor, das Meer zu überqueren; und obwohl die Amtsträger und die Bürger der Stadt von ihm erwarteten, in die Stadt einzuziehen, überzeugten sie ihn nicht. Während der Festtage schicke er allein seine Söhne, und diese kehrten schnell wieder zu ihm zurück, nachdem sie in der Kirche die heilige Liturgie gefeiert hatten. Und wann immer sie den Pferderennen beiwohnten, kehrten sie ebenso zurück zu ihrem Vater. Aber während er dort weilte, wurde ihm verkündet, dass sein Sohn Atalarichos und Theodor - vom Rang eines Magisters, der Sohn des Theodor, des Bruders des Kaisers - mit einigen anderen dabei waren, sich gegen ihn zu verschwören. Überzeugt von den Informanten schnitt er deren Nasen und Hände ab; den Atalarichos verbannte er auf die Insel Prinkipos, den Theodor auf die Insel Gaudomelete, und befahl dem dortigen Kommandeur, diesem, wenn er bei ihm ankäme, einen der Füße zu entfernen. Und

diskutiert auch im Detail den zeitgenössischen Bericht des Johannes von Nikiu, der allerdings erst 639 wieder einsetzt (ab Joh. Nik. 111).

249 Zum Schicksal des sassanidischen Reiches siehe Bonner 2019, 318-340.

250 Siehe zum Beispiel Stratos 1972, 135f.; Treadgold 1997, 303-305 besonders Kaegi 2003, 265-299. $251 \mathrm{Zu}$ Nikephoros siehe oben Anm. $23 \mathrm{f}$. 
entsprechend rächte er sich auch an denjenigen, die gemeinsam mit diesen von dem Plan gewusst hatten.

Nachdem ausreichend Zeit vergangen war, brachten die Amtsträger des Kaisers den Eparchen dazu, viele Schiffe zusammenzubringen und diese aneinander zu befestigen, um die Stenon genannte Wasserstraße zu überbrücken, und beidseitig mit Zweigen von Bäumen und Laub eine Absperrung zu errichten, damit [der Kaiser], wenn er dort anwesend wäre, nicht das Meer sähe. Das Werk schritt schnell voran und der Kaiser überquerte als Reiter das Meer wie festes Land zu der Küste der sogenannten Bucht von Phidaleia; dort ließ er den Küstenstreifen auf der Seite und zog über die Brücke des Flusses Barbyssos nach Byzantion ein. Danach krönte er den Caesar Herakleios zum Kaiser. ${ }^{252}$

Nikephoros’ Bericht besteht, grob gesagt, aus zwei Elementen: erstens Herakleios' Niederlassung im kleinasiatischen Hiereia und seine Rückkehr nach Konstantinopel über eine Schiffsbrücke, die errichtet wurde, um dem Kaiser den Anblick des Wassers zu ersparen; zweitens die missglückte Verschwörung gegen ihn durch seinen unehelichen Sohn und seinen Neffen. Die Forschung tendiert dazu, beide Elemente inklusive der von Nikephoros vorgebrachten Bewertungen als faktisch zu übernehmen, was sich vor allem in Hinblick auf die Episode zur Schiffsbrücke als fatal erweist. Mit Verweis auf Nikephoros' Bericht hat sich in der Forschung gar der Allgemeinplatz verfestigt, Herakleios habe unter Hydrophobie, der Angst vor Wasser/Gewässern, gelitten: Sowohl sein Verweilen in Hiereia, auf der asiatischen Seite des Bosporus, als auch der Bau der Schiffsbrücke sei vor diesem Hintergrund zu verstehen. ${ }^{253}$ Kritische

252 Nik. Brev. 24f.: Toút

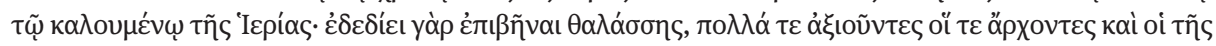

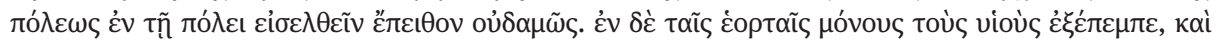

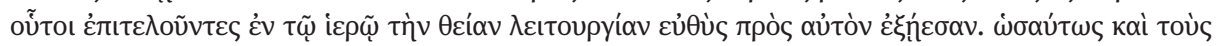

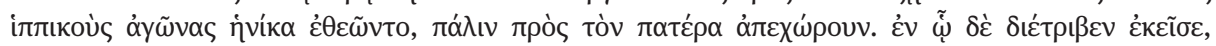

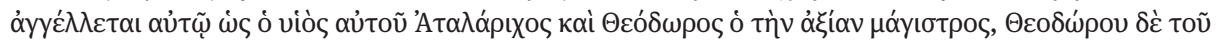

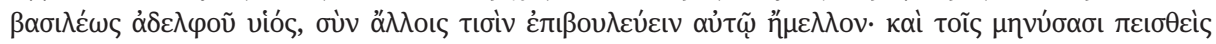

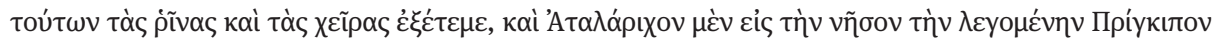

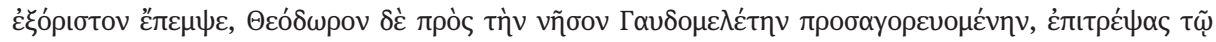

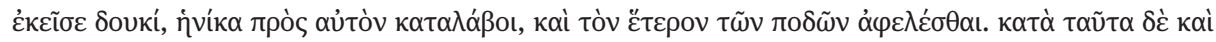

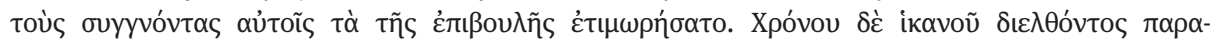

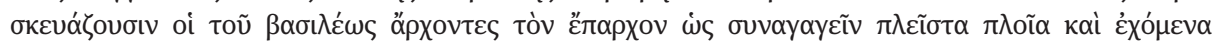

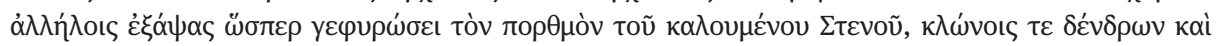

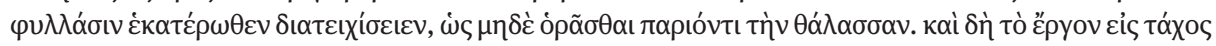

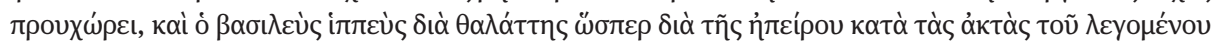

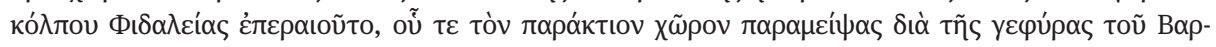

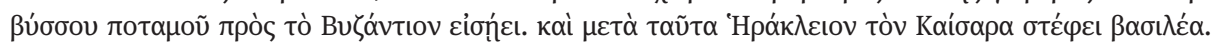
253 Siehe zum Beispiel Stratos 1972, 139; Treadgold 1997, 305: „Heraclius finally returned to his capital in 638, over a bridge of boats designed to allay his hydrophobia.“ Baynes 1952, 381: „[Heraclius] suffered so acutely from hydrophobia that he could return to Europe only over a bridge of boats closely shaded by boughs of trees so that the emperor might have no sight of water." Siehe auch Haldon 1990, 51 und Ma. Whitby 1998, 263; Mango 1990, 189 übergeht die Episode in seinem Kommentar zu Nikephoros schlichtweg. Es bleibt zu betonen, dass der Begriff hydrophobia weder in Nikephoros noch in

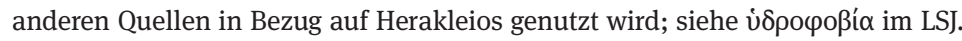


Stimmen dagegen gehen bisweilen so weit, die Episode zur Schiffsbrücke als Ganzes als Legende $\mathrm{zu}$ disqualifizieren. ${ }^{254} \mathrm{Um}$ den Gehalt von Nikephoros' Bericht angemessen zu erfassen, sollte indes ein Mittelweg eingeschlagen werden. Meiner Ansicht nach enthält die Episode einen authentischen Kern: Eine Schiffsbrücke, auf der Herakleios den Bosporus überqueren konnte, wurde tatsächlich gebaut; sie diente indes nicht dem Zweck, die vermeintliche Hydrophobie des Kaisers zu besänftigen, wie das Breviarium uns glauben machen will, sondern ist als triumphales Statement zu lesen.

$\mathrm{Zu}$ Beginn dieses Kapitels wurde bereits bemerkt, dass die Reintegration des Kaisers in die Hauptstadt nach längerer Abwesenheit prinzipiell mit spezifischen Anund Herausforderungen einherging und daher ein potentiell kritisches Moment darstellte. Im Jahr 636 hatte Herakleios allerdings - anders als ein knappes Jahrzehnt zuvor - keinen prestigereichen Sieg im Rücken, der seine Rückkehr nach Konstantinopel positiv konnotierte. Die Imago des glorreichen strategos, des kosmischen Siegers und Weltenerneuerers, die Georg von Pisidien nach 628 eindrucksvoll propagiert hatte, ${ }^{255}$ konnte den gewandelten Umständen kaum angepasst werden. Herakleios stand vor einem Dilemma: Einerseits musste die Stimmung in Konstantinopel nach dem Bekanntwerden der Niederlage unter Kontrolle gehalten werden - daher wohl seine rasche Rückkehr -, andererseits war er der praktischen und diskursiven Möglichkeiten beraubt, seinen Einzug in die Stadt gewinnbringend zu strukturieren. Anstatt Konstantinopel zu betreten und sich der direkten Konfrontation mit der hauptstädtischen Bevölkerung auszusetzen, saß Herakleios nun im kaiserlichen Palast von Hiereia fest. ${ }^{256}$ Das Verweilen in Hiereia erscheint in der Tat erratisch - vor allem vor dem Hintergrund eines wachsenden Unwillens gegenüber dem Kaiser. Doch lässt sich zumindest festhalten, dass Herakleios' Entscheidung kaum in einer vermeintlichen Angst vorm Wasser begründet lag, sondern eher in dem Umstand, dass die angespannte Gesamtsituation seine Handlungsmöglichkeiten massiv einschränkte. Dass Herakleios seine Söhne für öffentliche Auftritte bei religiösen Festen und Hippodromspielen an seiner Stelle in die Stadt schickte, war ein Notlösung, die von der

254 Kaegi 2003, 287f. (Zitat S. 288) kommentiert: „[Nicephorus'] unique story may be simply that: a story. [...] it may be an exaggerated elaboration of Heraclius' decision to remain in isolation during the crisis of the Muslim invasion [...]." Speck 1988, 406f. geht noch weiter und hält sowohl Herakleios' angebliche Hydrophobie als auch den Bau einer Schiffsbrücke für reine Legenden.

255 Dazu siehe oben S. 236-238.

256 Hiereia fungierte offenbar als Schwelle zwischen Provinz und Hauptstadt: 628 hatte die Bevölkerung Herakleios dort empfangen; 636 saß der Kaiser an eben diesem Ort fest; siehe McCormick 1986, $71 \mathrm{Anm} .130$ zu Hiereia als Treffpunkt. An einen Ort außerhalb der Stadt (eventuell auch Hiereia) hatte sich Herakleios gemäß Georg von Pisidien (Heracl. 2.108-121) bereits Anfang der 620er-Jahre zeitweise zurückgezogen, um sich auf den Feldzug gegen die Perser vorzubereiten; genauer gesagt, um Militärhandbücher zu studieren. Dass Georg darum bemüht ist, die Gründe für Herakleios' Verweilen außerhalb der Stadt zu betonen - nicht zum Vergnügen, sondern um sich in Ruhe den Staatsangelegenheiten widmen zu können - weist darauf hin, dass auch damals das hauptstädtische Umfeld das kaiserliche Verweilen auf der asiatischen Seite nicht gern sah; dies geht auch aus den darauffolgenden Versen (Heracl. 2. 122-132) deutlich hervor. 
hauptstädtischen Bevölkerung offenbar auch derart empfunden wurde. Konstantinopel forderte die Präsenz des Kaisers; das dauerhafte Ausharren in Hiereia war keine Option.

Tatsächlich dauerte es nicht lang, bis sich die Anspannung entlud: Eine Verschwörung, die Herakleios' Sturz zum Ziel hatte, wurde aufgedeckt, die Verschwörer hart bestraft. Nachdem Herakleios über beinahe drei Jahrzehnte weitgehend unangefochten geherrscht hatte, wurde er nun erstmals ernsthaft im hauptstädtischen Umfeld herausgefordert; dass dies in einem Moment kaiserlicher Schwäche geschah, als Herakleios' Akzeptanz in der Hauptstadt offenbar zu bröckeln begann, ist kaum verwunderlich. Die Maßnahmen, mit denen der Kaiser seine Herrschaft hatte stabilisieren können, allen voran die Betonung religiös konnotierter Sieghaftigkeit, verloren nach der katastrophalen Niederlage in Syrien an Wirkmächtigkeit. Abgesehen von dem Umstand, dass sich hiermit eine Usurpation im Zentrum der Macht, in Konstantinopel, zusammenbraute, ist auch die Identität der Herausforderer bemerkenswert: Die Verschwörung gruppierte sich um Herakleios' unehelichen Sohn Atalari$\operatorname{chos}^{257}$ und seinen Neffen Theodor; ${ }^{258}$ laut Sebeos hatten sich die beiden Männer mit einer Reihe armenischer Magnaten verbündet, die in Konstantinopel residierten. ${ }^{259}$

Obwohl die Details des Usurpationsversuches und seiner Aufdeckung im Dunkeln bleiben, treten die Mechanismen doch deutlich zu Tage: Eine Reihe einflussreicher Akteure formierte sich um Individuen mit dynastischem Prestige, um in das Machtvakuum in Konstantinopel, bedingt durch Herakleios' Verweilen in Hiereia, vorzustoßen und einen Regimewechsel einzuleiten. ${ }^{260}$ Seit dem Beginn seiner Regierung hatte Herakleios konsequent Mitglieder seiner Familie in hohe Ämter befördert, um sich gegen potentielle Herausforderer abzusichern; nun kam die Herausforderung aus den eigenen Reihen. Die Nachfolgeordnung, die Herakleios mit der Krönung seine Sohnes Herakleios Konstantin im Jahr 613 festgelegt hatte und seitdem öffentlich propagierte, stand erstmals zur Debatte. Ein besonders ernstzunehmendes Risiko scheint dabei Herakleios' Neffe Theodor dargestellt zu haben, der gleichnamige Sohn von Herakleios' Bruder Theodor, mit dem der Kaiser sich kurz zuvor angesichts der

257 PLRE IIIA, Ioannes qui et Atalarichus 260 (260). Atalarichos taucht erstmals in Nik. Brev. 17 auf, wo er im Jahr 622 als eine von mehreren Geiseln zu den Avaren geschickt wird; mehr Informationen finden sich zu ihm allerdings nicht. Der Name lässt auf einen nordafrikanischen Hintergrund schließen.

258 PLRE IIIB, Theodorus 171 (1284); Theodor war der Sohn des Theodor, Herakleios' Bruder.

259 Sebeos 41 (Thomson/Howard-Johnston I, 92-94) mit Kommentar in Thomson/Howard-Johnston 1999 II, $228-230$.

260 Dass Usurpationen sich um Verwandte eines regierenden oder bereits verstorbenen Kaisers gruppierten, ist im oströmischen Reich ein häufiges Phänomen; siehe zum Beispiel die Erhebung des Hypatios, Anastasios' Neffen, während des Nika-Aufstandes gegen Justinian 532; dazu Meier $2014 \mathrm{a}$. Auch die Nachfolger Justinians mussten sich gegen potentielle Herausforderer aus der Familie des Justin/Justinian erwehren; besonders die Familie des Germanos, ebenso wie Justinian ein Neffe des Justin I., stellte ein Risiko dar; dazu siehe oben S. 57 f., 59 f. 
katastrophalen Entwicklungen in Syrien überworfen hatte; ${ }^{261}$ der Neffe wurde nach dem Aufdecken der Verschwörung am härtesten bestraft. ${ }^{262}$ Während die Karriere des Atalarichos obskur bleibt, bekleidete Theodor laut Nikephoros das Amt des magistros - aller Wahrscheinlichkeit nach Magister militum. Er genoss damit also nicht nur dynastisches Prestige, sondern zählte auch zu den hohen militärischen Funktionsträgern - zu der Gruppe also, die den größten Druck auf den Kaiser ausüben konnte. ${ }^{263}$

Die Verschwörung wurde aufgedeckt, bevor konkrete Schritte hatten unternommen werden können; doch der vereitelte Usurpationsversuch hatte deutlich gemacht, dass es für Herakleios keine Option war, in Hiereia auszuharren und die Hauptstadt weitestgehend sich selbst zu überlassen. Nachdem seine Autorität herausgefordert worden war, musste der Kaiser ein deutliches Zeichen setzen. Was Nikephoros als eine Maßnahme der hauptstädtischen Funktionsträger beschreibt, Herakleios’ Angst vorm Wasser zu begegnen, offenbart in diesem Zusammenhang seine eigentliche Funktion: Die Schiffsbrücke über den Bosporus war von Herakleios als ein triumphales Statement intendiert, mit dem der Kaiser auf die nachlassende Akzeptanz in Konstantinopel reagierte; gerade im Moment außen- wie innenpolitischer Instabilität bedurfte es einer Inszenierung von größtmöglicher Öffentlichkeitswirkung.

Diese These wird unterstützt, wenn man den Blick weitet und auf den römischen Umgang mit militärischen Niederlagen im Allgemeinen lenkt. Für römische Kaiser stellten Niederlagen auf dem Schlachtfeld besonders prekäre Momente dar; das Sesshaftwerden der Kaiser ab dem späten 4. Jahrhundert hat Felix K. Maier überzeugend damit erklärt, dass die Monarchen sich den negativen Folgen militärischer Misserfolge zu entziehen suchten, welche sich in der Spätantike bekanntlich häuften. ${ }^{264}$ Dass militärische Niederlagen eine bedachte Reaktion von kaiserlicher Seite aus erforderten, zeigen die Jahren nach der verheerenden Schlacht von Adrianopel 378, bei der das römische Heer den auf Reichsboden siedelnden Goten unterlag. Nachdem der Kaiser Valens auf dem Schlachtfeld ums Leben gekommen war, bemühte sich sein Neffe Gratian, nun zum Senior Augustus aufgestiegen, um Schadensbegrenzung, indem er den erfahrenen Feldherren Theodosios zum Augustus erhob. ${ }^{265}$ Wie von Noel Lenski betont, zeichneten sich die darauffolgenden Jahre durch eine außerordentlich hohe Zahl an Siegesfeierlichkeiten aus, durchgeführt von Gratian und Theodosios, obwohl keine entscheidenden militärischen Siege hatten errungen werden können. Lenski schließt: „The emperors felt the need to glorify publicly their military achievements in order to counteract the ill effects of the Adrianople catas-

261 Nik. Brev. 20; Theodor hatte seinem Bruder Herakleios über Jahrzehnte als Befehlshaber zur Seite gestanden.

262 Er wurde verstümmelt und auf die Insel Gaudomelte nahe Malta verbannt; siehe Nik. Brev. 24. mit dem Kommentar bei Mango 1990, 190.

263 Dazu siehe oben S. 60 - 62.

264 Maier 2019, zusammenfassend 451-462; siehe dazu oben S. $31 \mathrm{f}$.

265 Zur Schlacht von Adrianopel siehe Lenski 1997. 
trophe.“266 Diese Beobachtung lässt sich direkt auf die Zeit nach der Schlacht am Yarmouk übertragen. Die Analyse von Herakleios' Rückkehr 628 hat gezeigt, dass triumphale Inszenierungen weiterhin einen zentralen Aspekt kaiserlicher Präsenz in Konstantinopel konstituierten; obwohl es nach der Niederlage in Syrien nichts zu feiern gab, bot der Kaiser der hauptstädtischen Öffentlichkeit ein knappes Jahrzehnt später mit der Schiffbrücke über den Bosporus ein triumphales Spektakel.

Ein Exkurs in die noch entferntere Vergangenheit kann die Deutung von Herakleios' Initiative weiter schärfen, war er doch nicht der erste römische Kaiser, der sich durch den Bau einer Schiffsbrücke hervortat. Ausgerechnet der als Tyrann verfemte Caligula (37-41 n. Chr.) ließ im Jahr 40 eine Schiffsbrücke im Golf von Neapel bauen, genauer gesagt zwischen Puteoli und Baiae, die der Kaiser zu Pferd mit einem ganzen Tross bewaffneter Reiter und Fußtruppen überquerte. Diese Inszenierung, die in vielerlei Hinsicht mit Versatzstücken eines traditionellen Triumphzuges spielte, löste Bewunderung ebenso wie Kritik aus, wie aus den Berichten von Sueton und Cassis Dio hervorgeht. ${ }^{267}$ Die Analogie gewinnt noch an Brisanz, wenn man bedenkt, dass Caligula zuvor bei einem Germanen- und Britannienfeldzug nicht die gewünschten Erfolge hatte erzielen können. Das Spektakel im Golf von Neapel ist nicht zuletzt vor dem Hintergrund des äußerst angespannten Verhältnisses zwischen dem Kaiser und dem römischen Senat zu verstehen. ${ }^{268}$ Als weiterer Verweis können die Schiffsbrücken angeführt werden, die der persische Großkönig Xerxes erbauen ließ, um seiner Armee 480 v. Chr. das Überqueren des Hellesponts zu ermöglichen. ${ }^{269}$ Dass Xerxes' Brücken auch im hauptstädtischen Umfeld des frühen 7. Jahrhunderts bekannt waren, zeigt eine Passage aus Georg von Pisidiens Expeditio Persica. ${ }^{270}$ Ich möchte an dieser Stelle nicht dafür plädieren, dass Herakleios sich mit seiner Schiffsbrücke direkt auf diejenige des Caligula oder des Xerxes bezog, zumal ein Vergleich mit dem Großkönig des Erzrivalen Persien nur dann eine positive Wirkung hätte entfalten können, wenn die Überlegenheit der herakleischen Konstruktion hätte herausgestellt werden können. ${ }^{271}$ Die angeführten Parallelen dienen an dieser Stelle schlichtweg als weiteres Indiz dafür, dass es sich bei einer derart aufwendigen und eindrucksvollen Konstruktion auch unter Herakleios um nichts anderes als um ein triumphales Statement gehandelt haben kann.

266 Lenski 1997, 140 -141 (Zitat 140) mit Verweis auf McCormick 1986, 41-46; Lenski (ebd. 138-140) zeigt außerdem, dass sich die Panegyriken auf die Kaiser, die im Nachklang der Niederlage von Adrianopel verfasst wurden, durch einen dezidiert optimistischen Ton auszeichnen.

267 Suet. Cal. 19.1-3; Cass. Dio 59.19.3; dazu siehe Stein-Hölkeskamp 2015, 127-133, die die verschiedenen Elemente der Inszenierung aufschlüsselt.

268 Stein-Hölkeskamp 2015, 130 - 132.

269 Herod. 7.34 ff.; ebd. 4.83-88 zu einer Schiffsbrücke des Dareios I.

270 Georg. Pis. Exped. Pers. 2.304-326; das Gedicht wurde 622/623 komponiert, hat also nichts mit Herakleios' Rückkehr zu tun; zum Zeitpunkt von Herakleios' Rückkehr nach Konstantinopel in Folge der Schlacht am Yarmouk war Georg von Pisidien offenbar nicht mehr aktiv.

271 Sueton (Cal. 19.3) etwa betont, dass die Schiffsbrücke im Golf von Neapel länger als die des Xerxes gewesen sei. 
Trotz seiner irreführenden Bewertung bietet Nikephoros’ Bericht wertvolle Informationen zur Rekonstruktion der Schiffsbrücke über den Bosporus. Der westliche Brückenkopf saß an der Küste von Phidaleia, also der Gegend von Pera/Galata, nördlich der Mündung des Goldenen Horns in den Bosporus; das östliche Gegenstück ist wohl in Chrysopolis zu lokalisieren, womit die Brücke die Wasserstraße an einem engen Punkt überspannte. ${ }^{272}$ Bedenkt man die Topographie Konstantinopels, war die Schiffsbrücke sowohl von der aufsteigenden Küstenlinie der Stadt aus als auch von Pera weithin sichtbar, sodass die Bevölkerung Augenzeuge davon werden konnte, wie Herakleios den Bosporus zu Pferd überquerte. Was Nikephoros als beidseitige Absperrung aus Zweigen und Laub beschreibt, die dem Kaiser den Anblick des Meeres ersparen sollte, enthüllt seine eigentliche Funktion beim Blick auf Herodots Bericht: In Hist. 7.36 heißt es, dass an beiden Seiten von Xerxes' Brücke Schranken angebracht wurden, sodass die Pferde nicht angesichts des Wassers in Panik gerieten. In Herakleios' Fall könnte die Absperrung darüber hinaus auch zum Schmuck der spektakulären Konstruktion gedient haben. Nachdem er den Bosporus überquert hatte, bewegte Herakleios sich in nordwestliche Richtung fort, um dann - so Nikephoros die Brücke über den Barbysses, den Fluss, der das Goldene Horn speist, zu überqueren. Sich Konstantinopel von Norden nähernd, erreichte der Kaiser die Stadtmauern aller Wahrscheinlichkeit nach auf der Höhe der Blachernenkirche, des zentralen Kultortes der Theotokos, die zuletzt zur wichtigsten Schutz- und Identifikationsfigur Konstantinopels aufgestiegen war. ${ }^{273}$ Obwohl Nikephoros hier keine weiteren Spezifika bietet, ist es durchaus vorstellbar, dass Herakleios der Kirche einen Besuch abstattete, damit seine Nähe zur Theotokos betonte und seinem triumphalen Einzug einen religiösen Anstrich verlieh. Wie sich die Inszenierung weiter innerhalb der Stadtmauern entfaltete, bleibt indes im Dunkeln.

Auf den triumphalen Einzug des nicht-siegreichen Kaisers folgte eine Phase erhöhter Aktivität. Nachdem Herakleios seinen erstgeborenen Sohn Herakleios Konstantin bereits 613 gekrönt hatte, erhob er nun - wie Nikephoros knapp vermerkt einen zweiten Sohn in den Rang des Augustus: Der Junge, in der Forschung in der Regel mit dem Namen Heraklonas bezeichnet, war als Sohn der Martina, Herakleios' zweiter Ehefrau, ca. 626 in Lazica geboren und bereits 632 zum Caesar ernannt worden; seine Krönung zum Augustus ist durch einen ausführlichen Bericht im Zeremonienbuch auf den 4. Juli 638 zu datieren. ${ }^{274}$ In der Stephanskirche im Palast wurde ihm in Anwesenheit seines Halbbruders, des Augustus Herakleios Konstantin, des Patriarchen Sergios und der Senatoren anstelle des Kamelaukions, der Kopfbedeckung der Caesaren, die kaiserliche Krone aufgesetzt. Sein im Jahr 630 geborener

272 Vgl. Mango 1990, 75. Herakleios’ Schiffsbrücke war demnach etwas kürzer als die sieben Stadien (etwa 1,3 km, gemäß Herodot) der Brücke des Xerxes.

273 Dazu siehe oben S. $227 \mathrm{f}$.

274 Ausführliche Beschreibung des Rituals in De cerim. 2.27, außerdem Nik. Brev. 25; PMBZ Heraklonas (\#2565). 
Bruder David rückte bei dieser Gelegenheit in den Rang des Caesars nach. ${ }^{275} \mathrm{Im}$ Anschluss an die eigentliche Krönung traf Herakleios mit seinen Söhnen im prunkvollen Empfangssaal, dem Augusteus, auf die Spitze der hauptstädtischen Elite, die Patrikioi, um sich dann im offenen Hof des Palastes von den kaiserlichen Garden sowie Vertretern der städtischen Demen akklamieren zu lassen. Die Feierlichkeiten wurden mit einem gemeinsamen Gottesdienst in der Hagia Sophia abgeschlossen. ${ }^{276}$ Das Datum von Heraklonas' Krönung gibt schließlich auch Aufschluss zur Dauer von Herakleios' Verweilen im suburbanen Palast von Hiereia: Geht man davon aus, dass er kurz vor der Krönung, also im Frühjahr bzw. Frühsommer 638, über die Schiffsbrücke in Konstantinopel einzog, scheint er sich ein Jahr oder gar länger auf der asiatischen Seite niedergelassen $\mathrm{zu}$ haben. ${ }^{277}$

Die Krönung des Heraklonas verfolgte zwei Ziele: Nachdem der Usurpationsversuch Herakleios' Nachfolgeregelung in Frage gestellt hatte, setzte der Kaiser mit der Betonung seiner Kernfamilie ein klares dynastisches Zeichen gegen potentielle Herausforderer; die Krönungszeremonie gab ihm außerdem die Möglichkeit, mit einer weiteren öffentlichen Inszenierung die verschiedenen Gruppen der Hauptstadt anzusprechen - von der weltlichen und geistlichen Elite im Palast bis hin zur Gemeinde in der Hagia Sophia. Als die versammelte Menge dem frisch gekrönten Jungen akklamierte, drückte sie damit auch die Unterstützung des Vaters aus. Herakleios gewährte der hauptstädtischen Öffentlichkeit nun die Aufmerksamkeit, die sie während seines Aufenthaltes in Hiereia eingefordert hatte. Auch in den darauffolgenden Monaten zeigte Herakleios sich und die kaiserliche Familie wiederholt der Bevölkerung. Anlässlich der Feierlichkeiten von Heraklonas’ Konsulatsantritt begab der Kaiser sich am 1. Januar 639 mit seinen Söhnen und umgeben von den höchsten Würdenträgern in einer Prozession vom Palast in die Hagia Sophia. ${ }^{278}$ Vier Tage später versammelte die kaiserliche Familie sich erneut im Palast: Herakleios, seine Frau, die Augusta Martina, sowie seine Söhne und Töchter empfingen im Augusteus die städtische Elite, bevor Herakleios sich in die kaiserlichen Loge im Hippodrom begab, um von dort den Spielen beizuwohnen. ${ }^{279}$

Herakleios beschränkte sich indes nach seiner Rückkehr in die Hauptstadt nicht auf dynastische Statements, sondern wurde auch erneut in der Kirchenpolitik aktiv.

275 PLRE IIIA, David 8 (390)

276 Vgl. Dagron 2003, 75f.; Kaegi 2003, 265-268.

277 Die Schlacht am Yarmouk wird in der Regel auf den 20. August 636 datiert; siehe Kaegi 1992, 114; ob Herakleios noch im Jahr 636 oder erst 637 an den Bosporus zurückkehrte, ist allerdings unklar. 278 Zur Prozession siehe De cerim. 2.28, wo der Konsulats-Antritt des Heraklonas nicht explizit erwähnt wird (vgl. allerdings Nik. Brev. 27); eine Verbindung dieser beiden Ereignisse ist wahrscheinlich, siehe dazu Mango 1990, 191. An der Prozession nahmen auch der Patrikios Niketas, wahrscheinlich der Sohn des persischen Generals Shahrbaraz, teil sowie der Sohn des persischen Adligen Iesdem (dazu siehe Mango 1985, 105, 116f.).

279 De cerim. 2.29; zu diesem Zeitpunkt waren auch die Töchter des Herakleios und der Martina, Augustina und Anastasia, in den Rang einer Augusta erhoben worden; ihr Sohn Martin war Nobilissimus. 
Nachdem seine Einigungsbemühungen im Nachklang der Restitutio Crucis offenbar kurzzeitig einen gewissen Erfolg hatten verzeichnen können, erhob sich schnell vor allem von chalkedonensischer Seite erbitterter Widerstand gegen die Formel von der einen Energie. Die kaiserlichen Schlichtungsversuche stagnierten, als das Vorrücken der Araber die römische Aufmerksamkeit zunehmend beanspruchte. Doch nach Herakleios' triumphaler Rückkehr in die Hauptstadt nahm die Angelegenheit erneut Fahrt auf: Herakleios und Sergios unternahmen einen letzten Versuch, ihr Ziel der Kircheneinigung zu erreichen; vor allem die strikten Verfechter des Chalkedonense sollten damit wieder eingebunden werden. Im Herbst 638 unterzeichnete Herakleios eine leicht abgewandelte Kompromissformel in Form eines reichsweit bindenden Edikts, der sogenannten Ekthesis: Die Frage nach ein oder zwei Energien in Christus sollte nicht weiter diskutiert werden; ausgehend vom expliziten Festhalten an den zwei Naturen Christi, dem Kern des chalkedonensischen Glaubensbekenntnisses, sollte künftig stattdessen der eine Wille (hen thelema) in Christus die Grundlage der orthodoxen Christologie bilden. Das Edikt wurde nicht nur an alle vier Patriarchate versandt, sondern auch im Narthex der Hagia Sophia ausgestellt. ${ }^{280}$

$\mathrm{Zu}$ Beginn der 630er Jahre waren die Details der kaiserlichen Kirchenpolitik - soweit wir das aus dem Contra Severum des Georg von Pisidien schließen können nicht Teil des öffentlichen Diskurses der Hauptstadt; stattdessen wurde Herakleios, nach dem Sieg über die Perser auf dem Zenit seines Triumphes, in Konstantinopel primär als theologische Autorität und Verfechter der (chalkedonensischen) Orthodoxie stilisiert. Einige Jahre später, als dem Kaiser neben der außenpolitischen Sicherung des Reiches auch die innenpolitische Stabilität zu entgleiten drohte, sah sich Herakleios jedoch offenbar genötigt, auch auf dem Feld der Kirchenpolitik ein noch stärkeres Zeichen in Form eines kaiserlichen Ediktes zu setzen. Dass die Ekthesis ausgerechnet im Herbst 638 herausgegeben und öffentlichkeitswirksam in der Hagia Sophia ausgestellt wurde, wenige Monate nach Herakleios' Einzug in die Hauptstadt, ist kaum als Zufall zu werten. ${ }^{281} \mathrm{Zu}$ diesem Zeitpunkt waren die Gemeinden, auf die die Einigungspolitik ursprünglich abgezielt hatte, durch die Besatzung der Araber bereits erneut dem Zugriff der Zentralmacht entzogen. Es entsteht der Eindruck, dass die Ekthesis, die zuallererst die zwei Naturen Christi gemäß dem chalkedonensischen Glaubensbekenntnis betont, nicht zuletzt auf eine Rezeption in der hauptstädtischen Öffentlichkeit abzielte. ${ }^{282}$ Als die monoenergetische Lehre von chalkedonensischer

280 Theoph. Conf. AM 6121 (De Boor 330); der Text der Ekthesis bei Allen 2009, 209 - 217; vgl. Stratos 1972, 141-144; Alexakis 1995/1996, 93 f.; Kaegi 2003, 269-271; Hovorun 2008, 73; Lange 2012, 606 - 614 zu den theologischen Details der Ekthesis.

281 Meier 2019a 1041 weist darauf hin, dass die Ekthesis kurz nach dem Einzug des Kalifen Umar in Jerusalem proklamiert wurde.

282 Zur Frage, welches Ziel Herakleios und Sergios mit der Veröffentlichung der Ekthesis verfolgten, siehe Van Dieten 1972, 46 f., der meint, dass es weiterhin um die Reintegration der miaphysitischen Gemeinden im Osten ging. Für Winkelmann 2001, 38 ging es eher darum, die im Reichsverband verbliebenen, chalkedonensischen Denominationen zusammenzuhalten; zusammenfassend Lange 2012, 
Seite zunehmend auf Ablehnung stieß, musste sich Herakleios auch in Konstantinopel noch deutlicher positionieren.

Ich habe versucht zu zeigen, dass die kaiserliche Politik im Nachklang der römischen Niederlage am Yarmouk nicht etwa von Herakleios' physischem wie psychischem Niedergang bestimmt war, wie es die Forschungsliteratur in der Regel darstellt. Während die sesshaften Kaiser des 5. und 6. Jahrhunderts sich zu einem gewissen Grad gegen die Folgen militärischer Niederlagen hatten immunisieren können, brachte Herakleios’ persönliches Engagement als Befehlshaber den Umstand mit sich, dass die römische Performance auf dem Schlachtfeld erneut in wesentlich höherem Maße auf kaiserliche Verantwortlichkeit verwies. Nach der Niederlage in Syrien und der Verschwörung des Athalarich und Theodor war Herakleios' Aktivität von der Notwendigkeit bestimmt, die kaiserliche Autorität nach dem Prestigeverlust wiederherzustellen und Konstantinopel zu sichern; die Akzeptanz der hauptstädtischen Interessengruppen konstituierte weiterhin die Basis monarchischer Herrschaft. Herakleios' Interaktion mit der hauptstädtischen Öffentlichkeit lässt sich als Erweiterung von Mustern verstehen, die bereits für seine früheren Regierungsjahre beobachtet wurden - allen voran die Förderung der Kernfamilie, die Betonung dynastischer Kontinuität und imperialer Triumphalismus.

Herakleios' Maßnahmen zeitigten offenbar den erhofften Erfolg: Die Stimmung in Konstantinopel beruhigte sich und für die darauffolgenden Jahre sind keine weiteren Unruhen bzw. Herausforderungen der kaiserlichen Autorität verzeichnet; 641 starb Herakleios eines natürlichen Todes. Doch die öffentlichen Stellungsnahmen, zu denen der Kaiser sich angesichts seiner prekären Position genötigt gesehen hatte - die Erhebung eines zweiten Sohnes in den Rang des Augustus und eine deutliche religionspolitische Positionierung -, sollten sich nicht als nachhaltig erweisen; bereits kurz nach Herakleios' Tod offenbarten sich die Negativfolgen dieser Maßnahmen. Da mit der Krönung eines zweiten Augustus die klare Hierarchie der Nachfolgeregelung aufgehoben worden war, entbrannte zwischen den Halbbrüdern Herakleios Konstantin und Heraklonas (bzw. dessen Mutter Martina) nach dem Tod des Vaters ein erbitterter Machtkampf, dessen Dynamiken im folgenden Kapitel genauer betrachten werde. Angesichts des innerfamiliären Ringens konnten sich erneut militärische Funktionsträger - die Gruppe also, die Herakleios versucht hatte einzuhegen machtpolitisch positionieren. Die Ekthesis indes führte nicht etwa zu einem Abklingen des religiösen Konfliktes, sondern verschärfte den Widerstand von ultra-chalkedonensischer Seite gegen die Konstantinopolitaner Kompromisspolitik nur noch mehr. Als Hauptverantwortlicher stand nicht nur der 638 verstorbene Patriarch Ser-

611-614. In diesem Zusammenhang möchte ich darauf hinweisen, dass auch Herakleios’ Nachfolger Konstans II. ein kirchenpolitisches Edikt, den sog. Typos, genau dann erließ, als seine Herrschaft durch die Usurpation des Gregorios in Afrika herausgefordert worden war; siehe dazu Haldon 1990, 56f. und ders. 2016, 36-38. Derart öffentlichkeitswirksame Proklamationen scheinen also besonders in prekären Phasen für notwendig erachtet worden zu sein. 
gios im Kreuzfeuer der Kritik, sondern auch Herakleios selbst. ${ }^{283}$ Nach dem Tod des Papstes Honorius weigerten sich dessen Nachfolger, die Beschlüsse der Ekthesis anzuerkennen. ${ }^{284}$ Anstatt wie erhofft die Einigung der christlichen Gemeinden zu erwirken, trieb der Monotheletismus die Kirchen von Rom und Konstantinopel in ein Schisma, das sich noch weit über die Regierung des Herakleios hinauszog und erst beim sechsten ökumenischen Konzil in Konstantinopel (680/1) mit der endgültigen Verdammung der Lehre vom einen Willen beigelegt werden konnte. ${ }^{285}$ Dass Herakleios sich mit der Ekthesis offiziell zum Monotheletismus bekannt hatte, war nicht nur ein schweres Erbe für seine Nachfolger, sondern schädigte auch seinen Ruf massiv.

Es bleibt zum Ende dieses Kapitels die Frage, wie Nikephoros' irreführende Bewertung von der kaiserlichen Rückkehr nach Konstantinopel zu verstehen ist. Die Passage zur Schiffsbrücke ist nicht die einzige Stelle im Breviarium, in der sich eine kritische Haltung gegenüber Herakleios äußert. ${ }^{286}$ Anstatt davon auszugehen, dass diese Haltung auf Nikephoros selbst zurückgeht, ist jedoch auch denkbar, dass der Autor um die Wende vom 8. zum 9. Jahrhundert damit die Position seiner Quelle übernahm. ${ }^{287}$ Die Beurteilungen, mit der die Nachwelt auf Herakleios als Kaiser zurückblickte, sind prinzipiell gespalten; sie schwanken zwischen der Bewunderung für seinen grandiosen Sieg über die Perser einerseits und einem bisweilen gar polemischen Standpunkt andererseits, der vor allem aus der Verurteilung der kaiserlichen Kirchenpolitik resultierte. ${ }^{288}$ Doch selbst angesichts der Fülle an negativen Bewertungen scheint die Geschichte von der Schiffsbrücke, die gebaut wurde, um Herakleios’ Angst vorm Wasser zu besänftigen, derart absurd, dass nur eine Erklärung bleibt: Es handelt sich dabei um politische Satire.

Kritik am regierenden oder häufiger am verstorbenen Kaiser ist für die römische Monarchie ein gut belegtes Phänomen. ${ }^{289}$ Als eine spezifische Form der Kaiserkritik

$283 \mathrm{Zu}$ Tod und Beerdigung des Sergios siehe Nik. Brev. 26; De cerim. 2.30; vgl. Stratos 1972, 145 und Hovorun 2008, 73-76. Sergios Nachfolger Pyrrhos erwies sich als loyal gegenüber der kaiserlichen Linie; siehe siehe Van Dieten 1972, 57-75. Nach Sergios' Tod scheint Herakleios die Verantwortung für die Ekthesis zu einem gewissen Grad von sich gewiesen zu haben; dies legt zumindest ein Brief an den Papst Johannes IV. nahe; siehe Meyendorff 1989, 354 Anm. 56. Sollte der Kaiser sich tatsächlich darum bemüht haben, sich von der Ekthesis zu distanzieren, so änderte dies die öffentliche Wahrnehmung allerdings auch nicht mehr.

284 Zum Widerstand aus Rom siehe etwa Theoph. Conf. AM 6121 (De Boor 330 -332); vgl. Alexakis 1996/1996 (hier auch zu der Frage, ob Herakleios bis zu seinem Tod am Monotheletismus festhielt) und Booth 2014, 259-269.

285 Überblick über die Entwicklungen bei Haldon 1990, 304-317; Ekonomou 2007, 79-112; Hovorun 2008, 76-91; Meyendorff 1989, 362-373.

286 Vgl. Nik. Brev. 27.

287 Zu Nikephoros' Quellen siehe Mango 1990, 12-14 und Howard-Johnston 2010, 244-250, der davon ausgeht, dass Nikephoros eine hauptstädtische Chronik, genauer gesagt eine Erweiterung des Johannes von Antiochia, nutzte; siehe oben $23 \mathrm{f}$.

288 Zur Herakleios-Rezeption siehe Sirotenko 2017, 2018.

289 Zu römischer Kaiserkritik siehe zum Beispiel Tinnefeld 1971; Av. Cameron 1977 und einen Sammelband zu 'antimonarchic discourse' (Börm 2015b). 
zieht politische Satire ihre Wirkung daraus, dass sie mit Übertreibung, Verzerrung und Polemik Elemente kaiserlicher Repräsentation oder enkomiastischer Stilisierung ins Gegenteil verkehrt; sie fungiert als „parody of panegyrics“. ${ }^{290}$ Auch im spätantiken Konstantinopel war Satire eine mögliche politische Ausdrucksform, wie Prokops Geheimgeschichte in Bezug auf Justinian besonders eindrücklich zeigt. ${ }^{291}$ Was Herakleios als triumphales Statement intendiert und vollzogen hatte - die Schiffsbrücke über den Bosporus -, wurde in der satirischen Betrachtung ins Gegenteil verkehrt: in eine Initiative der hauptstädtischen Funktionsträger, den mental inkompetenten Kaiser nach Konstantinopel zu überführen. ${ }^{292}$

Von welcher Person bzw. Gruppe die Satire auf Herakleios ursprünglich ausging, ist schließlich kaum mehr festzustellen. Die Quelle, die Nikephorors für Herakleios’ späte Regierungsjahre nutze, scheint nicht lang nach dessen Tod 641 verfasst worden zu sein, da der Bericht recht abrupt inmitten der Nachfolgestreitigkeiten abbricht; den Sturz von Heraklonas und Martina 642 übergeht Nikephoros und setzt erst mit der Ermordung des Konstans II. im Jahr 665 mit seiner Erzählung wieder ein. ${ }^{293}$ Geht man davon aus, dass Nikephoros die Bewertung von Herakleios' Schiffbrücke aus seiner Quelle übernahm, so liegt es nahe, dass die Satire noch zu Lebzeiten des Kaisers oder kurz nach dessen Tod entstand - in einer Zeit also, als klar wurde, dass sein grandioses Restitutionswerk der Expansion der Araber zum Opfer gefallen und eine religionspolitische Einigung in weite Ferne gerückt war. Angesichts dieser Entwicklungen konnte imperialer Triumphalismus, wie ihn die Schiffsbrücke über den Bosporus zu

290 Halsall 2002, 102. Als ein Beispiel aus dem Prinzipat wäre Senecas Apocolocyntosis auf den verstorbenen Kaiser Claudius zu nennen.

291 Av. Cameron 1996a, bes. 58 betont, dass man dem Charakter der Geheimgeschichte nicht gerecht werden würde, wenn man sie im Ganzen als Satire qualifiziert (vgl. Halsall 2002, 102f. mit Anm. 55); dennoch enthält der Text sicherlich satirische Elemente. Das Bild des frommen, asketischen und geradezu heiligmäßigen Kaisers, als der Justinian in der Regel stilisiert wurde, verkehrt Prokop in der Geheimgeschichte ins Gegenteil: Justinian erscheint als dämonischer Herrscher, als der Antichrist höchstpersönlich, der schlaflos mit seinem Kopf unterm Arm durch den nächtlichen Kaiserpalast streift (siehe Prok. Hist. arc. 12 und dazu Börm 2015b, 334f.). Ebenso wie Panegyrik lässt sich auch satirischer Inhalt in verschiedenen literarischen Genres nachvollziehen: Die Beschreibung von Justins II. Krankheit in Johannes von Ephesos’ Kirchengeschichte (Hist. eccl. 3.2) könnte unter Umständen auch als eine Form der politischen Satire verstanden werden; zum Schicksal des Justin II. siehe oben S. $69 \mathrm{f}$;; vgl. Börm 2013, $81 \mathrm{f}$.

292 Die Idee, der Kaiser leide an Angst vorm Wasser, ist indes nicht vollkommen willkürlich; sie könnte daher rühren, dass Herakleios offenbar in seinen späten Jahren an Wassersucht litt - wenn wir die Berichte in Theoph. Conf. AM 6132 (De Boor 341) und Nic. Brev. 27 in ihren Grundzügen ernst nehmen. Was Satire besonders wirkungsvoll macht, ist, dass sie mit authentischen Versatzstücken arbeitet (wie etwa dem Umstand, dass eine Schiffbrücke konstruiert wurde oder dass der Kaiser unter physischen Beschwerden litt) und diese neu arrangiert, um das Objekt der Satire ins Lächerliche zu ziehen.

293 Siehe den Zeitsprung zwischen Nik. Brev. 32 und 33; in der Regel wird davon ausgegangen, dass dieser Bruch den Quellen geschuldet ist, die Nikephoros bei der Verschriftlichung des Breviariums zur Verfügung standen; siehe Mango 1990, 14f.; Howard-Johnston 2010, 248. 
transportieren gedacht hatte, nicht mehr überzeugen. Die Satire könnte in Form eines Gerüchtes, als urbaner Mythos zirkuliert und schließlich verschriftlicht worden sein. In der kollektiven Erinnerung der Hauptstadt blieb Herakleios' spektakuläre Inszenierung also nicht als solche haften; stattdessen nahm man den Bau der Schiffsbrücke zum Anlass, um den Kaiser ins Lächerliche zu ziehen. Mit der Zeit entwickelte die Geschichte von Herakleios' Angst vorm Wasser ein Eigenleben; das Verständnis der satirischen Ebene ging verloren, sodass auch die moderne Forschung die in Nikephoros' Bericht erhaltene Bewertung unkritisch als historische Gegebenheit übernahm. 